\title{
Poverty and Vulnerability in Vietnam
}

\author{
Dissertation
}

zur Erlangung des wirtschaftswissenschaftlichen Doktorgrades der Wirtschaftswissenschaftlichen Fakultät der

Universität Göttingen

vorgelegt von

Quang-Van Tran, MA.

aus Ninh Binh, Vietnam

Göttingen, 2013 
Erstgutachter

Zweitgutachter
: Prof. Stephan Klasen, Ph.D.

: Prof. Dr. Hermann Waibel

Tag der mündlichen Prüfung : 26. September 2013 


\section{Acknowledgement}

This dissertation has my name on its cover, but its completion would not have been possible without the support of many. I am happy to have the opportunity here to acknowledge those that have made this happen.

First of all, I would like to express my gratitude to my supervisor Professor Stephan Klasen for giving me a chance to be involved in many interesting research projects as well as an opportunity to write this dissertation. He gave me extremely valuable support and guidance throughout the years. I would also like to thank Professor Hermann Waibel for his guidance with the fieldwork as well as his constructive comments, which improved my work considerably. In addition, J. Prof. Sebastian Vollmer agreed to serve on my thesis committee and I would like to thank him for this.

My colleagues deserve mentioning as well, as they shared interesting thoughts and comments on my research and provoked discussions during seminar sections, as well as side activities. I thank the members of the Vulnerability in Southeast Asia research project, particularly Tobias for his useful discussions and support. My special thanks goes to my colleagues from the Oxford Poverty and Human Development Initiative, particularly Sabina and Paola for their valuable comments. I would also like to thank the participants of the Vietnam Economist Annual Meeting 2011 and 2012, the HDCA conference 2012, the workshop on "Dynamic Comparison between Multidimensional Poverty and Monetary Poverty" in Oxford 2012, the workshop on "Poverty Reduction in Asia", and the workshop on "Impacts of shocks on the vulnerability to poverty" for their constructive comments.

I also thank the Vietnam National University that gave me the opportunity to study abroad. I am also grateful to the Ministry of Education and Training of Vietnam and the German Academic Exchange Service that funded me with scholarships during the years of my study. My deepest thanks goes to my family and Hang for always supporting me and organising things during my absence from home, as well as giving me energy and inspiration. Finally, I want to thank my friends who encouraged me pursue this endeavor, and provided me with support when I needed it. 


\section{Contents}

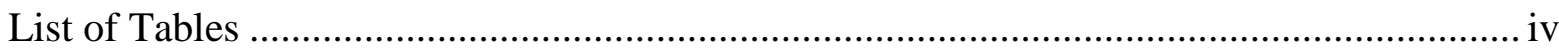

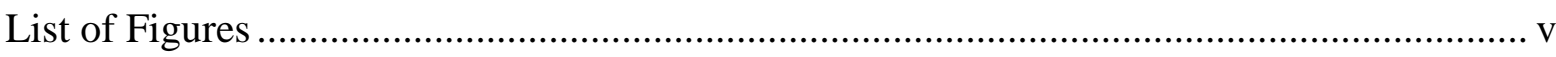

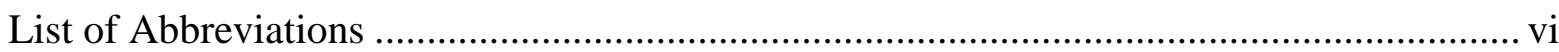

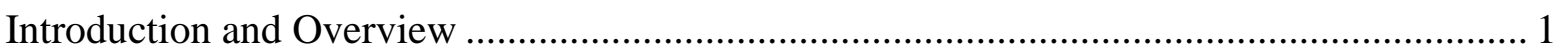

\section{Chapter 1 Disparities between Monetary and Multidimensional Measurements of} Poverty ............................................................................................................................ 11

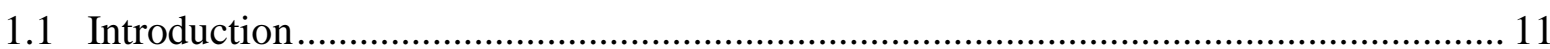

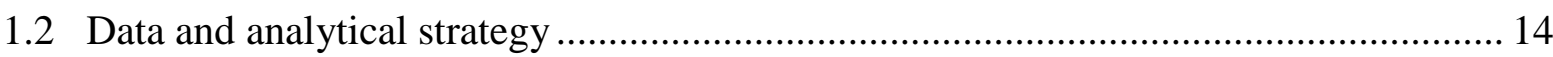

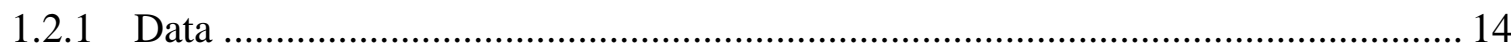

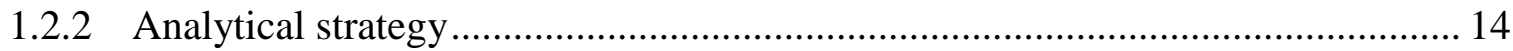

1.3 Disparities between monetary and multidimensional poverty across groups ................ 19

1.4 Disparities between monetary and multidimensional poverty over time....................... 24

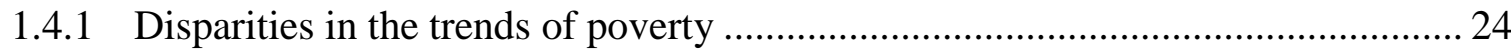

1.4.2 Disparities in the mobility of monetary and multidimensional poverty ................ 25

1.4.3 Disparities between the measures of poverty over time...................................... 27

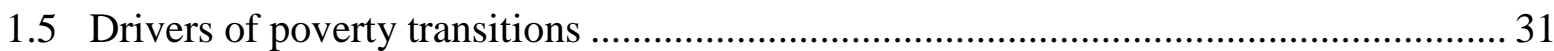

1.5.1 Drivers of monetary and multidimensional poverty transitions .......................... 31

1.5.2 Drivers of multidimensional poverty transitions ................................................ 34

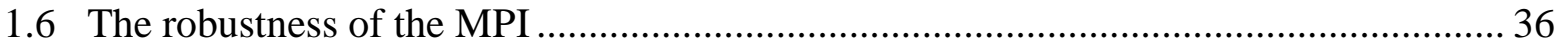

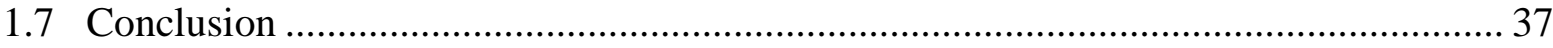

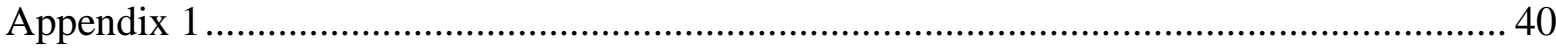

Chapter 2 Assets, Shocks and Poverty Dynamics ........................................................41

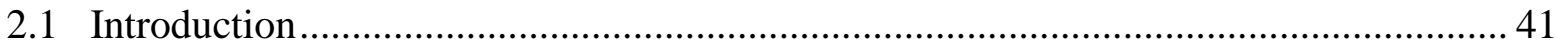

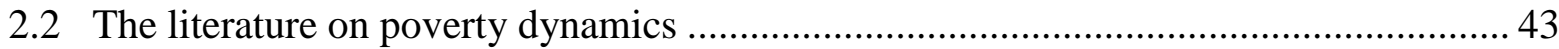

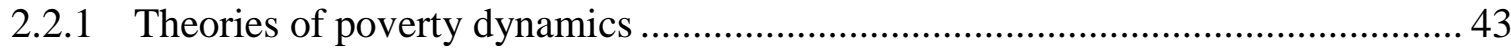

2.2.2 Empirical evidence from the literature on poverty dynamics ............................ 46

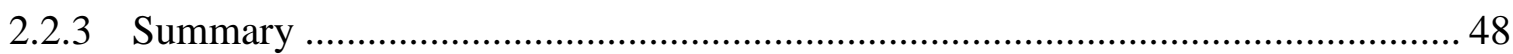

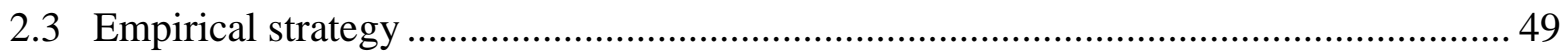

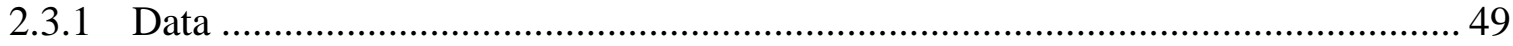

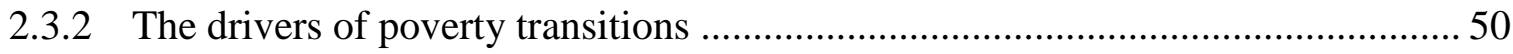

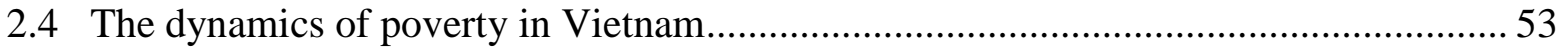

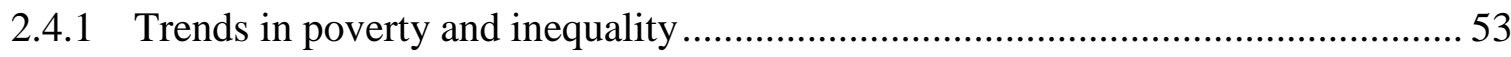




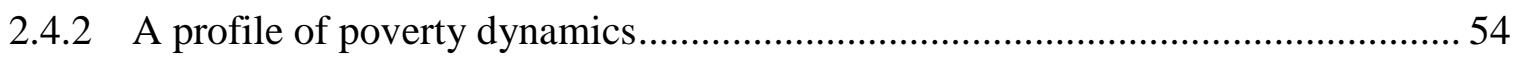

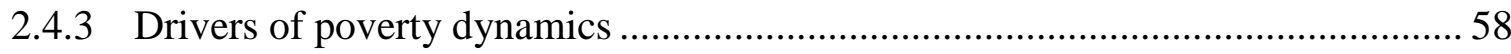

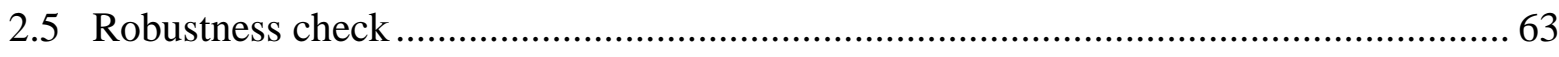

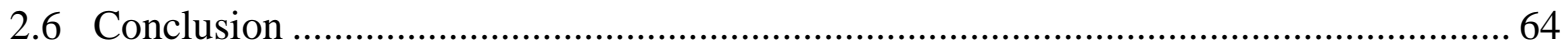

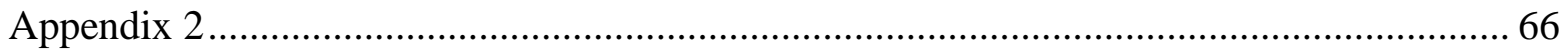

Chapter 3 Household's Coping Strategies and Recoveries from Shocks .......................... 71

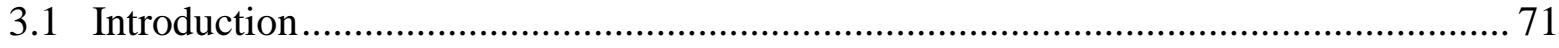

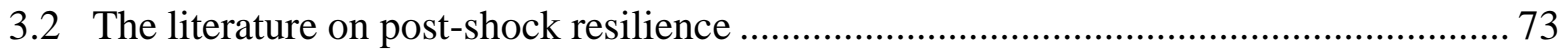

3.2.1 Household coping strategies and resilience paths ............................................. 73

3.2.2 Empirical evidence from the literature on shock recovery................................ 75

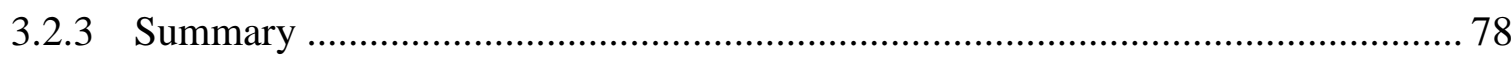

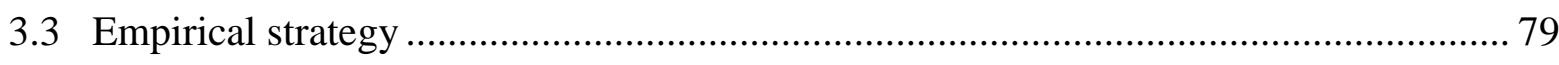

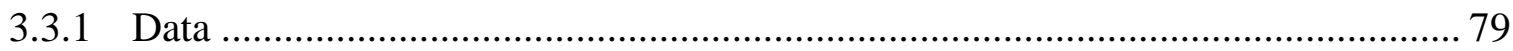

3.3.2 Discrete time proportional hazard model of shock recovery .............................. 79

3.4 The prevalence of shocks among household groups................................................ 83

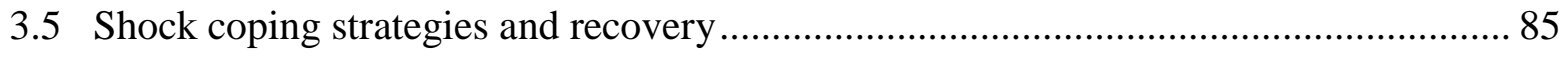

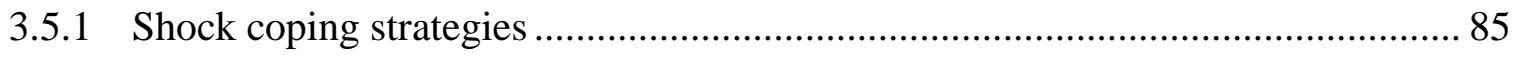

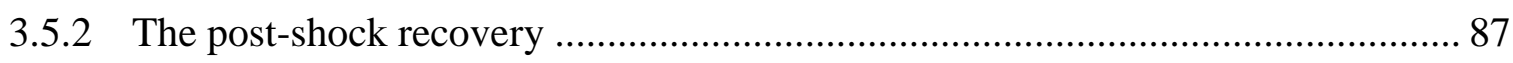

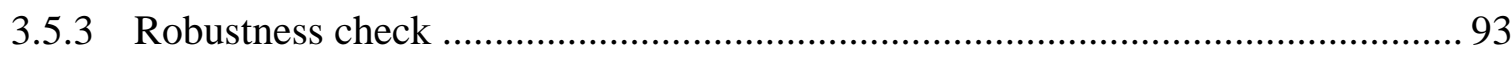

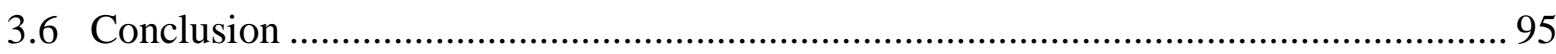

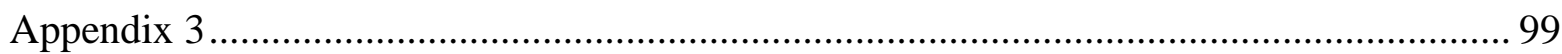

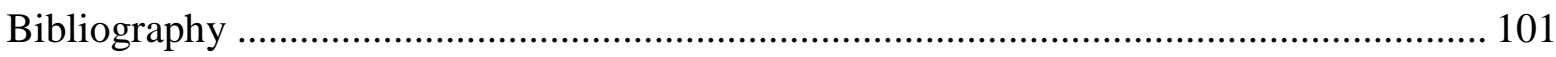




\section{List of Tables}

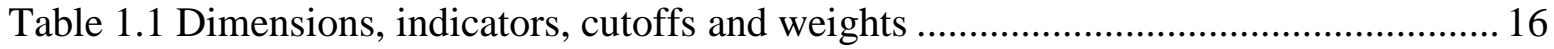

Table 1.2 Poverty rates at different cutoffs by measure of poverty and year, percent ......... 19

Table 1.3 The incidence of monetary and multidimensional poverty in 2008 , percent........ 20

Table 1.4 Marginal effects from probit models of being monetary or multidimensionally

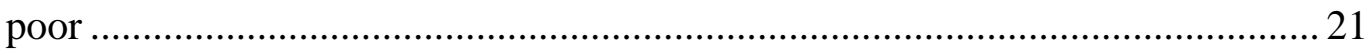

Table 1.5 Transitions of monetary and multidimensional poverty $2007-2008$, percent ....... 25

Table 1.6 Transitions of monetary and multidimensional poverty $2008-2010$, percent ....... 26

Table 1.7 Transitions of monetary and multidimensional poverty $2007-2010$, percent ....... 27

Table 1.8 The dynamics of monetary and multidimensional poverty, percent....................28

Table 1.9 Correlation across and within measures of poverty over time.............................29

Table 1.10 Marginal effects of monetary and multidimensional poverty transitions ........... 33

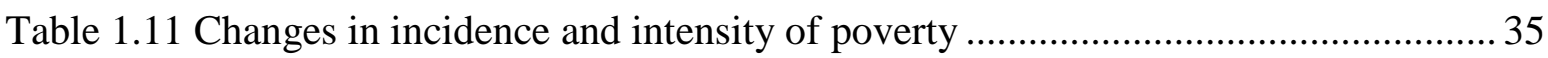

Table 1.12 Indicator deprivations and their changes, percent.......................................... 36

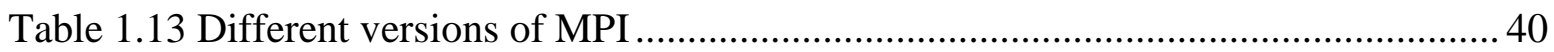

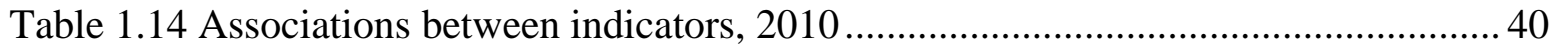

Table 2.1 Poverty rate by poverty line, province and year, percent ….............................. 54

Table 2.2 Household and head characteristics by poverty trajectory, percent ..................... 55

Table 2.3 Marginal effects from multinomial logit model with shocks since 2007 ............59

Table 2.4 Percentage predictions from multinomial logit models ..................................... 61

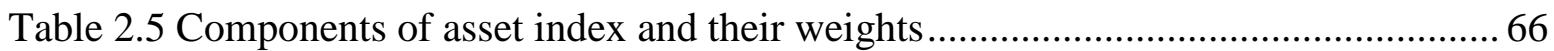

Table 2.6 Marginal effects from multinomial logit model with shocks since 2002 ............. 67

Table 2.7 Marginal effects from probit models with shocks since 2007 ........................... 68

Table 2.8 Marginal effects from MNL of poverty dynamics as referred to $\$ 2.5 \ldots \ldots \ldots \ldots \ldots . . . .69$

Table 2.9 Marginal effects from MNL of poverty dynamics based on equivalence scaled

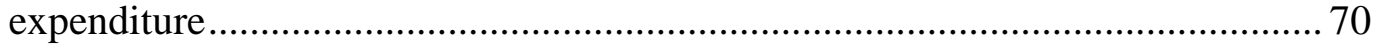

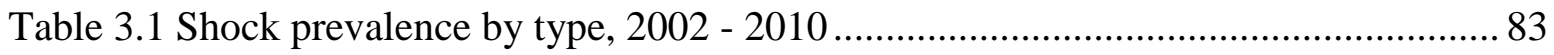

Table 3.2 Household characteristics and shock prevalence by shock type........................... 84

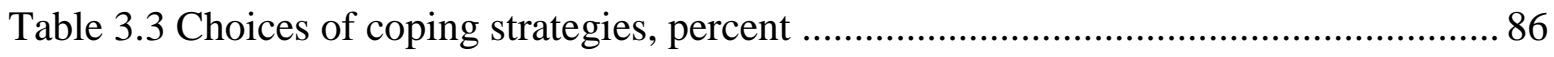

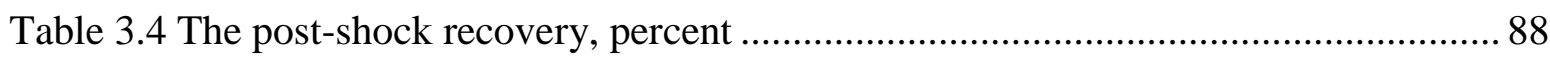

Table 3.5 The length of recoveries from shocks by shock type, months ........................... 89

Table 3.6 Odds ratios from discrete time proportional hazard models with gamma frailty .97

Table 3.7 Components of asset index and their weights by year..................................... 99

Table 3.8 Correlation between self reported recovery and objective recovery ................... 99 


\section{List of Figures}

Figure 1.1 Economic growth, inflation and poverty rates by year, percent ........................ 10

Figure 1.2 Value of losses due to natural disasters from 1990 to 2010, 1000 bil. VND ...... 10

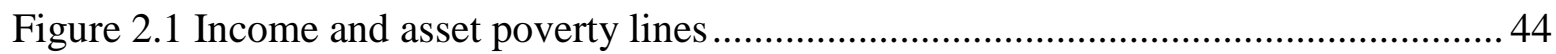

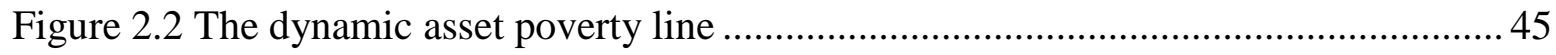

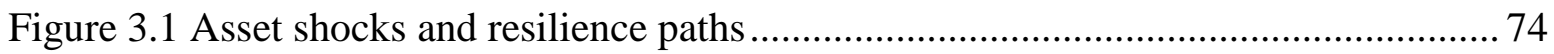

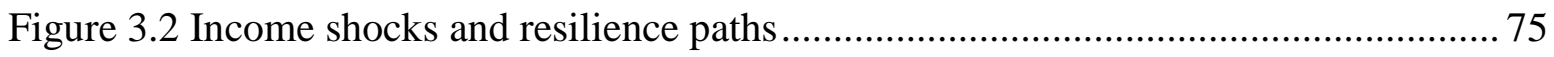

Figure 3.3 Distribution of shocks by the length of recovery ......................................... 99

Figure 3.4 Relationship between a household's characteristis and a shock's covariates ..... 100

Figure 3.5 Relationship between coping strategies and shock's covariates ...................... 100 


\section{List of Abbreviations}

$\begin{array}{ll}\text { BMI } & \text { Body mass index } \\ \text { DHS } & \text { Demographic and Health Survey } \\ \text { FHH } & \text { Female headed household } \\ \text { GDP } & \text { Gross Domestic Product } \\ \text { GSO } & \text { General Statistical Office of Vietnam } \\ \text { HDCA } & \text { Human Development and Capability Association } \\ \text { HDI } & \text { Human Development Index } \\ \text { IIA } & \text { independence of irrelevant alternatives } \\ \text { IMF } & \text { International Monetary Fund } \\ \text { MDG } & \text { Millennium Development Goals } \\ \text { MHH } & \text { Male headed household } \\ \text { MICS } & \text { Multiple Indicator Cluster Survey } \\ \text { MNL } & \text { Multinomial logit model } \\ \text { MPI } & \text { Multidimensional Poverty Index } \\ \text { OECD } & \text { Organization for Economic Co-operation and Development } \\ \text { OLS } & \text { Ordinary Least Squares } \\ \text { PH } & \text { Proportional Hazard model } \\ \text { PPP } & \text { Purchasing Power Parity } \\ \text { UN } & \text { United Nations } \\ \text { UNDP } & \text { United Nations Development Program } \\ \text { UNICEF } & \text { United Nations Children's Fund } \\ \text { USD } & \text { United States Dollar } \\ \text { VLSS } & \text { Vietnam Living Standard Survey } \\ \text { VND } & \text { Vietnamese Dong } \\ \end{array}$




\section{Introduction and Overview}

Vietnam is known as one of the most successful development stories among the developing countries. Since the start of its doi moi, or economic reform programme in the late 1980s, the country has been able to participate successfully in the global economy and had an unprecedented economic growth rate with an average of more than seven percent per annum. The country of 86 million inhabitants has been transformed from one of the poorest countries in the world with a per capita income of $\$ 130$ in 1990 to a lower middle-income country with a per capita income of nearly $\$ 1,200$ at the end of 2010 (World Bank, 2013). The ratio of the population in poverty has fallen sharply from nearly 60 percent in 1993 to less than 15 percent in 2010 (GSO, 2011a) lifting some 35 million people out of poverty. In addition, the country has been applauded for the equity of its development, which has been better than most other countries that have a similar level of development. The Gini index has not change significantly from the level of 0.36 during the last two decades, positioning the country in the top fifty out of 133 countries in terms of equality (see Global Finance, 2013).

Along with these economic successes, the country has also made great achievements in human development. The health and education indicators are better than might be expected for a country at its stage of overall development, and they continue to improve at rates that equal or surpass those in many neighbouring countries. The life expectancy has reached 75 in 2010, ranking the country at 64th among 169 countries and territories, placing it higher than both Thailand and Malaysia. The nation has also continued to make impressive progress in child health by halving the infant mortality rate and the under-five mortality rate to 18 per thousandth and 23 per thousandth in 2010 respectively (UNICEF, 2013). The average years of schooling increased by 1.5 years between 1990 and 2010 and expected years of schooling increased by almost three years. The overall Human Development Index has increased impressively from 0.41 in 1990 to 0.57 , positioning the country at 113 th out of 169 countries and territories by the end of 2010 (UNDP, 2010). The nation has already attained five out of eight Millennium Development Goal targets and is well on the way to reaching two more by 2015 (UNICEF, 2012).

Though the country has made remarkable achievements in many sectors, there are still some remaining issues within the development process. Poverty is still a big issue where two fifths of the population, or approximately 37 million people, still live on less than $\$ 2.00 \mathrm{a}$ day and the rate of poverty reduction has slowed down in recent years (see Figure 1). In addition, the progress in education has stagnated since the early 2000s and has performed 
worse than some other countries in the region. In the past five years, the expected years of schooling have only increased marginally from 10.3 years to 10.4 years $^{1}$. A Vietnamese student is expected to stay at school three years less than a Thai student does and two years less than a Malaysian does. In addition, progress in the health dimension has been slower than in other dimensions. For instance, the under five mortality rate was 23 per thousandth and the stunting rate of children was 23 percent in 2010 (GSO, 2011b). There has also been slow progress in some living standards as 29 percent of households had no access to safe drinking water and 46 percent of households had no access to improved sanitation facilities in 2010 (GSO, 2011a).

In addition, in the context of a rapidly growing economy and in an increasingly complex global economy, households in developing countries generally face many uncertainties as a result of macroeconomic instability. The reduction of trade barriers and protection has exposed the domestic market to the fluctuation of the international market. The combination of unfamiliar market risks, commodity price shocks, and misguided economic policies can lead to increased levels of vulnerability. The economic growth rate in Vietnam has been lower since the start of the 2000 s and the inflation rate has fluctuated substantially since 2007 (see Figure 1).

Moreover, the livelihood of a large share of the population is reliant on natural resources, which exposes them to greater risk. Farming remains a major livelihood in rural areas, which absorbed nearly two thirds of the total labour force in rural areas in 2008 and contributed nearly two fifths of rural household's total income (GSO, 2011a). Unfortunately, agricultural activities have been increasingly affected by livestock diseases such as the Avian Flu and Swine Flu as well as by climate change. Vietnam is among the top five countries most heavily affected by the consequences of climate change due to the fact that the country is situated at the end of one of the most powerful cyclone tracks (Kelly and Adger, 2000). Additionally, the country's long coastline makes it prone to sea-level rises, which would inundate many residential areas and agricultural lands (see Dasgupta et al., 2009). Moreover, the extreme weather conditions could be partially blamed on the poor forest quality, which has not improved significantly since its worst period in the start of the 1990s though the forest coverage has increased as a result of reforestation efforts (see Sunderlin and Huynh, 2005).

Although various definitions and concepts for well-being exist, this study focuses on just three of its aspects. Firstly, it addresses the many dimensions of poverty including income

\footnotetext{
${ }^{1}$ Author's calculation from UNDP (2010) data
} 
and non-income indicators. Poverty has been understood as having less than the minimum income or consumption level needed to meet basic needs, having low levels of human capital including health and education, and having poor living conditions. The literature has recently paid more attention to the vulnerability dimension of well-being, which is understood as being a household's vulnerability to poverty, uninsured exposure to risk, low expected utility, and expected poverty. This study will secondly focus on vulnerability to poverty, which is the current probability or risk of being in poverty or falling deeper into poverty at some point in the future (see Coudouel et al., 2002). Finally, the study discusses another facet of vulnerability, which is the lack of resilience against risk and shocks (World Bank, 2001: 139). Vulnerability affects an individuals' behavior in terms of investment, production patterns, and coping strategies and their perception of their own situation.

This dissertation focuses mainly on the case of Vietnam using data from the Vulnerability Surveys conducted in 2007, 2008 and 2010 under the research project "Vulnerability in Southeast Asia" being run by a consortium of German universities and some local research institutes (see Klasen and Waibel, 2012). The survey covers more than 2000 households in rural and peri-urban areas in the two central provinces of Ha Tinh and Thua Thien Hue and a central highlands province of Dak Lak in Vietnam. The two central provinces are located on the coastline and are characterised by three ecological zones of coastal, lowland and mountainous areas. This area is known as the most vulnerable to natural disasters in the country as it suffers from frequent floods and storms. On the contrary, Dak Lak is described as a highland and mountainous area where droughts are the major threats rather than floods and storms.

The three provinces account for more than seven percent of the entire country's land area (GSO, 2013) and contain nearly five percent of the nation's population (GSO, 2010). These areas are home to various ethnic groups including the Kinh, Tay, Thai, Muong, Nung, Ê Đê (Rhade), Pa Co, Co Tu, Ta Oi, etc. which are part of the 54 ethnic groups in the entire country. Among them, the Kinh is the majority group, which accounts for more than 86 percent of the national population and usually lives in lowlands and near urban areas. The location enables them to have better access to infrastructure and thus to markets and public services such as health and education, giving them more advantages than the other groups in many aspects (see Baulch et al., 2007). The three provinces are also situated in the second and third poorest regions in Vietnam after the Northern midlands and mountainous areas ${ }^{2}$ (GSO, 2013).

\footnotetext{
${ }^{2}$ A proper name of a region in Vietnam
} 
In addition, the economies in the three provinces are characterised by agricultural activities, which accounted for 36, 18 and 54 percent of the provincial GDP of Ha Tinh, Thua Thien Hue and Dak Lak in 2010 respectively. Industrial and service sectors are still at an early stage of development, particularly in Ha Tinh. Therefore, people usually migrate to big urban areas such as the Northern and Southern Economic Focal Zones ${ }^{3}$ to find job opportunities. The livelihood in the coastal areas is mainly characterised by fishery and agricultural activities while in the lowlands it is primarily agricultural. The main income sources in the highlands come from export oriented agricultural products such as coffee, pepper, cashews, and rubber while incomes in mountainous and forest margin areas come from crop production and forestry. Additionally, the livelihood in the three provinces are characterised by small-scale farming and use mainly household labour.

This dissertation aims to contribute to the literature on poverty, particularly on the many dimensions of poverty, vulnerability to poverty and exposure to shocks. It analyses the disparities between monetary and multidimensional measures of poverty, estimates the effects of a household's asset levels and their changes on the transitions into and out of poverty, and examines the forces that shape a household's recovery path from shocks. These analyses are crucial for a better understanding of the situation and the determinants of poverty and vulnerability in the developing world as well as for policymaking purposes.

The first chapter of this dissertation provides an introduction to the disparities between monetary and multidimensional measures of poverty across sub-groups of the population as well as their disparities over time. The second chapter investigates the dynamics of poverty in relation to a household's wealth level and particularly to the effects of shocks. Embarking from the notion that vulnerability is an important dimension of poverty, the third chapter presents the recovery during the aftermath of the shocks, illustrated by applications to Vietnam.

\section{Disparities between monetary and multidimensional measurements of poverty}

It is often believed that income and wealth as measures of a household's well-being are almost interchangeable. Families with a high income usually, or necessarily, have a high level of wealth, and low-income families have low levels of wealth (see Wolff and Zacharias, 2006). Nevertheless, there has been an increasing amount of critiques on the imperfections of the monetary measurement of poverty and the need for alternative approaches. They argue that human lives are comprehended in many ways and aspects (see Sen, 2000), that money might not a good measure of poverty because of market

\footnotetext{
${ }^{3}$ Proper names of two economic focal zones in Vietnam
} 
imperfections, measurement errors, and its time variation (see Deaton, 1997; Tsui, 2002; Clark and Hulme, 2005). Additionally, improving the level of human development is more important than the increase in income or consumption. Therefore, the analysis of poverty and of poverty dynamics has been focused on many dimensions rather than only the money dimension of poverty (Clark and Hulme, 2005; Hulme and Shepherd, 2003).

The first chapter of this dissertation contributes to the literature on the many dimensions of poverty by comparing monetary and multidimensional poverty measures across sub-groups of the population and over time. In an application to Vietnam, this study analyses whether the two measures identify the same poor groups and whether the improvements in one dimension are accompanied by improvements in another. In a broader sense, the study is concerned with how inclusive the recent growth experience was of rural households in the successful country. By any account, the country has been highly successful in transferring sustained economic growth into poverty reductions where a large share of the population has escaped poverty. Additionally, most indicators of human development have been improved upon including education and health (UNICEF, 2012). This provides excellent examples that can be used to investigate inclusiveness in terms of poverty in many dimensions.

Using unique panel data from three provinces in Vietnam the study investigates the incidence of poverty, the transitions of poverty, and the compositional changes of the poverty measures over time. This work contributes to the ongoing discussion by examining whether (i) the monetary poor are also multidimensionally poor and vice versa, whether the monetary non-poor are also multidimensionally non-poor, (ii) whether an improvement in the monetary dimension is accompanied by the same improvement in multidimensional poverty, and (iii) what factors drive the changes in both types of poverty. The analyses will classify different household groups by household's and head's characteristics, as well as by ethnic groups, income quintiles, and physical location.

In general, much discrepancy exists between monetary and multidimensional measurements of poverty. In Vietnam, the two measures of poverty do not always identify the same poor individuals and the mismatch between the two measures varies according to the groups' identities such as a household's characteristics and levels of wealth. The monetary non-poor have a rather high risk of being multidimensionally poor. The Kinh have a much lower risk of being monetary poor than ethnic minority people, but this difference is smaller in the case of multidimensional poverty. This implies that those who benefit more from the sustained economic growth are able to improve their income but they might need a longer amount of time to improve their non-income indicators. 
Although the two measures show improvements over the period of time, the monetary dimension has made faster progress. Additionally, the poor had higher levels of mobility in the monetary dimension while the non-poor had higher levels of mobility in

multidimensional poverty. The downward mobility in multidimensional poverty was slightly greater than that in the monetary dimension over the period. The results confirm the findings from previous studies that non-income indicators change more slowly than the income indicator. They also suggest that in the context of macroeconomic fluctuations, the monetary poor are more prone to the exogenous changes than the multidimensionally poor.

In addition, the study shows that different household groups, as characterised by households' characteristics, have different levels of access to markets and public services, have made different rates of improvement in the monetary dimension. However, the improvements in multidimensional poverty have weaker significant differences across household groups. This implies that an economic solution might be not enough to help people escape multidimensional poverty. Moreover, the transitions in the Multidimensional Poverty Index are driven more by the change in incidence rather than by the intensity of poverty. They are also driven more by the changes in deprivation of the two health indicators of nutrition and health functioning.

The findings of this study suggest that poverty alleviating policies should not only focus on income but on non-income indicators as well, particularly health and living standards. This also means that policy makers should pay attention to the improvement in non-income indicators of the poor as well as of people from all ranges of income. They should also pay more attention to ethnic minority groups, who have a higher risk of being poor in both measures of poverty.

\section{Assets, shocks and poverty dynamics}

Besides addressing the many dimensions of poverty, the literature has also paid attention to the specific determinants of poverty dynamics in the monetary dimension. There have been a number of theoretical and empirical studies on the dynamics of monetary poverty. They have distinguished the difference between persistent and transient poverty and have identified the characteristics of sub-groups of the population that escape or fall into poverty. They have also examined the effects of macroeconomic changes, particularly trade reforms, on households of different livelihoods and different levels of market participation. The literature has recently shifted its focus to the effects of positive and negative shocks on a household's well-being, leading to an increasing number of studies on the effects of different types of shocks on a households' income level and poverty status. 
The second chapter contributes to the literature on poverty dynamics, particularly to the literature that discusses the impact of shocks on poverty transitions. In an application to Vietnam, this study examines which household groups are able to move out of poverty and which groups fall into poverty during the period of fast economic growth. Moreover, it investigates under which circumstances a household falls into poverty when faced with a shock. Vietnam has been one of the most successful countries among the developing world in attacking poverty. During the last twenty years, the poverty rate in the country has decreased dramatically from 58 percent in 1993 to just slightly over 14 percent in 2010 . Despite this great achievement, the rate of poverty reduction has slowed down in recent years and there are disparities in the rate of poverty across rural and urban areas as well as across regions in the entire country. Additionally, the country has been increasingly affected by natural disasters and economic shocks. An adverse event might cause a decline in income and assets and thus make a household fall into poverty. Nevertheless, the poor suffer from many shocks, which might make them diversify their income source portfolios into ways that would insure that they face fewer risks, or become immune to shocks because of having little to lose.

The estimations show a sharp poverty reduction over the period. However, the rate of poverty reduction varied across sub-periods of time and a large share of the population was found to be vulnerable to poverty, being more than 35 percent of households. The risk of being poor was particularly high for households with limited human capital as well as limited access to markets and public services. These households largely included ethnic minority groups and households with low levels of education. This suggests that the fast poverty reduction was not stable because the progress was uneven across household groups as well as over time.

A shock usually causes a decline in assets, in income, and perhaps in other dimensions such as health and happiness as well. Nonetheless, a shock does not always make a household fall into or become trapped in poverty. This could be attributed to the fact that the effects of a shock do not necessary bring the household down into poverty. It could be that the shock had already been recovered from before the following survey. Another possibility is that households face a series of shocks every year, for example frequent storms, floods, and droughts, causing households to adjust their livelihoods and diversify their income sources in ways that allow them to avoid being affected by shocks and losing a great deal from shocks.

The findings of this study suggest that poverty reduction policies should focus not only on the poor but on vulnerable groups as well. Among the vulnerable group, households from 
ethnic minority groups, households of a large size and households with low education attainment should be given more attention.

\section{Coping with and recovering from shocks}

Besides focusing on the consequences of shocks on a household's moving out of or falling into poverty, development policies also pay attention to the ability of households to cope with and to recover from the adverse events. This is particularly crucial when a large share of the world's population lives in developing countries whose livelihoods are typically poor and prone to risks. It is therefore necessary to understand how households respond to disturbances and how they employ their inherent strengths and resources to recover from the adverse events. The findings will also be beneficial for policy makers so that they can help households cope with and recover quickly and fully from shocks.

The third chapter contributes to the literature on vulnerability that examines how households cope with shocks and how they recover from the adverse events. The study is situated in a particular context characterised by agricultural based livelihood, a high rate of poverty, unstable macroeconomic conditions, a high risk to extreme weather conditions and livestock diseases, and a diversified agricultural and ecological conditions. Vietnam is a useful example to study in this regard, as findings are likely to apply to a number of Southeast Asian countries, where a large share of the population is poor and is facing increasing uncertainties. In fact, Vietnam is considered to be one of the countries most affected by climate change. The evidence on the effects of shocks and the resilience paths that Vietnamese households experience today will be useful for countries that experience similar situations, which might be helpful for them to reduce the effects of shocks in the short-run as well as in the long-run.

This study proceeds by first establishing the vulnerability profile of rural and peri-urban households in Vietnam, which types of shocks they are more likely to be vulnerable to and which household groups are most prone to shocks. It then discusses the coping strategies applied to different types of shocks ultilised by different household groups. The final part of the study presents the empirical estimations of the forces including a household's characteristics and shock covariates that shape a household's post-shock recovery.

The results suggest that poorer households experience more agriculture and health shocks while richer households are the major victims of business shocks. Additionally, people from different ethnic groups, age, education, and occupation background are affected differently from shocks. When facing a shock, poorer households are more likely to either apply no coping action or rely on external resources and additional resources to cope with the shocks 
since they own a limited resource. Conversely, wealthier households are more likely to use their own resources to cope with the shocks.

Households with better human and physical capital are better able to cope with shocks thus making them recover quickly from the disturbance. Nevertheless, the effects of these types of capital are not robust because of possible endogeneity, i.e. shocks that are reported by wealthier households might be of higher severity levels and cause more losses than they do to poorer households because the formers report big shocks only and they have more resources to lose. This consequently makes the recovery from shocks to wealthier household harder than the recovery from shocks to poorer households holding other things constant.

The findings also suggest that the more losses the shock causes and the more severe its affects the longer time the household needs to recover. Business and health shocks usually cause more income and asset losses than other types of shocks and health shocks might result in worse health conditions as well, making it harder for households to recover from it. Interestingly, many coping strategies appear to have negative effects on the recovery because coping strategies are usually applied to massive losses and severe shocks, and the positive effects of the coping strategies are smaller than the negative effect of the severity. Nonetheless, coping strategies show that they are helpful to poor households in recovering from the adverse events because poor households lose little from shocks. Additionally, if the shock is followed by another shock on its way to recovery, the shock is then more difficult to recover from.

Another interesting finding is that the subjective and self reported recovery is weakly correlated with a subjective measure of recovery. This suggests that incomes or expenditures might not be good measures of recovery because shocks might cause losses in other dimensions of a household's well-being. The measures of recovery thus should focus on not only the money dimension but other dimensions such as happiness and health as well. Additionally, poor households usually have limited access to external resources that are needed to cope with shocks, policies should therefore aim at helping households to employ the external resources such as insurance, credit, and additional job opportunities by giving households better access to formal and informal financial markets as well as to labour markets.

\section{Concluding remarks}

In sum, this dissertation contributes to the understanding of the different facets of poverty including the monetary and multidimensional measurement of poverty, the vulnerability to 
poverty as well as coping and recovery from shocks. It shows that the dimensions of poverty do not always reinforce one another. The monetary and multidimensional measurements have much discrepancy across sub-groups of the population. They also show different trends and rates of improvement over time. In addition, the transitions into and out of poverty are driven by a household's characteristics and its ability to access to markets. Conversely, shocks do not show strong effects on these transitions because of endogeneity between shocks and a household's covariates. When faced with a shock, households of different wealth levels respond differently. Wealthier households tend to use their own resources to cope with the shocks while poorer households tend to use external resources or stay idle. Interestingly however a household's wealth is not strongly correlated with the recovery due to endogeneity, rather shock covariates determine the recovery. Shock coping strategies are not helpful to all households but they do sometimes help poor households with their recovery. The findings of this dissertation are also helpful for policy implications in developing countries which aim at sustainable development.

Figure 1.1 Economic growth, inflation and poverty rates by year, percent

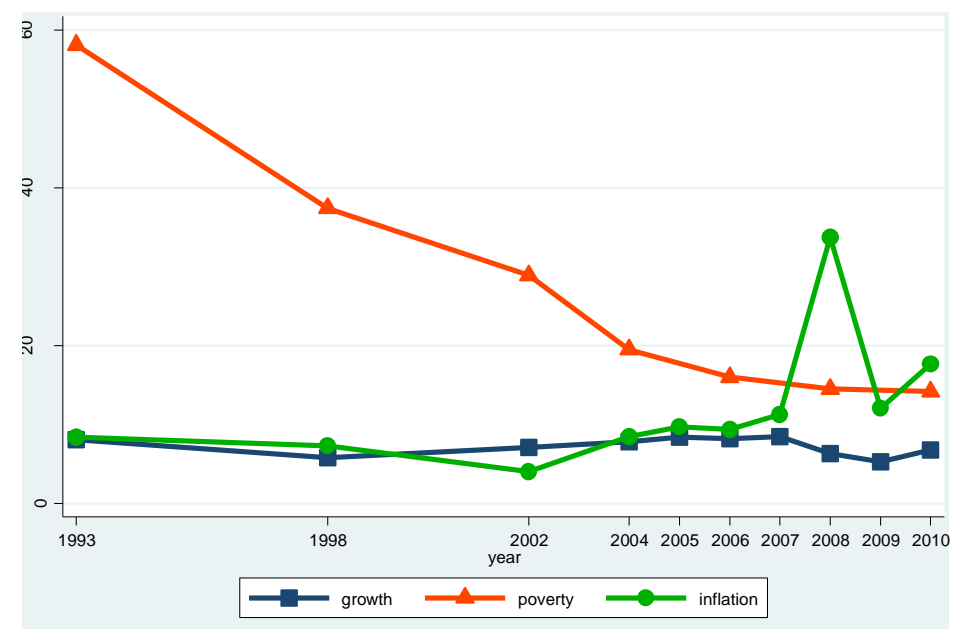

Source: Author's analysis of World Bank (2013), IMF (2013), and GSO (2011) data.

Figure 1.2 Value of losses due to natural disasters from 1990 to 2010, 1000 bil. VND

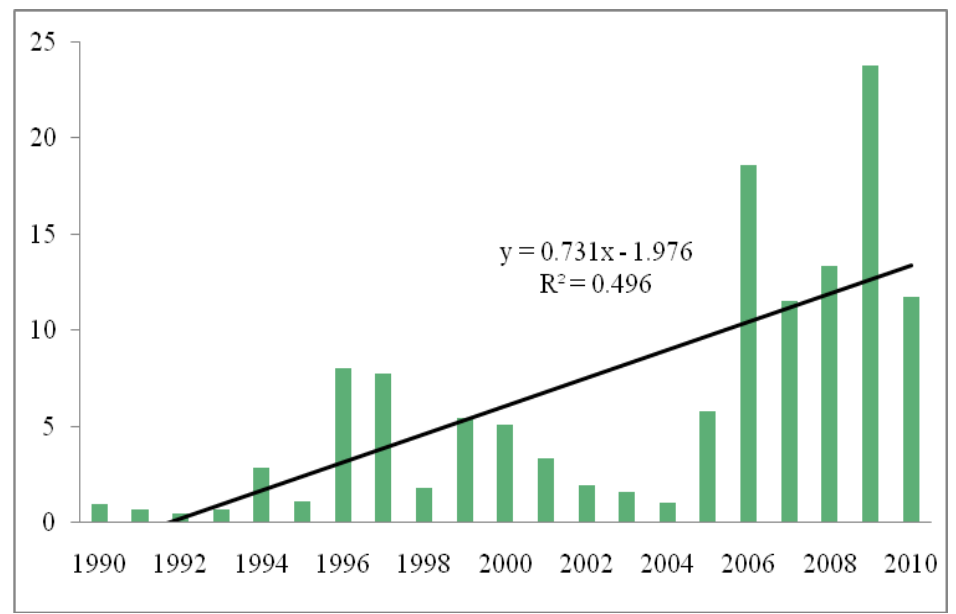

Source: Author's analysis of CCFSC damage data. 


\title{
Chapter 1
}

\section{Disparities between Monetary and Multidimensional Measurements of Poverty ${ }^{4}$}

\begin{abstract}
There has been a rapid expansion in the literature on the measurement of multidimensional poverty in recent years. Nevertheless, researchers have paid little attention to the longitudinal aspects of poverty in multidimensional measure. This study will combine the two strands of multidimensional poverty together with monetary poverty in an application to the developing country of Vietnam. Panel household survey data from years 2007, 2008 and 2010 will be employed in the analyses of the prevalence and the dynamics of both measures of poverty. The estimates show that the monetary poor (or non-poor) are not always multidimensionally poor (or non-poor). Additionally, the monetary poverty shows faster progress as well as a higher level of fluctuation than multidimensional poverty. Monetary poverty is also more sensitive to the changes in a household's characteristics than multidimensional poverty. Moreover, improvements in multidimensional poverty are attributed mainly to the reduction in the incidence of poverty rather than the intensity of poverty. The study conveys that the effects of rapid economic growth are greater and more elastic on monetary poverty than on multidimensional poverty.
\end{abstract}

\subsection{Introduction}

In the literature, there is increasing discussion of the conceptual and methodological shortcomings of the monetary measurement of poverty and the need for alternative approaches. Following the seminal work by Sen $(1979,1981)$ on the capabilities approach, there have been extensive investigations on the matter, including theoretical studies by Sen (2000), Tsui (2002), Atkinson (2003), Bourguignon and Chakravarty (2003), Duclos et al. (2006a), and Alkire and Foster (2011) and empirical studies by Klasen (2000), Baulch and Masset (2003), Duclos et al. (2006b), Asselin and Vu (2008), and Günther and Klasen (2009). They argue that "human lives are battered and diminished in all kinds of different ways" (Sen, 2000: 18), and that "all the issues around poverty are interconnected and demand crosscutting solutions" (UN, 2001: 3). In addition, markets do not exist or function imperfectly (Tsui, 2002; Bourguignon and Chakravarty, 2003; Thorbecke, 2008) and monetary values cannot be assigned to specific attributes (Hulme and McKay, 2008; Thorbecke, 2008). In any case, having sufficient income for the purchase of a basic basket

\footnotetext{
${ }^{4}$ Based on a joint work with Sabina Alkire and Stephan Klasen
} 
of goods does not directly imply that it is also spent on this basket of goods (Thorbecke, 2008). Moreover, income and consumption might not be good measures of poverty dynamics since they are highly variable over short periods of time and thus tend to report much higher levels of dynamics than do stocks such as health, education, and physical assets (Clark and Hulme, 2005). Furthermore, the measurement of household income or consumption might not be accurate because of data collection and estimation errors (see Deaton, 1997; Dercon and Krishnan, 2000). Hulme et al. (2001) also argue that the multidimensionality and severity of poverty are likely to reinforce one another. From the capability perspective, the improvement in outcomes, or human development, is more important than the changes in inputs, such as income or consumption. Therefore, the analysis of poverty and of poverty dynamics has focused more on assets, stocks and outcomes rather than on flows or inputs (Clark and Hulme, 2005; Hulme and Shepherd, 2003; Carter and Barrett, 2006) and uses non-monetary indicators more extensively (Baulch and Masset, 2003; McKay and Lawson, 2003, Günther and Klasen, 2009).

There is limited but growing amount of literature on the dynamics of poverty over several dimensions of human development. In a study from African countries, Sahn and Stifel (2000) find a declining trend in poverty as measured by a household's wealth, especially in rural areas, which is due to economic openness and the removal of distortions that discriminate against rural areas. A shortcoming of this study is that it has no comparison with the improvement in incomes because of data constraints. In another study, Harttgen, Klasen and Vollmer (2013) compare income growth and assets growth as measured by asset indices in Africa and show that the relationship between the two measures is extremely weak. Comparing income poverty with malnutrition and education deprivations in Vietnam in the 1990s, Baulch and Masset (2003) find that non-monetary indicators generally report higher levels of poverty persistence than do monetary indicators. Additionally, there is more correlation within the same measure of poverty over time than between different measures of poverty in the same time period. Günther and Klasen (2009) find that nutrition and education deprivations in Vietnam show much smaller improvements than income poverty does. They note that there is high heterogeneity in intra-household non-income poverty dynamics, which would not normally be captured by income poverty measures. A further examination of the disparities between the monetary and multidimensional measurement of poverty is therefore an important contribution to the literature on the many dimensions of poverty as well as for making effective poverty-alleviating policies. This study aims to identify which sub-groups of the population are poor in one or both measures of poverty, 
which measure of poverty shows faster progress in poverty reduction over time, and what drives the dynamics in both measures of poverty.

This study finds the answers to the research questions in the context of Vietnam although we believe that the approach is applicable to other developing countries. Vietnam has been extremely successful in sustaining a high economic growth rate of more than seven percent per annum during the last two decades. It has also been successful in translating the results of economic growth into poverty reduction by lifting some 35 million people out of poverty since the implementation of a renovation programme. Along with the economic achievements, there have been significant improvements in human capital such as health and education. The country has already attained five out of eight Millennium Development Goal targets including MDG1, MDG2, MDG3, MDG5, and MDG6 and is well on its way to reaching two more targets MDG4 and MDG8 by 2015 (UNICEF, 2012). As is evident from the previous literature and the context of fast economic growth in Vietnam, this study proposes a hypothesis that there are mismatches between monetary and multidimensional measures of poverty in identifying the poor. It is also based on a hypothesis that the monetary poverty has made faster progress over time since economic growth is transferred more directly to the reduction of income poverty. Additionally, it proposes that monetary poverty is more sensitive to the changes in macroeconomic conditions as well as to the changes in a household's assets.

The analyses of multidimensional poverty are based on the Alkire-Foster method and panel data from more than 2000 households in Vietnam collected in 2007, 2008 and 2010 to identify which sub-groups of the population are monetary poor and/or multidimensionally poor and to analyse the dynamics of those two measures of poverty over time. An advantage of this rare data set is that it allows for the analysis of both monetary poverty and multidimensional poverty in the same time period and over time.

This chapter is organised as follows: the introduction is followed by Section 1.2 which presents the data source and analytical strategy. Section 1.3 shows the multidimensional poverty profile across different sub-groups of the population and discusses the mismatch between monetary and multidimensional poverty by sub-groups of the population. After that, Section 1.4 finds the mismatch between the two measures of poverty over time and Section 1.5 reveals the drivers of poverty dynamics. Section 1.6 discusses the reasoning of the multidimensional measurement of poverty. Lastly, Section 1.7 concludes with the key messages of this study. 


\subsection{Data and analytical strategy}

\subsubsection{Data}

This study employs panel household data from 2007, 2008 and 2010 collected from the provinces of Ha Tinh, Thua Thien Hue, and Dak Lak in Vietnam in the context of the research project "Vulnerability in Southeast Asia" being run by a consortium of German universities and local research institutes in Thailand and Vietnam (see Klasen and Waibel, 2012). The Vulnerability Surveys cover more than 2000 households located in coastal, plain and mountainous areas. It contains information on household demographics, health, education, economic activities, shocks and risks, employment, financial market access, public transfer, household consumption, assets, and housing conditions.

There have been a number of household surveys in Vietnam including the Multiple Indicator Cluster Surveys (MICS) since 2000, the Demographic and Health Survey (DHS) 2002, and the Vietnam Living Standard Surveys (VLSS) from the 1990s and 2000s. However, these surveys are in the form of either repeated cross-sections such as the MICSs or pseudo-panel such as the VLSSs making them ineffective in analysing the changes of households' and individuals' poverty statuses over time. Furthermore, there is no information on income or consumption in the MICSs and DHSs and little information regarding nutrition in the VLSSs. Therefore, the Vulnerability Surveys provide good data for the analyses in this study.

\subsubsection{Analytical strategy}

In order to find answers to the research questions, this study first identifies the monetary poor using household consumption levels and then applies the newly proposed AlkireFoster method (see Alkire and Foster, 2011) to identify the multidimensional poor. It then compares the two measures of poverty across sub-groups of the population using statistical and empirical probit models to find if the two measures identify the same poor group. The dynamics of both measures of poverty are then compared via transition matrices to find which measure recorded that faster progress was being made over time. Subsequently, the study finds the key drivers of poverty dynamics in both measures by estimating probit models and by decomposing the components of the Multidimensional Poverty Index.

\subsubsection{Identification of the monetary poor}

Although households' aggregate income and consumption are available in the data set, this study is based on consumption because it is believed to be a better measure than income (see Coudouel et al., 2002: 30) and poverty lines at the national and international levels are 
usually set on the basis of consumption. Vietnam's national poverty line is approximately $\$ 1.67$ a day, or 280 thousand VND per month, which is estimated by the World Bank and General Statistics Office of Vietnam using the Vietnam Living Standard Survey 2008. In addition, we also refer to the international poverty line of $\$ 1.25, \$ 2.0$ and $\$ 2.5$ a day as references in some analyses.

\subsubsection{Identification of the multidimensionally poor}

\section{Notation}

To identify the multidimensionally poor using the Alkire-Foster method, the first step is to choose dimensions, indicators and weights that will be used in the multidimensional poverty index (MPI). The second step is to set indicator cutoffs and then create deprivation vectors of each indicator and individual. Suppose there are $N_{t}$ individuals and $D$ indicators in time period $t$. A person $n$ is deprived in indicator $d$ if his/her attainment is not higher than the indicator deprivation cutoff $\left(x_{n d} \leq z_{d}\right), x_{n d}(\in \mathrm{R})$. The weighted sum of deprivations of person $n$ is then counted as:

$$
c_{n}^{t}=\sum_{d=1}^{D} w_{d} I\left(x_{n d}^{t} \leq z_{d}\right)
$$

where $w_{d}\left(\in \mathrm{R}_{+}\right)$is the weight assigned to indicator $d$ and $\sum_{d}^{D} w_{d}=1$. The third step is to set a multidimensional poverty cutoff $(k)$; a person is identified as multidimensionally poor if he or she is deprived in at least $k$ dimensions $\left(c_{n}{ }_{n} \geq k\right)$. Thus, the multidimensional headcount ratio, or the incidence of poverty, in period $t$ is now defined as:

$$
H^{t} \equiv \frac{1}{N^{t}} \sum_{n=1}^{N^{t}} I\left(c_{n}^{t} \geq k\right)
$$

The multidimensional headcount ratio measures the percentage of the population that is multidimensionally poor. Another important measure is the average number of deprivations among the poor, or the intensity of poverty, $A^{t}$, which is defined as:

$$
A^{t} \equiv \frac{1}{N^{t} H^{t} D} \sum_{n=1}^{N^{t}} I\left(c_{n}^{t} \geq k\right) c_{n}^{t}
$$

The multidimensional poverty index (adjusted-headcount ratio), $M_{0}$, is then defined as:

$$
M_{0}^{t} \equiv H^{t} \times A^{t}=\frac{1}{N^{t} D} \sum_{n=1}^{N^{t}} I\left(c_{n}^{t} \geq k\right) c_{n}^{t}
$$

which quantifies the weighted average number of deprivations across the population, but censors the deprivations of those who are multidimensionally non-poor.

\section{Dimensions, indicators, deprivation cutoffs and weights}


The multidimensional poverty index in this study is constructed with reference to the international MPI that was presented in the Human Development Report 2010. Since people usually live in households and share common resources, it is reasonable identify deprivations and poverty at the household level. If a household is deprived in an indicator then all of its members are considered to be deprived in that indicator as well. Likewise, if a household is multidimensionally poor then all of its members are considered to be multidimensionally poor.

Table 1.1 Dimensions, indicators, cutoffs and weights

\begin{tabular}{|c|c|c|}
\hline $\begin{array}{l}\text { Dimensions } \\
\text { Indicators }\end{array}$ & Deprived if... & $\begin{array}{l}\text { Relative } \\
\text { weight }\end{array}$ \\
\hline \multicolumn{3}{|l|}{ Health } \\
\hline Nutrition & Any adult (16 years old or older) has BMI of less than 17 & $16.7 \%$ \\
\hline Health functioning & $\begin{array}{l}\text { Any member suffering serious disease/injury and unable to pursue } \\
\text { main occupation for at least four weeks }\end{array}$ & $16.7 \%$ \\
\hline \multicolumn{3}{|l|}{ Education } \\
\hline Schooling & No household member has completed five years of schooling & $16.7 \%$ \\
\hline Child enrolment & Any school-aged child is not attending school in years 1 to 8 & $16.7 \%$ \\
\hline \multicolumn{3}{|l|}{ Standard of living } \\
\hline Cooking fuel & The household cooks with dung, wood, rice leaf or charcoal & $5.6 \%$ \\
\hline Sanitation & $\begin{array}{l}\text { The household's sanitation facility is not improved, or it is improved } \\
\text { but shared with other households }\end{array}$ & $5.6 \%$ \\
\hline Drinking water & The household does not have access to clean drinking water & $5.6 \%$ \\
\hline Electricity & The household has no electricity & $5.6 \%$ \\
\hline Housing & $\begin{array}{l}\text { The walls are of metal/clay/canvas/bamboo and/or the roof is of } \\
\text { straw/wood }\end{array}$ & $5.6 \%$ \\
\hline Assets & $\begin{array}{l}\text { The household does not own more than one of: radio, television, } \\
\text { telephone, bike, motorbike or refrigerator, and does not own a car or } \\
\text { tractor }\end{array}$ & $5.6 \%$ \\
\hline
\end{tabular}

Source: Normative choice by authors with reference to MDGs and Human Development Report 2010.

Nutrition and health functioning are chosen as the two indicators of the health dimension. Unlike the MICSs and DHSs used in the Human Development Report 2010, the height and weight of household members are not measured in the Vulnerability Surveys but are subjectively reported by a respondent. In addition, age is not measured in months for children but in years. Therefore, this study focuses on the body mass index (BMI) of adults who are 16 years old or older to identify the deprivation in nutrition instead of using the weight-for-age for children as in the Human Development Report 2010. A household is deprived in nutrition if any adult has a BMI of less than 17. This lower cutoff, as compared to the cutoff of 18 in UNDP (2010), was proposed by James et al. (1988) and Himes (2000) and applied by Baulch and Masset (2003) and is reasonable for the case of Vietnam where people have lower BMIs in general. Health functioning is used as another indicator of the 
health dimension because the Vulnerability Surveys have no information on child mortality. A household is deprived in health functioning if any member had any disease or injury during the 12 month reference period and was unable to pursue his or her main occupation for more than four weeks (see Table 1.1).

The education indicators and their cutoffs are the same as those in the Human Development Report 2010. A household is deprived in schooling if none of its member has at least five years of schooling. A household is deprived in child enrollment if any 6 to 14 year old child in the household is not attending school for years one to eight (see Table 1.1).

The six indicators of living standards and their cutoffs are similar to the ones in the Human Development Report 2010. A household is deprived in cooking fuel if its main cooking fuel is dung, wood, rice leaf or charcoal. It is deprived in sanitation if it has no flushing toilet or if it has a flushing toilet but must share it with another household. A household is deemed as being deprived in drinking water if it has no access to clean (tap, purified or rain) drinking water. Since no information is recorded on a household's distance from a water source, this indicator is slightly different from that in the Human Development Report 2010. A household is deprived in electricity if the main lighting fuel is not electricity. This study also focuses on housing conditions instead of flooring because the Vulnerability Surveys have better information on the former. A household is deprived in housing if the main walls of the main house $\mathrm{s}^{5}$ are made from metal, clay, canvas, or bamboo or if the roof of the main house is made from straw or wood. Lastly, a household is deprived in assets if it does not own more than one of the following: radio, television, telephone, bike, motorbike, or refrigerator, and if the household does not own a car or tractor.

The three dimensions are assigned equal weights of 33.3 percent each, and indicators of the same dimension are then assigned equal weights (see Table 1.1). Hence, the two health indicators have weights of 16.7 percent each, the two education indicators also have weights of 16.7 percent, and the six indicators showing the standard of living have weights of 5.6 percent each.

\section{Association among indicators}

Generally, dimensions of a household's well-being are correlated with one another. For instance, education is believed to be correlated with health (see Ross and Wu, 1995; Cutler and Lleras-Muney, 2006) and with income (see Becker, 1994; Farrell and Fuchs, 1982; Berger and Leigh, 1989), and income and consumption can sometimes be correlated with

\footnotetext{
${ }^{5}$ A household might have more than a house. This study focuses on the main house only.
} 
dwelling conditions, physical assets, etc. Table 1.14 shows the results of contingency tables, the Cramer's V values, which show the correlation between every two indicators.

In general, correlations between one indicator and another turn out to be quite weak. Nutrition is found to be weakly correlated with other indicators (see Table 1.14) because a person's body mass index depends not only on the household wealth and characteristics at the present moment but, also on their genes, early childhood mental and physical conditions, household health practices, and environmental conditions, i.e. climate, pollution, availability of food stores, etc. (see Powell et al., 2007; Gonzalez et al. 2012). Health functioning is also weakly correlated with other indicators of well-being (see Table 1.14) since it is measured by a proxy of diseases and injuries which is correlated not only with household covariates such as wealth and characteristics but also with exogenous factors such as environment conditions and health shocks, etc. Schooling is moderately correlated with most other indicators; this is in line with Becker's (1994) discussion. However, child enrollment is weakly correlated with other indicators because it has a low deprivation ratio (see Raw headcount ratios in Table 1.12), which is thanks to the universal primary education programme that was started in the 1990s. Among the six indicators of living standard, cooking fuel, sanitation and drinking water all have high deprivation ratios so they are moderately correlated with one another (see Table 1.14). Three other dimensions, namely electricity, housing, and assets are loosely correlated with one another (see Table 1.14), which might be the result of the fact that they have very low deprivation ratios (see Raw headcount ratios in Table 1.12). Since most of the households have access to electricity yet use non-improved cooking fuel and non-improved sanitation facilities there is a negative correlation between electricity, cooking fuel and sanitation (see Table 1.14).

By and large, most indicators are not strongly correlated with one another. However, they are vital dimensions of human development. These dimensions are also mentioned in the Millennium Development Goals (MDGs), such as MDG2 - education, MDG4 and MDG5 health, and MDG7 - environment, and are also included in the Human Development Index, i.e. education and health. Therefore, it is reasonable to include the ten indictors in the MPI.

\section{Setting a multidimensional poverty cutoff}

The 2011 Human Development Report defines a person as being vulnerable to poverty if he or she is deprived of between 20 and 33 percent of the dimensions. This range of cutoff has its logical reasoning as it is believed that if a household is deprived in one or two indicators, i.e. being deprived in 10 or 20 percent of the dimensions, it is able to improve those indicators. Even if the improvement in those indicators is impossible, it is still not bad for 
overall human development. This study defines a person as being multidimensionally poor if he or she is deprived in at least 30 percent of the dimensions. The poverty rate at this cutoff is approximately equal to the poverty rate measured by consumption at $\$ 2.00$ in 2007 . In addition, the poverty rate at $\$ 1.67$, as measured by consumption at the national poverty line is approximately equal to the poverty rate measured by the multidimensional method at the cutoff of 38 percent in 2008 (see Table 1.2). Hence, this study will use these two pairs of cutoffs for some of the comparisons.

Table 1.2 Poverty rates at different cutoffs by measure of poverty and year, percent

\begin{tabular}{ccccc|ccccc}
\multicolumn{1}{c}{ Monetary poverty } \\
\hline cutoff $(\$)$ & 2007 & 2008 & 2010 & $2007-10$ & 2007 & 2008 & 2010 & $2007-10$ & cutoff (\%) \\
\hline 2.50 & 57.8 & 43.3 & 43.4 & -14.4 & 56.6 & 51.3 & 51.6 & -5.0 & 20 \\
2.00 & 41.9 & 26.9 & 27.9 & -14.0 & 41.6 & 35.8 & 32.7 & -8.9 & 30 \\
1.67 & 30.1 & 16.3 & 18.9 & -11.2 & 22.0 & 16.0 & 17.1 & -4.9 & 38 \\
1.25 & 13.3 & 5.6 & 6.8 & -6.5 & 16.2 & 11.9 & 13.2 & -3.0 & 40 \\
\hline
\end{tabular}

Source: Author's calculations based on Vulnerability Surveys in Vietnam

\subsection{Disparities between monetary and multidimensional poverty across groups}

In order to find if the two measures identify the same poor group, this section will compare the monetary with the multidimensional poverty across sub-groups of the population. The comparison will be supported by statistical evidence at the individual level and by empirical probit models at the household level. For simplicity, monetary poverty is set at the cutoff of $\$ 1.67$ a day and multidimensional poverty is set at the cutoff of 38 percent, where both measures show poverty headcounts of approximately 16 percent in 2008 (see Table 1.2). Sub-groups of the population are classified by household size, ethnicity, head's education attainment, consumption quintiles, ecological zones, and provincial location. Probit models are defined as:

$$
\operatorname{Pr}\left(Y_{i t}=1\right)=\alpha_{i t}+\beta_{i t} X_{i t}+\varepsilon_{i t},
$$

where $\operatorname{Pr}\left(Y_{i t}=1\right)$ is the probability of being monetary or multidimensionally poor of household $i$ at time period $t$. $X_{i t}$ captures household covariates, $\alpha_{i t}$ and $\beta_{i t}$ are parameters that need to be estimated and $\varepsilon_{i t}$ is the error term. The time period refers to the three survey years of 2007, 2008 and 2010. Likelihood-ratio tests show that all probit models are significant at the 95 percent level, which mean the hypotheses that "all coefficients in the probit models equal to zero" are rejected. Pseudo R2 of the probit models for being monetary poor are not that small, however those for multidimensional poverty are rather small indicating that the 
effects of the household and head's characteristics on being multidimensionally poor are less important than those effects on being monetary poor (see Table 1.4).

Table 1.3 The incidence of monetary and multidimensional poverty in 2008, percent

\begin{tabular}{|c|c|c|c|c|c|c|c|}
\hline & $\mathrm{MN}$ poor & $\begin{array}{l}\text { MD non, } \\
\text { MN poor }\end{array}$ & Both & $\begin{array}{l}\text { MD poor, } \\
\text { MN non }\end{array}$ & MD poor & $\begin{array}{c}\text { Average } \\
\text { dep. share }\end{array}$ & $\begin{array}{c}\text { Population } \\
\text { share }\end{array}$ \\
\hline \multicolumn{8}{|l|}{ Household size } \\
\hline 1 & 11.1 & 0.0 & 11.1 & 32.7 & 43.8 & 48.9 & 0.6 \\
\hline 2 & 9.5 & 2.2 & 7.4 & 25.9 & 33.3 & 49.5 & 6.3 \\
\hline 3 & 9.2 & 4.1 & 5.1 & 10.0 & 15.1 & 44.3 & 10.7 \\
\hline 4 & 9.2 & 5.7 & 3.6 & 8.2 & 11.8 & 46.5 & 24.3 \\
\hline 5 & 15.8 & 11.7 & 4.0 & 7.4 & 11.4 & 48.6 & 25.0 \\
\hline 6 & 21.4 & 14.9 & 6.5 & 8.7 & 15.3 & 49.2 & 16.4 \\
\hline $7+$ & 30.1 & 21.2 & 9.0 & 14.3 & 23.3 & 50.3 & 16.7 \\
\hline \multicolumn{8}{|l|}{ Head's education } \\
\hline None & 30.3 & 13.6 & 16.6 & 17.2 & 33.9 & 49.5 & 12.8 \\
\hline Primary & 19.0 & 10.8 & 8.2 & 14.2 & 22.4 & 49.1 & 23.6 \\
\hline Middle & 14.9 & 12.1 & 2.8 & 8.3 & 11.1 & 47.4 & 43.4 \\
\hline Secondary & 9.8 & 8.3 & 1.5 & 7.9 & 9.5 & 47.1 & 15.4 \\
\hline Tertiary & 0.0 & 0.0 & 0.0 & 4.0 & 4.0 & 43.9 & 4.9 \\
\hline \multicolumn{8}{|l|}{ Head's ethnicity } \\
\hline Minority groups & 34.4 & 22.9 & 11.3 & 11.7 & 22.7 & 49.1 & 19.5 \\
\hline Kinh (majority) & 11.9 & 7.9 & 4.1 & 10.3 & 14.5 & 48.2 & 80.5 \\
\hline \multicolumn{8}{|l|}{ Income quintile } \\
\hline First (poorest) & 87.6 & 58.1 & 29.5 & 4.3 & 33.7 & 49.7 & 18.7 \\
\hline Second & 0.0 & 0.0 & 0.0 & 16.4 & 16.4 & 49.1 & 19.9 \\
\hline Third & 0.0 & 0.0 & 0.0 & 15.8 & 15.8 & 46.1 & 20.5 \\
\hline Fourth & 0.0 & 0.0 & 0.0 & 8.9 & 8.9 & 48.7 & 20.1 \\
\hline Fifth (richest) & 0.0 & 0.0 & 0.0 & 7.0 & 7.0 & 46.5 & 20.8 \\
\hline \multicolumn{8}{|l|}{ Province } \\
\hline Ha Tinh & 18.7 & 13.8 & 4.9 & 10.9 & $15.8^{\circ}$ & 48.6 & 35.4 \\
\hline Thua Thien Hue & $13.9^{\circ}$ & 6.7 & 7.2 & 11.6 & $18.8^{\circ}$ & 49.1 & 22.2 \\
\hline Dak Lak & $15.5^{\circ}$ & 10.5 & $5.0^{\circ}$ & 9.7 & 14.8 & 47.8 & 42.4 \\
\hline \multicolumn{8}{|l|}{ Ecological zone } \\
\hline Coastal & 16.1 & 9.0 & 7.0 & 11.7 & 18.7 & 49.5 & 26.4 \\
\hline Plain & 15.5 & 10.0 & 5.5 & 10.1 & 15.6 & 48.1 & 36.7 \\
\hline Mountainous & 17.2 & 12.9 & 4.3 & 10.2 & 14.5 & 47.9 & 36.8 \\
\hline Average & 16.3 & 10.8 & 5.5 & 10.6 & 16.0 & 48.4 & \\
\hline
\end{tabular}

Notes: MN poor refers to monetary poor and is based on the threshold of $\$ 1.67$ a day, MD poor refers to multidimensionally poor and is based on the threshold of 38 percent, non refers to non-poor, Average dep. share refers to average deprivation share and is related to MPI only, ${ }^{\circ}$ refers to insignificant difference. Population shares in each column category sum to 100 percent.

Household size has a negative relationship with monetary poverty but a convex relationship with multidimensional poverty. Particularly, people from households of more than five members have a higher risk of being monetary poor than their peers. People from households of less than three or more than six members have a higher risk of being multidimensionally poor than their counterparts. Consequently, people from middle sized households, having from three to five members, have a lower risk of being poor in both 
measures (see Table 1.3). These figures are confirmed by empirical results from the probit models, which show that household size has a positive and relatively strong effect on monetary poverty but negative and insignificant effect on multidimensional poverty (see Table 1.4). Additionally, these households experience a lower intensity of multidimensional poverty than their counterparts. This evidence tells us that monetary poor families usually have more members because they have many children and they tend to live together to share their limited resources. Another fact is that monetary poverty in this study is identified on the basis of per capita consumption, which is more likely to indentify people from large sized families as being poorer because it ignores the economies of scale in household consumption (see Deaton and Paxson, 1998). Conversely, small sized families are usually home to single old men or women or old couples who are often deprived in health, education, and some other living standards that makes them have a higher risk of being multidimensionally poor.

Table 1.4 Marginal effects from probit models of being monetary or multidimensionally poor

\begin{tabular}{lcccccc}
\hline & \multicolumn{2}{c}{2007} & \multicolumn{2}{c}{2008} & \multicolumn{2}{c}{2010} \\
& MN poor & MD poor & MN poor & MD poor & MN poor & MD poor \\
\hline Household size & $0.0513 * * *$ & -0.00155 & $0.0310 * * *$ & $-0.0117 * *$ & $0.0326 * * *$ & -0.00590 \\
& $(0.00634)$ & $(0.00566)$ & $(0.00453)$ & $(0.00499)$ & $(0.00481)$ & $(0.00499)$ \\
Minority groups & $0.431 * * *$ & $0.113 * * *$ & $0.372 * * *$ & $0.0940 * * *$ & $0.413 * * *$ & $0.0807 * * *$ \\
& $(0.0352)$ & $(0.0327)$ & $(0.0388)$ & $(0.0299)$ & $(0.0389)$ & $(0.0293)$ \\
Primary school & $-0.0667 * *$ & $-0.0929 * * *$ & $-0.0498 * *$ & $-0.0793 * * *$ & $-0.0727 * * *$ & $-0.0607 * * *$ \\
& $(0.0310)$ & $(0.0250)$ & $(0.0202)$ & $(0.0208)$ & $(0.0208)$ & $(0.0225)$ \\
Middle school & $-0.199 * * *$ & $-0.303 * * *$ & $-0.135 * * *$ & $-0.254 * * *$ & $-0.227 * * *$ & $-0.244 * * *$ \\
& $(0.0331)$ & $(0.0301)$ & $(0.0259)$ & $(0.0275)$ & $(0.0288)$ & $(0.0289)$ \\
Secondary+ & $-0.252 * * *$ & $-0.223 * * *$ & $($ omitted) & $-0.166 * * *$ & $-0.149 * * *$ & $-0.148 * * *$ \\
Coastal & $(0.0159)$ & $(0.0125)$ & & $(0.0113)$ & $(0.0111)$ & $(0.0140)$ \\
Plain & -0.0477 & 0.0405 & 0.0141 & 0.0283 & $-0.0623 * * *$ & -0.0105 \\
& $(0.0296)$ & $(0.0297)$ & $(0.0239)$ & $(0.0262)$ & $(0.0208)$ & $(0.0242)$ \\
Dak Lak & 0.0335 & 0.0133 & -0.00368 & 0.00105 & $-0.0443 * *$ & $-0.0373 *$ \\
Ha Tinh & $(0.0278)$ & $(0.0252)$ & $(0.0210)$ & $(0.0221)$ & $(0.0202)$ & $(0.0206)$ \\
& $-0.141 * * *$ & -0.0212 & $-0.121 * * *$ & $-0.0572 * * *$ & $-0.166 * * *$ & -0.00696 \\
Observations & $(0.0255)$ & $(0.0255)$ & $(0.0174)$ & $(0.0209)$ & $(0.0177)$ & $(0.0226)$ \\
LR chi2(2) & $0.220 * * *$ & $0.109 * * *$ & $0.127 * * *$ & $0.0441 *$ & $0.178 * * *$ & $0.108 * * *$ \\
\hline Notes: MN R2 & $(0.0308)$ & $(0.0281)$ & $(0.0256)$ & $(0.0242)$ & $(0.0268)$ & $(0.0259)$ \\
& 1,865 & 1,865 & 1,761 & 1,866 & 1,866 & 1,866 \\
& 0.18 & 0.10 & 0.19 & 0.10 & 0.26 & 0.09 \\
& $127.8 * * *$ & $22.6 * * *$ & $93.5 * * *$ & $15.7 * * *$ & $169.9 * * *$ & $24.1 * * *$ \\
\hline
\end{tabular}

Notes: MN poor refers to monetary poor and is based on the threshold of $\$ 1.67$, MD poor refers to multidimensionally poor and is based on the threshold of 38 percent. Omitted categories: the head is the majority (Kinh), the head has no schooling, mountainous area, Thua Thien Hue. Standard errors in parentheses, $* * * \mathrm{p}<0.01, * * \mathrm{p}<0.05, * \mathrm{p}<0.1$.

The literature argues that the education of household members, especially of the head, has positive spillover effects on other members and hence on overall household's well-being (see Becker, 1967). This study also finds that people from a less educated background, i.e. 
the head of the household has no schooling or attains primary education only, are more likely to be poor in both measures of poverty. They also have a higher intensity of poverty (see Table 1.3). The poverty rates in both measures and the intensity of multidimensional poverty decrease substantially as the head attains higher education levels. Only four percent of individuals from households where the heads attained tertiary education is multidimensionally poor (see Table 1.3). These figures are also confirmed by the empirical results from the probit models that show that the education attainments of household heads have a strong, highly significant, and negative impact on being poor in all measures of poverty. The effects become much stronger when the head attains higher levels of education (see Table 1.4).

There are gaps between the risks of being poor in each measures of poverty across ethnic groups. Ethnic minority groups account for 16 percent of the three provinces' population and usually live in mountainous and remote areas where the infrastructure is in poor conditions. They also have less access to education, health care services, and markets, thus they are more likely to be poor in each measure of poverty as well as have a higher intensity of multidimensional poverty (see Table 1.3). Additionally, there are gaps in the risks of being poor in the two measures of poverty in each group. A person from the Kinh background is more likely to be multidimensionally poor than monetary poor. In contrast, a person from one of the ethnic minority groups has a lower risk of being multidimensionally poor than monetary poor (see Table 1.3). These facts are in line with the empirical results from probit models, which show that in each year households from ethnic minority groups have higher probabilities of being multidimensionally poor and much higher probabilities of being monetary poor than their counterparts (see Table 1.4).

In addition, the risk of being poor varies substantially across measures of poverty for the same income quintile as well as across income quintiles. A nearly 88 percent of the individuals from the poorest quintile are monetary poor while only about 34 percent of them are multidimensionally poor. People from the second poorest quintile have no risk of being monetary poor but more than 16 percent of them are multidimensionally poor. This pattern is similar to those in the third and fourth quintiles. The richest quintile still has a rather high rate of multidimensional poverty, at 7 percent (see Table 1.3). The fact is that the Vietnamese are still generally poor, more than two fifths of the population live on less than $\$ 2$ a day and the whole population lives on an average of $\$ 4$ a day. Hence, they have a high risk of being deprived in one or several dimensions of human development. The disparity in the poverty profiles suggests that being poor in the monetary measure is not necessary 
attributed to being poor in the multidimensional measure, and vice versa being poor in the multidimensional measure is not necessary attributed to being poor in monetary measure.

People from different provinces and ecological zones have slightly different risks of being poor in each measure of poverty. Since these differences are statistically insignificant in Table 1.3, the discussion focuses more on the econometric results in Table 1.4. Ha Tinh households have the highest risk of being poor in both measures because the province generally has less advantages than its two peers in economic activities and land fertility, as well as suffers from more natural disasters. Dak Lak households have the lowest risk of being monetary poor since economic activities are more dynamic there than in the other two, which is in part thanks to the coffee industry. However, they do not significantly have a lower risk of being multidimensionally poor than Thua Thien Hue households because the latter group benefited from the development of education, health care, science, and tourism services in the provincial town (see Table 1.4). The insignificant differences in the risk of being poor across provinces in Table 1.3 could be attributed to the differences across ecological zones. Thua Thien Hue households have the lowest risk of being monetary poor, but a number of households in this province are located in coastal areas, particularly the Tam Giang lagoon, that are usually poor in the money dimension as well as in multidimensional measure (see Table 1.3).

In summary, the headcount ratios in both measures of poverty varies significantly across sub-groups of the population, yet there is little variation in the intensity of multidimensional poverty. There is also a high level of mismatch between the two measures of poverty in general as well as across sub-groups. Among those who are monetary poor (16.3 percent of the population), only a third is also multidimensionally poor (5.5 percent of the population). The other two thirds (10.6 percent of the population) are non-poor in the multidimensional measure (see Table 1.3). This matching is smaller than that noted by a review of the literature on poverty by Perry (2002), which finds the matching to be between 40 and 50 percent. Nevertheless, it is bigger than the matching between income poverty and nutrition deprivation found in Vietnam by Günther and Klasen (2009), at 30 percent and 14.5 percent in 1992 and 1997 respectively; these numbers between income poverty and educational poverty are 31 percent and 17 percent respectively. The low matching between the two measures of poverty suggests that being poor in one measure is not necessary attributed to being poor in another. This is in line with the argument that having sufficient income for the purchase of a basic basket of goods does not imply that it is also spent on this basket of goods (Thorbecke, 2008) and that the measurement of households' income or consumption might not be accurate (Deaton, 1997; Dercon and Krishnan, 2000). 


\subsection{Disparities between monetary and multidimensional poverty over time}

\subsubsection{Disparities in the trends of poverty}

The poverty rates measured by the monetary and multidimensional methods have in general decreased over time at different cutoffs. Monetary poverty made particularly fast progress over the three year period. At the cutoff of 38 percent for instance, the multidimensional poverty rate decreased by nearly five percentage points while the monetary poverty ratio fell by more than 11 percentage points (see Table 1.2). Poverty reduction in the three provinces was in line with the reduction in poverty at the national level where poverty fell from 16.0 percent to 14.5 percent and to $14.2^{6}$ percent over years 2006, 2008 and 2010 (see GSO, 2009; GSO, 2011a). However, poverty rates in the three provinces were higher than that of the entire country because the three provinces are located in the second and third poorest regions of Vietnam. In studies from Vietnam from the 1990s, Baulch and Masset (2003) and Günther and Klasen (2009) also find faster progress in income poverty reduction than in non-income poverty reduction. These are also consistent with the argument of Clark and Hulme (2005) that flows are more time variant than stocks.

However, there are slight differences in the trends of the two measures of poverty in the first period (2007-2008) and second period (2008-2010), specifically at several poverty thresholds. Monetary poverty at cutoffs of $\$ 2.00$ a day and below showed a sharp reduction in the first period but a slight increase in the second period (see Table 1.2). The fast reduction in the poverty rate in the first period can be explained by the fast increase in per capita consumption of more than 20 percent. Consumption still grows at the rate of 0.3 percent in the second period yet the poverty rate increased. The fast increase in consumption in the first period could be blamed in part on the high inflation rate of more than 30 percent. Conversely, the slow increase in consumption in the second period could be the result of a lower inflation rate and the economic recession that started in late 2008 that caused a high rate of unemployment and reverse migration. Deflation factors are applied when converting household consumption but they might not have captured all the price changes to household consumption because Vietnamese households spend a large share, nearly 40 percent, of their income on food and food prices increased at a higher rate than the overall consumer price index did in those years. Poverty rates in that period at the national level showed a lower level of fluctuation. This might be the result of a better measurement of household income and consumption in national surveys, or households in

\footnotetext{
${ }^{6}$ These poverty rates are referred to national poverty line estimated by the World Bank and General Statistics Office of Vietnam
} 
the entire country were affected less by the macroeconomics fluctuation during the period. Additionally, the fast reduction in poverty in the first period and slight increase in the second period in the three provinces are also found in the multidimensional measure at higher cutoffs of 38 percent or more. The discussion of these changes will be presented in Section 1.5.2.

\subsubsection{Disparities in the mobility of monetary and multidimensional poverty}

The disparities in the mobility of the two measures of poverty are compared via transition matrices over each period of time. The left panel of Table 1.5 shows the transitions of monetary poverty at different cutoffs between 2007 and 2008. The rows show what share of the population was extremely poor, moderately poor, and non-poor in 2007 . The columns also show the share of the population belonging to those three ranges. The extremely poor classified in this matrix refers to those who lived on less than $\$ 1.48$ a day, the moderately poor are those who lived on between $\$ 1.48$ and $\$ 2.46$ a day, and the non-poor are those who lived on more than $\$ 2.46$ a day. Note that these cutoffs refer to the national poverty line of $\$ 1.67$ and the international poverty line of $\$ 2.50$ and have been slightly adjusted to match with the multidimensional poverty rate for ease of comparison. The values in the diagonal of this matrix show the shares of the population that stayed in the same poverty statuses over the first period. Similarly, the right panel of Table 1.5 shows the transitions of multidimensional poverty at different cutoffs between 2007 and 2008. For the sake of comparison, poverty cutoffs in this panel should show the same poverty rates as the ones at the cutoffs in the left panel. Hence, the two panels show the same population share in each row.

Table 1.5 Transitions of monetary and multidimensional poverty 2007-2008, percent

\begin{tabular}{ccccc|ccccc}
\hline MN poor & \multicolumn{4}{c|}{ Monetary poor 2008 } & \multicolumn{4}{c}{ Multidimensionally poor 2008 } & MD poor \\
\cline { 2 - 8 } 2007 & Ext. & Mod. & Non. & Total & Ext. & Mod. & Non. & Total & 2007 \\
\hline Ext. & 7.8 & 10.3 & 3.7 & 21.8 & 9.7 & 9.2 & 3.1 & 22.0 & Ext. \\
Mod. & 2.8 & 15.0 & 17.2 & 34.9 & 4.5 & 15.6 & 14.4 & 34.6 & Mod. \\
Non. & 0.5 & 5.7 & 37.1 & 43.3 & 1.8 & 10.5 & 31.1 & 43.4 & Non. \\
Total & 11.0 & 31.0 & 58.0 & 100.0 & 16.0 & 35.3 & 48.7 & 100.0 & Total \\
\hline
\end{tabular}

Notes: MN poor refers to monetary poor, MD poor refers to multidimensionally poor. Ext. refers to extremely poor, which refers to the thresholds of $\$ 1.48$ a day in monetary measure and 31 percent in multidimensional measure. Mod. refers to moderately poor, which refers to the range of $\$ 1.48-\$ 2.46$ in monetary measure and 23-36 percent in multidimensional measure. Non. refers to non-poor, which refers to $\$ 2.46$ monetary measure and 19 percent in measure.

The results show that among those who were extremely poor in 2007 , accounting for nearly 22 percent of the population, almost 8 percent (in absolute terms) stayed the same and more than 10 percent (in absolute terms) moved up to moderately poor. The numbers for 
multidimensional poverty are bigger, nearly 10 percent and over 9 percent respectively. Similarly, among those who were moderately monetary poor in 2007 , accounting for over a third of the population, 15 percent (in absolute terms) stayed the same in 2008 and more than 17 percent (in absolute terms) escaped poverty. Among those who were moderately poor in multidimensional measure, nearly 16 percent stayed the same in 2008 and more than 14 percent escaped poverty. In addition, more than 37 percent of the population was nonpoor in the money dimension but only 31 percent of the population was non-poor in multidimensional measure over that period. Conversely, the share of the population who stayed non-poor in the monetary dimension is larger than that in multidimensional measure, and the share of the population who fell into monetary poverty is smaller than that in multidimensional poverty. These numbers suggest that in that period the poor had a higher mobility while the wealthy had a lower mobility in monetary poverty than in multidimensional poverty. Additionally, there were more people who fell into multidimensional poverty than into monetary poverty.

In a similar vein, Table 1.6 shows the transition matrix of monetary poverty and multidimensional poverty between 2008 and 2010. Note that the poverty cutoffs in this table are not the same as the ones in Table 1.5, but they are still rather close. The shares of the population who stayed in the same poverty statuses in the monetary measure were larger than the shares of the population who stayed at the same poverty statuses in the multidimensional measure. In addition, the shares of the population who moved forward in the monetary measure were larger among the poor but were smaller among the wealthy. These results suggest that there was a slightly higher forward mobility in the multidimensional than in the monetary measure.

Table 1.6 Transitions of monetary and multidimensional poverty 2008-2010, percent

\begin{tabular}{ccccc|ccccc}
\hline MN poor & \multicolumn{4}{c|}{ Monetary poor 2010 } & \multicolumn{4}{c}{ Multidimensionally poor 2010 } & MD poor \\
\cline { 2 - 8 } 2008 & Ext. & Mod. & Non. & Total & Ext. & Mod. & Non. & Total & 2008 \\
\hline Ext. & 9.8 & 4.2 & 2.3 & 16.3 & 7.6 & 4.4 & 4.1 & 16.0 & Ext. \\
Mod. & 6.2 & 11.7 & 9.9 & 27.9 & 5.9 & 11.0 & 11.3 & 28.2 & Mod. \\
Non. & 2.9 & 9.8 & 43.2 & 55.8 & 3.6 & 11.0 & 41.2 & 55.8 & Non. \\
Total & 18.9 & 25.7 & 55.5 & 100.0 & 17.1 & 26.3 & 56.6 & 100.0 & Total \\
\hline
\end{tabular}

Notes: MN poor refers to monetary poor, MD poor refers to multidimensionally poor. Ext. refers to extremely poor, which refers to the thresholds of $\$ 1.67$ a day in monetary measure and 36 percent in multidimensional measure. Mod. refers to moderately poor, which refers to the range of \$1.67-\$2.53 in monetary measure and 23-36 percent in multidimensional measure. Non. refers to non-poor, which refers to the thresholds of $\$ 2.53$ in monetary measure and 23 percent in multidimensional measure.

Like the other two counterparts, Table 1.7 compares the mobility of the two measures of poverty for the whole three-year period. It shows that the mobility in monetary poverty was 
higher among the poor but lower among the wealthy, or the non-poor. This finding is in line with those in Günther and Klasen (2009). Additionally, multidimensional poverty showed a slightly higher downward mobility as compared with the monetary measure.

Table 1.7 Transitions of monetary and multidimensional poverty 2007-2010, percent

\begin{tabular}{ccccc|ccccc}
\hline MN poor & \multicolumn{4}{c|}{ Monetary poor 2010 } & \multicolumn{4}{c}{ Multidimensionally poor 2010 } & MD poor \\
\cline { 2 - 8 } 2007 & Ext. & Mod. & Non. & Total & Ext. & Mod. & Non. & Total & 2007 \\
\hline Ext. & 8.1 & 9.8 & 3.9 & 21.8 & 9.0 & 8.7 & 4.4 & 22.0 & Ext. \\
Mod. & 3.3 & 13.7 & 17.9 & 34.9 & 6.0 & 13.8 & 14.9 & 34.6 & Mod. \\
Non. & 1.1 & 6.1 & 36.1 & 43.3 & 2.1 & 12.1 & 29.2 & 43.4 & Non. \\
Total & 12.5 & 29.6 & 57.9 & 100.0 & 17.1 & 34.5 & 48.4 & 100.0 & Total \\
\hline
\end{tabular}

Notes: MN poor refers to monetary poor, MD poor refers to multidimensionally poor. Ext. refers to extremely poor, which refers to the thresholds of $\$ 1.48$ a day in monetary dimension and 31 percent in multidimensional measure. Mod. refers to moderately poor, which refers to the range of $\$ 1.48-\$ 2.46$ in monetary measure and 19-31 percent in multidimensional measure. Non. refers to non-poor, which refers to $\$ 2.46$ in monetary measure and 19 percent in multidimensional measure.

On the whole, the two measures of poverty show different levels of mobility across subgroups of the population as well as over time. The poor had a higher mobility in monetary poverty in the first and the whole periods but a slower mobility in the second. On the contrary, the wealthy, or the non-poor, had higher mobility in multidimensional poverty. Additionally, all groups showed a more downward mobility in the multidimensional than in monetary measure. The disparities in the mobility between the two measures of poverty reflect the fact that non-monetary indicators usually have slower changes than monetary indicators. Additionally, a high inflation in late 2007 and the economic recession that started in 2008 (see Section 1.5.2) could partly explain the fast improvements in monetary indicators in the first period but their slow improvements in the second. The fast increase in consumption could also explain the more forward mobility in monetary poverty than in multidimensional poverty.

\subsubsection{Disparities between the measures of poverty over time}

As discussed in Section 1.3, there are disparities between the two measures of poverty in the same time period. This section will discuss the disparities between them over time using transition matrices.

\section{Reverse transitions between the two measures of poverty}

The matrix in the upper panel of Table 1.8 (excluding the last two columns) shows whether the transitions in monetary poverty are accompanied by the same transitions in multidimensional poverty in the period 2007-2008. Likewise, the matrix in the lower panel (excluding the last two columns) shows their companion in the period 2008-2010. The first 
row of the upper matrix reveals that there was about two thirds of the population that stayed non-poor in the monetary dimension in the first period. Among them, nearly 81 percent stayed non-poor in multidimensional measure, while another 9 percent moved out of it. However, nearly 6 percent fell into multidimensional poverty and more than 4 percent stayed poor in multidimensional measure in 2007-2008. The remaining rows in the table are interpreted in a similar fashion.

Table 1.8 The dynamics of monetary and multidimensional poverty, percent

\begin{tabular}{lccccccc}
\hline \multirow{2}{*}{$\begin{array}{l}\text { Monetary poverty } \\
\text { trajectory }\end{array}$} & \multirow{2}{*}{$\begin{array}{c}\text { Population } \\
\text { share }\end{array}$} & \multicolumn{3}{c}{ Multidimensional poverty trajectory } & \multirow{2}{*}{ MPI } & \multirow{2}{*}{$\Delta$ MPI } \\
\cline { 3 - 6 } & Non-poor & Rising & Falling & Staying & & \\
\hline 1st period (07-08) & & & & & & 2007 & $(2007-08)$ \\
\hline Non-poor & 65.9 & 80.7 & 9.0 & 5.6 & 4.6 & 0.505 & -0.009 \\
Rising & 17.8 & 61.6 & 16.9 & 5.2 & 16.3 & 0.517 & $-0.036^{* * * *}$ \\
Falling & 4.0 & 58.9 & 20.6 & 5.7 & 14.9 & 0.501 & $-0.031^{* * *}$ \\
Staying poor & 12.3 & 41.4 & 20.6 & 12.2 & 25.8 & 0.504 & -0.007 \\
Average & & 71.6 & 12.3 & 6.3 & 9.7 & 0.508 & $-0.012^{* * *}$ \\
\hline 2nd period (08-10) & & & & & & 2008 & $(2008-10)$ \\
\hline Non-poor & 74.7 & 81.0 & 6.5 & 7.9 & 4.7 & 0.481 & -0.007 \\
Rising & 6.5 & 61.4 & 15.9 & 11.5 & 11.2 & 0.510 & $-0.051^{* * *}$ \\
Falling & 9.1 & 63.4 & 9.9 & 12.3 & 14.4 & 0.500 & -0.010 \\
Staying poor & 9.8 & 43.4 & 17.3 & 18.6 & 20.7 & 0.508 & $0.015^{*}$ \\
Average & & 74.4 & 8.5 & 9.5 & 7.6 & 0.496 & -0.004 \\
\hline
\end{tabular}

Notes: Monetary poverty refers to the threshold of $\$ 1.67$, multidimensional poverty refers to the threshold of 38 percent. Population shares of the same period sum to 100. Values showing four multidimensional poverty trajectories of the same raw sum to 100. The upper matrix: Cramér's $V=0.19$ and is significant at 99 percent, the lower matrix: Cramér's V $=0.17$ and is significant at 99 percent.

The high values of nearly 81 percent in the first cells of the first rows in the two panels (see Table 1.8) suggest that there was a strong correlation between the transitions of the two measures of poverty over time among the wealthy or the non-poor. Conversely, among those who rose in the monetary dimension, only about 17 percent also rose in multidimensional measure while more than 5 percent fell in the first period. Interestingly, more than 16 percent stayed poor while 62 percent stayed non-poor in multidimensional measure. These dynamics in the second period show a similar pattern to the first. Similarly, among those who fell into monetary poverty, only less than 6 percent also fell in multidimensional poverty while more than 20 percent rose out of it in the first period. These numbers in the second period were around 12 and 14 percent respectively, showing a higher matching between the two transitions. The numbers from these two groups of rising and falling suggest that the transitions out of and into monetary poverty are not usually accompanied by the same transitions in the multidimensional poverty. The two measures of poverty tended to have a better companion at the bottom, when the companion of the two 
measures reached 26 percent in the first period and 21 percent in the second period (see Table 1.8).

On the whole, there was a high level of disparity between the dynamics of the two measures of poverty, which also varied across sub-groups of the population. The two measures tended to show the same poverty transitions of an individual if he or she is at the top (is non-poor) or at the bottom (is chronically poor). The correlation between the two dynamics was highest for the wealthy group then came the chronically poor group, after which the correlation was rather low for those who escaped or fell into monetary poverty (see Table 1.8). This suggests that the transitions in monetary poverty do not necessary result in the same transitions in multidimensional poverty and vice versa. This finding is not in line with the argument by Hulme et al. (2001) that the multidimensionality and the severity of poverty are likely to reinforce one another. The disparities in the transitions of the two measures could be the result of the high level of fluctuation in consumption over the period, this is in line with the argument made by Clark and Hulme (2005) that money might not be a good measure of poverty dynamics since it is highly variable over short periods of time. The disparities could also be the result of the variations in the health dimension, which will be discussed in Section 1.5.2.

Table 1.9 Correlation across and within measures of poverty over time

\begin{tabular}{lcccccc}
\hline & $\begin{array}{c}\text { MD poor } \\
2007\end{array}$ & $\begin{array}{c}\text { MD poor } \\
2008\end{array}$ & $\begin{array}{c}\text { MD poor } \\
2010\end{array}$ & $\begin{array}{c}\text { MN poor } \\
2007\end{array}$ & $\begin{array}{c}\text { MN poor } \\
2008\end{array}$ & $\begin{array}{c}\text { MN poor } \\
2010\end{array}$ \\
\hline MD poor 2007 & $1.00^{*}$ & & & & & \\
MD poor 2008 & $0.40^{*}$ & $1.00^{*}$ & & & & \\
MD poor 2010 & $0.33^{*}$ & $0.35^{*}$ & $1.00^{*}$ & & & \\
MN poor 2007 & $0.26^{*}$ & $0.22^{*}$ & $0.21^{*}$ & $1.00^{*}$ & & $1.00^{*}$ \\
MN poor 2008 & $0.23^{*}$ & $0.22^{*}$ & $0.18^{*}$ & $0.43^{*}$ & $0.47^{*}$ & $1.00^{*}$ \\
\hline
\end{tabular}

Notes: MN poor refers to monetary poor and is based on the threshold of $\$ 1.67$. MD poor refers to multidimensionally poor and is based on the threshold of 38 percent, * refers to $99 \%$ significant.

The correlation between the dynamics of the two measures of poverty for the poor groups are lower than the correlation between the two measures of poverty in the same time period. This correlation is lower than that found by Whelan et al. (2004) in European countries, which is more than 40 percent. It is even smaller than the correlations between the dynamics of income and non-income indicators, i.e. nutrition and education, found by Günther and Klasen (2009), being rather high for the chronically poor and non-poor groups, which are above 65 percent, and fairly low for the transient poor group, which are in the range of 15 to 39 percent. Nevertheless, the correlations found in this study are higher than that between the monetary chronic poverty and malnutrition chronic poverty found by 
Baulch and Masset (2003), which is less than 14 percent. This suggests that the similarity between the two measures of poverty over time is lower than the similarity in the same time period.

This finding is confirmed by correlation tests between the two measures of poverty in the same time period as well as within a measure of poverty over time. There is a strong correlation within both multidimensional poverty and monetary poverty from one year to another. The correlation within multidimensional poverty between 2007 and 2008 is stronger than that of 2008 and 2010 as well as 2007 and 2010. This is in line with the finding from the previous section that there was a higher level of fluctuation in multidimensional poverty in the second period than in the first. The correlation within monetary poverty between 2008 and 2010 was stronger than that between 2007 and 2008 (see Table 1.9). This is explained by the massive change in consumption in the first period and the small change in the second period.

The correlation between monetary and multidimensional poverty in the same time periods is weak and has a declining trend. It is fairly level in 2007 where the Cramer's $\mathrm{V}^{7}$ is 0.26 and became weaker over 2008 and 2010 with the Cramer's Vs of 0.22 and 0.21 respectively. These numbers suggest that the two measures of poverty are more likely to tell similar stories about poverty in 2007 while they are less likely to do so in the following years. Moreover, the correlation between being monetary poor in one year and being multidimensionally poor in another year also becomes weaker over time. The correlation between being monetary poor in 2007 and being multidimensionally poor 2010 is smaller than that between 2007 and 2008, and they are both smaller than that in the same year of 2007. Similarly, the correlation between being monetary poor in 2008 and being multidimensionally poor in the years 2008 and 2010 show the same pattern (see Table 1.9).

\section{Reverse improvements between monetary poverty and multidimensional poverty}

The aim of this sub-section is to find if well-being is still improved when an individual's monetary poverty fluctuates up, down or horizontally. To simplify the comparison, we focus on those who stayed poor in multidimensional poverty in two sub-periods only. The last two columns of Table 1.8 show the MPI in the base year and the change in the MPI over each period for those who stayed poor in multidimensional measure in different monetary poverty trajectories. Note that these are the individuals who stayed poor in the multidimensional measure so there is no change in the incidence of poverty, thus any change in the MPI is attributed to the change in the intensity of poverty.

\footnotetext{
${ }^{7}$ The Cramer's V is calculated from a contingency table
} 
In general, most groups make progress in the MPI regardless of whether they are rising, falling or staying in the same status in the monetary dimension. However, the progress is not enough to lift them out of multidimensional poverty. The improvements in the first period are more likely to be significant than those in the second period. This is in line with the fast decrease of the poverty rate in the first period and the slight increase in the second period. In exceptional cases, those who stayed poor in both multidimensional and in the monetary measures experienced a decline in the MPI in the second period. This implies that the poor in both measures of poverty are the major victims of the bad performance of income and in well-being in this period. This also implies that changes in income in the short-term do not necessary positively affect other dimensions.

\subsection{Drivers of poverty transitions}

\subsubsection{Drivers of monetary and multidimensional poverty transitions}

The dynamics of monetary and multidimensional poverty might be driven differently by different factors. This hypothesis will be tested by probit models at the household level which are defined as:

$$
\operatorname{Pr}\left(Y_{i t}=1\right)=\alpha_{i t}+\beta_{i t} X_{i t}+\varepsilon_{i t},
$$

where $\operatorname{Pr}\left(Y_{i}=1\right)$ is the probability of entry (or exit from) poverty of household $i$ in period $t$. $X_{i t}$ captures the household covariates, $\alpha_{i t}$ and $\beta_{i t}$ are the parameters need to be estimated and $\varepsilon_{i t}$ is the error term. The time periods in this case are 2007-2008 and 2008-2010. Household covariates include the head's ethnicity, and head's education attainment; ecological zones and provincial location are controlled variables. The likelihood-ratio tests show that all probit models are significant at the 90 percent of confidence or higher levels, thus the null hypotheses that "all coefficients in the probit models are zero" are rejected. The pseudo R2 of the probit models for entry and exit from monetary poverty are not very small, however those for multidimensional poverty are small indicating that the effects of the head's characteristics on multidimensional poverty transitions are less important than their effects on monetary poverty (see Table 1.10).

The marginal effects from the probit models show that the dynamics of poverty are correlated with household and head characteristics. Large sized households have a higher probability of falling into monetary poverty and lower probability of moving out of it. They also have a higher probability of falling into multidimensional poverty and their probability of escaping it is insignificant (see Table 1.10). These are in line with the discussion in 
Section 1.3 that household size has a negative relationship with monetary poverty but a nonlinear relationship with multidimensional poverty.

Old households, or households with older heads, have a lower probability of falling into monetary poverty but a higher probability of falling into multidimensional poverty. In addition, they have a higher probability of escaping monetary poverty but a lower probability of escaping multidimensional poverty (see Table 1.10). Older heads usually have more experience and have had enough time to accumulate assets, which enable them to generate higher incomes. Nonetheless, older heads are less likely to be aware of certain living standards such as particular sanitation practices and the importance of clean water. In addition, the older they get the more health problem they are likely to develop.

Male headed households had a higher probability of falling into poverty between 2008 and 2010 than their counterparts but there is no difference in the advancement between these two groups in the other period (see Table 1.10). Male headed households usually have a larger size which causes them to have a higher risk of being deprived in the health dimension because the deprivation cutoffs of two health indicators are set on the basis of health status of all household members. In addition, in the period of economic recession, increasing livestock diseases, and increasing extreme weather conditions, people might have more health problems.

Ethnic minority households find it harder to escape poverty and have a higher probability of falling into both measures of poverty as when compared with Kinh households. Particularly, the probabilities of the ethnic households' moving out and falling into monetary poverty are larger and at higher levels of significance. Additionally, those probabilities in the first period are higher and at higher levels of significance than those in the second (see Table 1.10). Since the ethnic groups have fewer advantages than the Kinh in accessing education, health care services, and markets, their income and non-income indicators consequently improve slower. Moreover, the Kinh have better access to markets, which enables them to benefit more from economic growth than the ethnic groups, but their improvements in nonincome indicators might be not as fast as in income. Lastly, the consequences of the high inflation in 2008 and the start of the economic recession explain for the slower and smaller changes in the second period.

Households with educated heads, i.e. the head attains at least primary school, find it easier to rise from poverty and have a lower risk of falling into poverty than their peers. The effect is even stronger if the head attains middle or secondary school. The differences in the effects of middle school and secondary school are small and vary across groups and over 
time. That being said, education is one of the important determinants of a household's wellbeing (see Becker, 1967), and the higher the education the head attains the more access he or she has to public services, labour and other markets. Therefore, education has positive effects on improvements and prevents households from falling into monetary as well as into multidimensional poverty.

Table 1.10 Marginal effects of monetary and multidimensional poverty transitions

\begin{tabular}{|c|c|c|c|c|c|c|c|c|}
\hline & \multicolumn{4}{|c|}{ Monetary poverty } & \multicolumn{4}{|c|}{ Multidimensional poverty } \\
\hline & \multicolumn{2}{|c|}{$2007-2008$} & \multicolumn{2}{|c|}{ 2008-2010 } & \multicolumn{2}{|c|}{$2007-2008$} & \multicolumn{2}{|c|}{$2008-2010$} \\
\hline & Entry & Exit & Entry & Exit & Entry & Exit & Entry & Exit \\
\hline Household size & $\begin{array}{c}0.00762 * * \\
(0.00320)\end{array}$ & $\begin{array}{c}-0.0425 * * * \\
(0.0138)\end{array}$ & $\begin{array}{l}-0.00120 \\
(0.00433)\end{array}$ & $\begin{array}{l}-0.0186 \\
(0.0177)\end{array}$ & $\begin{array}{c}0.00466 \\
(0.00438)\end{array}$ & $\begin{array}{l}0.0232 \\
(0.0144)\end{array}$ & $\begin{array}{l}0.00770 * \\
(0.00466)\end{array}$ & $\begin{array}{c}0.0227 \\
(0.0164)\end{array}$ \\
\hline Head's age & $\begin{array}{c}-0.000542 \\
(0.000419)\end{array}$ & $\begin{array}{c}0.000244 \\
(0.00164)\end{array}$ & $\begin{array}{c}-0.000518 \\
(0.000533)\end{array}$ & $\begin{array}{l}0.00167 \\
(0.00221)\end{array}$ & $\begin{array}{c}0.00148 * * * \\
(0.000556)\end{array}$ & $\begin{array}{r}-0.00239 \\
(0.00188)\end{array}$ & $\begin{array}{c}0.00220 * * * \\
(0.000619)\end{array}$ & $\begin{array}{c}0.000302 \\
(0.00201)\end{array}$ \\
\hline Minority groups & $\begin{array}{c}0.179 * * * \\
(0.0470)\end{array}$ & $\begin{array}{c}-0.366^{* * *} \\
(0.0732)\end{array}$ & $\begin{array}{c}0.314 * * * \\
(0.0461)\end{array}$ & $\begin{array}{c}-0.290 * * * \\
(0.104)\end{array}$ & $\begin{array}{c}0.0707 * * \\
(0.0281)\end{array}$ & $\begin{array}{l}0.00728 \\
(0.0800)\end{array}$ & $\begin{array}{l}0.0454^{*} \\
(0.0275)\end{array}$ & $\begin{array}{l}-0.153^{*} \\
(0.0822)\end{array}$ \\
\hline Head is male & $\begin{array}{c}0.0125 \\
(0.0128)\end{array}$ & $\begin{array}{c}0.0193 \\
(0.0698)\end{array}$ & $\begin{array}{c}-0.00547 \\
(0.0201)\end{array}$ & $\begin{array}{c}0.0253 \\
(0.0906)\end{array}$ & $\begin{array}{l}0.00717 \\
(0.0204)\end{array}$ & $\begin{array}{c}0.0495 \\
(0.0699)\end{array}$ & $\begin{array}{l}0.00748 \\
(0.0215)\end{array}$ & $\begin{array}{c}-0.00464 \\
(0.0763)\end{array}$ \\
\hline Primary school & $\begin{array}{l}-0.0197 \\
(0.0123)\end{array}$ & $\begin{array}{c}0.0283 \\
(0.0629)\end{array}$ & $\begin{array}{c}-0.0343 * \\
(0.0183)\end{array}$ & $\begin{array}{l}0.0827 \\
(0.0872)\end{array}$ & $\begin{array}{c}-0.0370 * * \\
(0.0179)\end{array}$ & $\begin{array}{c}0.118^{*} \\
(0.0671)\end{array}$ & $\begin{array}{c}-0.00474 \\
(0.0251)\end{array}$ & $\begin{array}{c}-0.00304 \\
(0.0774)\end{array}$ \\
\hline Middle school & $\begin{array}{c}-0.0721 * * * \\
(0.0253)\end{array}$ & $\begin{array}{c}0.0889 \\
(0.0635)\end{array}$ & $\begin{array}{c}-0.111 * * * \\
(0.0268)\end{array}$ & $\begin{array}{c}0.280 * * * \\
(0.0883)\end{array}$ & $\begin{array}{c}-0.0881 * * * \\
(0.0281)\end{array}$ & $\begin{array}{c}0.287 * * * \\
(0.0698)\end{array}$ & $\begin{array}{c}-0.0776 * * * \\
(0.0294)\end{array}$ & $\begin{array}{l}0.185^{* *} \\
(0.0846)\end{array}$ \\
\hline Secondary+ & (omitted) & (omitted) & $\begin{array}{c}-0.0782 * * * \\
(0.0120)\end{array}$ & (omitted) & $\begin{array}{c}-0.0651 * * * \\
(0.0154)\end{array}$ & $\begin{array}{l}0.0715 \\
(0.270)\end{array}$ & $\begin{array}{c}-0.0518 * * \\
(0.0248)\end{array}$ & $\begin{array}{l}-0.286 \\
(0.192)\end{array}$ \\
\hline Non-agriculture & $\begin{array}{c}-0.00984 \\
(0.0126)\end{array}$ & $\begin{array}{c}-0.184 * * \\
(0.0867)\end{array}$ & $\begin{array}{c}-0.0503 * * * \\
(0.0153)\end{array}$ & $\begin{array}{l}0.0971 \\
(0.114)\end{array}$ & $\begin{array}{c}-0.0409 * * \\
(0.0165)\end{array}$ & $\begin{array}{l}0.191 * * \\
(0.0923)\end{array}$ & $\begin{array}{c}-0.0400 * * \\
(0.0187)\end{array}$ & $\begin{array}{c}0.132 \\
(0.106)\end{array}$ \\
\hline Land area & $\begin{array}{c}-0.000306 \\
(0.00344)\end{array}$ & $\begin{array}{c}0.110 * * * \\
(0.0347)\end{array}$ & $\begin{array}{c}6.08 \mathrm{e}-05 \\
(0.000799)\end{array}$ & $\begin{array}{c}0.0195 \\
(0.0224)\end{array}$ & $\begin{array}{c}-0.000553 \\
(0.00449)\end{array}$ & $\begin{array}{c}0.0356 \\
(0.0278)\end{array}$ & $\begin{array}{r}-0.00306 \\
(0.00669)\end{array}$ & $\begin{array}{r}-0.00491 \\
(0.00739)\end{array}$ \\
\hline Coastal & $\begin{array}{c}-0.00549 \\
(0.0135)\end{array}$ & $\begin{array}{l}-0.128^{*} \\
(0.0714)\end{array}$ & $\begin{array}{c}-0.0320 * \\
(0.0175)\end{array}$ & $\begin{array}{c}0.204 * * \\
(0.0970)\end{array}$ & $\begin{array}{l}0.00803 \\
(0.0218)\end{array}$ & $\begin{array}{l}-0.0360 \\
(0.0758)\end{array}$ & $\begin{array}{c}-0.00219 \\
(0.0219)\end{array}$ & $\begin{array}{c}0.0454 \\
(0.0818)\end{array}$ \\
\hline Plain & $\begin{array}{c}-0.00414 \\
(0.0131)\end{array}$ & $\begin{array}{c}0.0288 \\
(0.0603)\end{array}$ & $\begin{array}{l}-0.0156 \\
(0.0173)\end{array}$ & $\begin{array}{c}0.134 \\
(0.0871)\end{array}$ & $\begin{array}{c}0.000884 \\
(0.0179)\end{array}$ & $\begin{array}{c}0.0123 \\
(0.0676)\end{array}$ & $\begin{array}{c}-0.0370 * * \\
(0.0175)\end{array}$ & $\begin{array}{c}-0.00171 \\
(0.0737)\end{array}$ \\
\hline Dak Lak & $\begin{array}{c}-0.0483 * * * \\
(0.0121)\end{array}$ & $\begin{array}{c}0.156^{* * * *} \\
(0.0597)\end{array}$ & $\begin{array}{c}-0.109 * * * \\
(0.0155)\end{array}$ & $\begin{array}{c}0.176^{*} \\
(0.0957)\end{array}$ & $\begin{array}{c}-0.0394 * * \\
(0.0163)\end{array}$ & $\begin{array}{c}0.0872 \\
(0.0675)\end{array}$ & $\begin{array}{c}0.0227 \\
(0.0219)\end{array}$ & $\begin{array}{c}0.0728 \\
(0.0766)\end{array}$ \\
\hline Ha Tinh & $\begin{array}{c}0.0509 * * * \\
(0.0188)\end{array}$ & $\begin{array}{r}-0.0640 \\
(0.0701)\end{array}$ & $\begin{array}{c}0.0613 * * * \\
(0.0210)\end{array}$ & $\begin{array}{c}-0.276^{* * * *} \\
(0.0805)\end{array}$ & $\begin{array}{c}-0.0189 \\
(0.0185)\end{array}$ & $\begin{array}{c}-0.0228 \\
(0.0727)\end{array}$ & $\begin{array}{c}0.0632 * * * \\
(0.0245)\end{array}$ & $\begin{array}{l}-0.126 \\
(0.0792)\end{array}$ \\
\hline Observations & 1,209 & 513 & 1,518 & 289 & 1,390 & 415 & 1,486 & 321 \\
\hline Pseudo R2 & 0.15 & 0.09 & 0.18 & 0.12 & 0.08 & 0.09 & 0.07 & 0.05 \\
\hline LR chi2(2) & $33.5 * * *$ & $8.9 * * *$ & $71.8 * * *$ & $14.7 * * *$ & $5.2 *$ & $2.2 *$ & $7.72 * *$ & $4.71 *$ \\
\hline
\end{tabular}

Notes: Monetary poverty refers to the threshold of $\$ 1.67$, multidimensional poverty refers to the threshold of 38 percent. Omitted categories: the head is the majority (Kinh), the head is female, the head has no schooling, the head engages in agricultural activities, mountainous area, Thua Thien Hue. Standard errors in parentheses, $* * * \mathrm{p}<0.01, * * \mathrm{p}<0.05, * \mathrm{p}<0.1$.

Households from a non-agricultural background where the household head is engaged in non-agricultural activities, generally have both a higher probability of rising out of and a lower probability of falling into poverty. People engaged in non-agricultural activities usually have a better education and higher incomes and thus make faster progress. The effect of the head's labour market participation on exiting monetary poverty in the first period is unexpectedly negative. This could be attributed to the massive consumption 
growth in that period, which crowds out the effect of occupation that is considered to be per se small because the earning gap between the two job categories is small as well.

Physical assets as measured by land area also play a role in the improvement of households' wealth. It helps households escape poverty more easily in both measures and prevents them from falling into poverty. However, the effects appear to be insignificant in most of the probit models except for the rising out of monetary poverty in the first period. In fact, in some mountainous areas in Ha Tinh and Thua Thien Hue, households in the forest margins are usually poor and are allocated forest from local governments. Yet, forest is still a low value added activity in Vietnam so households there are land rich but wealth poor.

The two provinces of Thua Thien Hue and Ha Tinh are on the coastline and frequently suffer from extreme weather conditions such as storms, floods, and heat waves. However, being located in the highland, Dak Lak households suffers frequent droughts, which usually come slowly and are thus much less destructive and less likely to cause multiple losses than the short duration events of storms and floods. In addition, economic activities are more dynamic in Dak Lak which is due in part to the coffee industry and also in part to the fact that a large share of the population in Dak Lak are immigrants who have greater incentives to move forward than their peers in other two provinces. Compared to Ha Tinh, economic activities in Thua Thien Hue are more dynamic owing to the development of the tourism sector and industrial parks which create job opportunities for a number of people. Therefore, Dak Lak households have the highest probabilities of escaping both types of poverty, then come Thua Thien Hue households, while Ha Tinh households come in last. The probabilities of moving out of poverty also show the same pattern for the three provinces (see Table 1.10).

\subsubsection{Drivers of multidimensional poverty transitions}

\section{Incidence and intensity drivers}

The changes in multidimensional poverty will be decomposed to find out what the contribution they had on the incidence and intensity of poverty. As an extension of the Alkire-Forster method, the percentage change in the MPI, or $\mathrm{M}_{0}$, over the period of time from $t$ - $a$ to $t$ is defined as $\Delta \% M_{0}^{t} \equiv\left(M_{0}^{t}-M_{0}^{t-a}\right) / M_{0}^{t-a}$, as are the percentage changes in the incidence and intensity of poverty (see Apablaza and Yalonezky, 2011; Roche, 2013). Then we have:

$$
\Delta \%_{a} M_{0}^{t}=\Delta \%_{a} H^{t}+\Delta \%_{a} A^{t}+\Delta \%_{a} H^{t} \cdot \Delta \%_{a} A^{t}
$$


A percentage change in the MPI can be decomposed into the percentage change in the number of multidimensionally poor, the percentage change in the average number of deprivation of the multidimensionally poor, and a multiplicative effect.

Table 1.11 shows the changes in the incidence of poverty, the intensity of poverty, and in the MPI over the two sub-periods 2007-2008 and 2008-2010 and for the whole period. It also shows how the incidence and intensity contribute to the changes in the MPI at the cutoff of 38 percent. There were strong improvement made in the incidence of poverty and in the MPI over the first period but the incidence of poverty increased slightly over the second period. Despite this fact, there was still an improvement in the intensity of poverty in both sub-periods, albeit a slow one. The changes in the MPI in both sub-periods and the whole period were mainly attributed to the change in the incidence of poverty, at nearly 92 percent, while only 8 percent was attributed to the change in the intensity of poverty. The results suggest that there was a reduction of the number of multidimensionally poor in Vietnam over the three years but little improvement was made among those who stayed poor. The reason why there is a reverse trend in poverty in the second period and changes in the dimensions of the MPI will be discussed in the following section.

Table 1.11 Changes in incidence and intensity of poverty

\begin{tabular}{|c|c|c|c|c|c|c|c|c|c|}
\hline \multirow[t]{3}{*}{ Year } & \multicolumn{3}{|c|}{ Absolute value } & \multirow[t]{3}{*}{ Period } & \multicolumn{5}{|c|}{ Contribution to the changes in MPI } \\
\hline & & & & & \multicolumn{3}{|c|}{ Absolute contribution } & \multicolumn{2}{|c|}{ Relative con. } \\
\hline & $\mathrm{H}(\%)$ & $\mathrm{A}(\%)$ & MPI & & $\Delta \mathrm{H}$ & $\Delta \mathrm{A}$ & $\Delta \mathrm{MPI}$ & $\mathrm{H}(\%)$ & $\mathrm{A}(\%)$ \\
\hline 2007 & 22.0 & 48.9 & 0.108 & $2007-08$ & -0.029 & -0.001 & -0.030 & 97.1 & 2.9 \\
\hline 2008 & 16.0 & 48.4 & 0.078 & $2008-10$ & 0.005 & -0.001 & 0.004 & 125.9 & -25.9 \\
\hline 2010 & 17.1 & 47.8 & 0.082 & $2007-10$ & -0.024 & -0.002 & -0.026 & 91.9 & 8.1 \\
\hline
\end{tabular}

Note: Multidimensional poverty refers to the threshold of 38 percent

\section{Dimensional drivers}

Apparently, the dynamics of multidimensional poverty are attributed to the changes in deprivations of the indicators. Raw headcount ratios $^{8}$ show in general that nutrition, health functioning, and the three living standards of cooking fuel, sanitation, and drinking water had the highest deprivation ratios while education and the three remaining living standards showed remarkable achievements. There were also improvements in most indicators, especially in cooking fuel, sanitation and drinking water. However, fluctuations were found in health functioning and particularly in nutrition, the deprivation ratios increase slightly over the two sub-periods. This makes a slight increase in the multidimensional poverty rate between 2008 and 2010 because nutrition contributes a large share (nearly a fourth) to the

\footnotetext{
${ }^{8}$ Raw headcount ratio refer to the share of the population being deprived in an indicator
} 
MPI (see Table 1.12). Since cooking fuel, sanitation and drinking water have high deprivation ratios, and the two health indicators are assigned high weights, these five indicators contribute a big share of nearly 84 percent to the overall MPI.

Table 1.12 Indicator deprivations and their changes, percent

\begin{tabular}{|c|c|c|c|c|c|c|c|c|}
\hline \multirow[t]{3}{*}{ Indicator } & \multirow{2}{*}{\multicolumn{3}{|c|}{ Raw headcount ratio $(\%)$}} & \multirow{3}{*}{$\begin{array}{l}\text { Contribution } \\
\text { to MPI } \\
\text { (in } 2010 \text { ) }\end{array}$} & \multicolumn{4}{|c|}{ Change in raw head count ratio } \\
\hline & & & & & \multicolumn{2}{|c|}{$2007-2008$} & \multicolumn{2}{|c|}{$2008-2010$} \\
\hline & 2007 & 2008 & 2010 & & Entry & Exit & Entry & Exit \\
\hline Nutrition & 27.4 & 28.1 & 29.6 & 24.6 & -28.1 & 45.6 & -45.6 & 51.5 \\
\hline Functioning & 30.3 & 21.7 & 26.0 & 23.1 & -57.9 & 53.9 & -60.0 & 64.1 \\
\hline Schooling & 11.1 & 10.2 & 8.8 & 8.2 & -10.5 & 9.8 & -7.0 & 0.9 \\
\hline Child enrollment & 5.1 & 4.9 & 5.1 & 4.9 & -12.9 & 17.6 & -7.3 & 11.2 \\
\hline Cooking fuel & 82.8 & 80.0 & 68.3 & 12.6 & -0.6 & 1.1 & -9.5 & -4.8 \\
\hline Sanitation & 79.2 & 76.8 & 66.3 & 11.8 & -5.7 & 0.3 & -13.1 & -8.7 \\
\hline Drink water & 81.1 & 75.8 & 69.7 & 11.7 & -8.2 & 3.1 & -18.1 & -1.4 \\
\hline Electricity & 2.2 & 1.1 & 1.1 & 0.1 & -1.9 & 0.0 & -0.8 & 1.3 \\
\hline Housing & 7.2 & 6.0 & 5.7 & 1.1 & -9.6 & 5.3 & -5.1 & 1.1 \\
\hline Asset & 12.4 & 9.3 & 6.6 & 1.9 & -18.2 & 3.6 & -11.6 & 3.4 \\
\hline Population share & & & & & 12.9 & 6.2 & 8.6 & 9.6 \\
\hline
\end{tabular}

Notes: Functioning refers to health functioning. Values in the same column "Contribution to MPI" sum to 100

Table 1.12 displays raw headcount ratios for the entire population by indicator and year in the first three columns, the contribution of each indicator to the overall MPI in 2010 for the entire population in the fourth column, and the differences in raw headcount ratios between the end and beginning of each period for those who entered and those who exited poverty by indicator in the last four columns. Among the ten indicators, nutrition and health functioning are the two key drivers of multidimensional poverty transitions. Among those who entered poverty in the first period, more than 28 percent fell into deprivation of nutrition and nearly 58 percent fell into deprivation of health functioning. For those who exited poverty in the second period, nearly 46 percent escaped deprivation of nutrition and almost 52 percent escaped deprivation of functioning. Similar changes are also found in the second period, except in the case of cooking fuel, sanitation, and drink water, which still show strong improvements despite the overall MPI showing a fall into poverty.

\subsection{The robustness of the MPI}

In order to support the discussion of the robustness of the current version of the MPI (MPI1), this version is compared with four other versions of the MPI as well as with monetary poverty. In the second version, MPI-2, health functioning is replaced by health feeling. A household is indentified as being deprived in health feeling if any member was sick in the reference period of 12 months. All the indicators of MPI-3 are the same as MPI-1 but are 
assigned equal weights, 10 percent each. Two health indicators are excluded from MPI-4 and two remaining dimensions are given a weight of 50 percent each. The MPI-5 replaces the health dimension by monetary poverty at the threshold of $\$ 1.67$ a day (see Table 1.13). Each additional version of the MPI is then tested for its correlation with MPI-1 and monetary poverty.

Thus, the health dimension has a smaller weight in MPI-3 and MPI-4 than in MPI-1, consequently making poverty rates measured by MPI-3 and MPI-4 smaller than the poverty rate measured by MPI-1 (see Table 1.13). In addition, the correlation tests show that all the Pearson's chi-square values are significant at the 99 percent of confidence level. This implies that each version of the MPI is correlated with MPI-1 and with monetary poverty. Cramer's Vs show MPI-1 is weakly correlated with monetary poverty, so are MPI-2, MPI-3 and MPI-4, with the exception of MPI-5 which is strongly correlated with monetary poverty because consumption poverty is included as a dimension. MPI-2 and MPI-3 have a strong correlation with MPI-1 but MPI-4 and MPI-5 do not (see Table 1.13). These results suggest that any multidimensional measure of poverty has a low matching with the monetary measure regardless of how the MPI is measured. Differently put, being poor in the monetary dimension is not always correlated with being poor multidimensionally. Among the five versions of the MPI, the MPI-1 is the most reasonable because the three vital dimensions of human development are assigned equal weights and the monetary dimension is not included because the main purpose of the MPI is to double check with the monetary measure of poverty.

\subsection{Conclusion}

This study uses panel household data from three provinces in Vietnam applied to the Alkire-Foster method to investigate the achievements in human development in the monetary measure as well as multidimensional measure. The two measures of poverty are compared in the same time period to find if they identify the same poor groups. They are also analysed over time to find which measure shows faster progress and the reasons behind that by examining the drivers of the poverty transitions.

The results show that there is much disparity between the monetary and multidimensional measures of poverty. Also, the disparity varies across sub-groups of the population depending on households' characteristics and their access to markets. Those who have better access to markets and public services benefit more from economic growth and perform better in the monetary dimension. However, their performance in the multidimensional measure has a tendency to be less impressive. These facts imply that the results of economic 
growth are transferred more directly to the reduction in income poverty during the early years of development. The increase in income is necessary but not sufficient for the improvements in non-income indicators, which usually require a longer amount of time and additional efforts. These findings confirm the arguments made by Tsui (2002), Thorbecke (2008), Deaton (1997), and Dercon and Krishnan (2000) that monetary is not a good measure of poverty.

Although both the monetary dimension and multidimensional measure of well-being have made good progress over time, the former has made faster progress than the latter. Particularly, the poor have made faster progress but with more fluctuations in the monetary dimension than in multidimensional measure. Conversely, the non-poor show more fluctuations and more downward mobility in the multidimensional poverty as compared to the monetary poverty. These disparities tell us that incomes of the poor are highly variable with changes in macroeconomic conditions while non-income indicators of the wealthy have a tendency to become worse in the context of poor economic performance. Additionally, during the period of economic recession and the consequence of high inflation in the first sub-period, health became worse in the second sub-period. These results have some agreement with Clark and Hulme (2005) that income is highly variable over short periods of time.

Furthermore, monetary poverty is more sensitive to the differences in household characteristics than the multidimensional one is. This suggests that moving out of monetary poverty is easier than out of multidimensional poverty, and that being successful in escaping monetary poverty does not necessary mean that success in multidimensional poverty will follow. Moreover, the transitions in the MPI are driven more by the change in the incidence rather than by the intensity of poverty. They are also driven more by the changes in deprivation of the two health indicators nutrition and health functioning. These facts suggest that there has been little improvement in the non-income indicators among the poor community.

The findings from this study suggest that poverty alleviating policies should pay more attention to the improvement in the non-income indicators which have shown slower progress during the last years. The policies should particularly pay attention to the improvements in the health indicators of income poor households, whose multidimensional index has changed little during the last years. However, this does not mean that little attention should be paid to the monetary non-poor since they have a rather high risk of being multidimensionally poor. 
This study investigates the disparities between the two measures of poverty over a short period of time in a small sample of three provinces. Embarking from the notion that nonincome indicators usually take time to improve, further study on this issue might extend to a wider range of time and apply to a larger sample size and might include more indicators such as employment and access to financial markets to the MPI. 


\section{Appendix 1}

Table 1.13 Different versions of MPI

\begin{tabular}{lccccc}
\hline & MPI-1 & MPI-2 & MPI-3 & MPI-4 & MPI-5 \\
\hline Indicators and weights & & & & & \\
Monetary poor & 0 & 0 & 0 & 0 & 33.3 \\
Health feeling & 0 & 16.7 & 0 & 0 & 0 \\
Nutrition & 16.7 & 16.7 & 10 & 0 & 0 \\
Health functioning & 16.7 & 0 & 10 & 0 & 0 \\
Schooling & 16.7 & 16.7 & 10 & 25 & 16.7 \\
Child enrollment & 16.7 & 16.7 & 10 & 25 & 16.7 \\
Cooking fuel & 5.6 & 5.6 & 10 & 8.3 & 5.6 \\
Sanitation & 5.6 & 5.6 & 10 & 8.3 & 5.6 \\
Drink water & 5.6 & 5.6 & 10 & 8.3 & 5.6 \\
Electricity & 5.6 & 5.6 & 10 & 8.3 & 5.6 \\
Housing & 5.6 & 5.6 & 10 & 8.3 & 5.6 \\
Assets & 5.6 & 5.6 & 10 & 8.3 & 5.6 \\
\hline Poverty rate in 2008 at & & & & & \\
cutoff of 38 \% & 17.1 & 13.4 & 12.0 & 8.2 & 14.4 \\
\hline Correlation with & & & & & \\
MPI-1 & & $0.67^{*}$ & $0.71^{*}$ & $0.39^{*}$ & $0.25^{*}$ \\
Monetary poor & $0.21^{*}$ & $0.21^{*}$ & $0.26^{*}$ & $0.32^{*}$ & $0.97^{*}$ \\
\hline
\end{tabular}

Notes: Values in the first and second panels are in percent, Cramer's Vs are in the third panel, * refers to $99 \%$ significant.

Table 1.14 Associations between indicators, 2010

\begin{tabular}{|c|c|c|c|c|c|c|c|c|c|c|}
\hline & 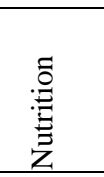 & 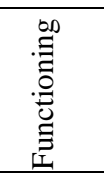 & 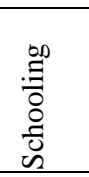 & 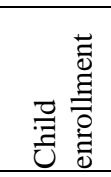 & 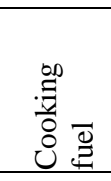 & 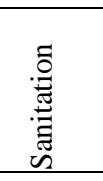 & 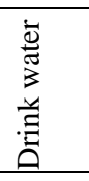 & 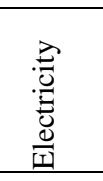 & 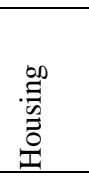 & $\begin{array}{l}\vec{w} \\
\text { D. } \\
\end{array}$ \\
\hline Nutrition & 1.00 & & & & & & & & & \\
\hline Functioning & 0.13 & 1.00 & & & & & & & & \\
\hline Schooling & -0.03 & -0.03 & 1.00 & & & & & & & \\
\hline Enrollment & -0.01 & 0.02 & 0.11 & 1.00 & & & & & & \\
\hline Cooking fuel & 0.11 & 0.14 & 0.13 & 0.10 & 1.00 & & & & & \\
\hline Sanitation & 0.03 & 0.03 & 0.10 & 0.08 & 0.39 & 1.00 & & & & \\
\hline Drink water & 0.03 & 0.04 & 0.02 & 0.00 & 0.12 & 0.26 & 1.00 & & & \\
\hline Electricity & 0.01 & -0.01 & 0.03 & -0.02 & -0.07 & -0.05 & 0.01 & 1.00 & & \\
\hline Housing & 0.03 & 0.00 & 0.08 & 0.02 & 0.09 & 0.13 & 0.03 & 0.04 & 1.00 & \\
\hline Asset & 0.03 & 0.01 & 0.32 & 0.08 & 0.14 & 0.15 & 0.05 & -0.01 & 0.18 & 1.00 \\
\hline MN poor & 0.09 & 0.03 & 0.18 & 0.15 & 0.28 & 0.25 & 0.06 & 0.00 & 0.16 & 0.24 \\
\hline
\end{tabular}

Notes: Functioning refers to health functioning, enrollment refers to child enrollment. MN poor refers to monetary poor and is set at the threshold of $\$ 1.67$ a day. Values in this table are Cramer's Vs, and are significant at 99 percent of confidence. 


\title{
Chapter 2
}

\section{Assets, Shocks and Poverty Dynamics}

\begin{abstract}
A large share of the population in developing countries still lives in poverty and their livelihoods are reliant on natural resources, which exposes them to greater risk. A better understanding of possible effects of adverse events on a household's well-being would therefore be an important contribution to the literature on vulnerability as well as beneficial to evaluating poverty alleviating policies. This study applies an asset-based approach to household panel data collected in the 2000s from Vietnam to explain the effects of shocks and household assets on the dynamics of poverty. The analyses are based on a multinomial logit model which estimates the effects of a household's asset levels and their changes that resulted from investments and negative shocks on the transitions into and out of poverty. The results show that a household's well-being is positively determined by levels of and changes in human, physical and social capital, and that some household groups become more vulnerable to poverty when faced with shocks while others are immune to shocks.
\end{abstract}

\subsection{Introduction}

The dynamics of poverty have been one of the central issues in development economics. There has been a great deal of theoretical studies (Pistaferri, 2001; Cappellari and Jenkins, 2004; Carter and Barret, 2006) and empirical studies (Bane and Ellwood, 1986; McCulloch and Baulch, 1999, Glewwe, 2000; Woolard and Klasen, 2005, Justino et al., 2008) which discuss the transitions into and out of poverty using different approaches and country cases. They have distinguished the difference between persistent and transient poverty and have identified the characteristics of sub-groups of the population that escape and fall into poverty. They have also examined the effects of macroeconomic changes, particularly the trade reforms, on households of different livelihoods and different levels of market participation on moving out of poverty. The literature has recently shifted its focus to the effects of positive and negative shocks on a household's well-being, leading to an increasing number of studies on the effects of different types of shocks on households' income and poverty levels.

An investigation of the effects of shocks on poverty dynamics is thus an important contribution to literature on vulnerability, particularly to the literature that conceptualises the effects of shocks on a household's well-being. It is also an important contribution to policy implication, as it is helpful for designing sound poverty alleviating policies. The 
main goal is to identify which household groups are more vulnerable to poverty and if the changes in some key assets lead to the changes in the poverty status. Particularly, this study investigates whether an unexpected event causes a household to fall into poverty or traps a household in poverty.

This study examines these research questions in the context of Vietnam although the approach can be applied to other developing countries. Vietnam has been one of the most successful countries among the developing world in economic growth and poverty reduction. The rapid economic growth, together with market liberalisation and trade openness that took place during the last two decades, has lifted a large share of the population out of poverty. The share of the population living below the poverty line has decreased dramatically from 58 percent in 1993 to 14.2 percent in 2010 causing some 35 million people to move out of poverty.

Nonetheless, poverty is still a central issue in the country as nearly 43 percent of the population still lives on less than \$2 a day (World Bank, 2013) and many people earn their living by engaging in agricultural activities. Various sub-groups of the population have benefited less from this development. Households in rural areas have made slower progress than those in urban areas. The results of the Vietnam Living Standard Survey 2010 show that the poverty rates in urban and rural areas are 6.9 and 17.4 respectively (GSO, 2011a). Households in mountainous areas are major victims of poverty while only a small share of households in lowland areas is vulnerable to poverty. The poverty rate for the mountainous northeast region is nearly 40 percent while that in the southeast region is just a little more than 3 percent (GSO, 2011a). Additionally, ethnic minority groups have lower living standards than the majority group, or the Kinh; their poverty rates are 47.5 and 7.4 respectively (Badiani et al., 2012). Moreover, the livelihood in this transition economy has been increasingly affected by extreme weather conditions, macroeconomic instabilities including inflation, policy changes, and unemployment spells, in addition to the consequences of rapid liberalisation that causes market imperfections. Therefore, a large share of the population faces many uncertainties and has a high risk of falling into poverty.

This study uses three waves of a panel surveys from 2007, 2008 and 2010 of more than 2000 rural and peri-urban households from three provinces in Vietnam. The drivers of poverty transitions are investigated via descriptive statistics and empirical results from multinomial logit models. The analyses are based on the hypothesis that households that have good access to infrastructure and markets find it easier to escape poverty. Contrarily, households from ethnic minority groups are more vulnerable to poverty. Shocks that cause a decline in assets and incomes might make households fall into poverty. The findings 
confirm that a household's well-being is positively determined by levels of and changes in human, physical and social capital but is negatively correlated with shocks.

This chapter is organised as follows. Section 2.2 discusses the theories and reviews findings of empirical studies on poverty dynamics. Section 2.3 describes the household panel data used in the analysis and presents the estimation strategy. Section 2.4 discusses results of the multinomial logit models that highlight the relationship between asset endowments, exposure to shocks, and household well-being. After that, Section 2.5 discusses the robustness of the estimation results. Lastly, Section 2.6 concludes with the key messages of this paper.

\subsection{The literature on poverty dynamics}

\subsubsection{Theories of poverty dynamics}

In the literature on poverty dynamics, there has been an extensive discussion on the conceptual and measurements of vulnerability using various approaches. The first follows the pioneer work of Bane and Ellwood (1986) and is known as the spells approach. A number of theoretical and empirical studies have used this approach to discuss the ability of households to move out of poverty (Stevens, 1994; Iceland, 1997; Gaiha and Deolalikar, 1993; Duncan and Rodgers, 1988; Cappellari and Jenkins, 2004), as well as the risk of falling into poverty, and the persistence of being chronically poor. The second is known as the components approach, exemplified by Jalan and Ravallion (1998), which constructs a permanent component of income and identifies a chronically poor person as one for whom this component lies below an appropriate poverty line. In an extension work of the components approach, Pistaferri (2001) attempted to identify the effects of shocks on a household's income. The shortcomings of the spell and component approaches are that they distinguish transient and chronic poverty predominantly in the monetary dimension. Yet, a household's income or consumption might be affected by good or bad luck in one period.

Hence, a promising alternative approach may be one that is based on household assets to distinguish between the structurally poor and the stochastically poor. This approach originates from macro-level growth literature and was conceptualised by Carter and May (2001), Zimmerman and Carter (2003), and Carter and Barrett (2006) for a micro setting. Assets include human, social, physical, financial, and natural capital, which generate a household's well-being and are measured on the horizontal axis in Figure 2.1. The vertical axis measures utility, which can be measured by income or expenditures, the money poverty line on this axis is denoted by $u$. The relationship between assets and well-being is 
illustrated by the curve $u_{l}$. The asset poverty line is the level of assets that predicts a level of well-being equal to the monetary poverty line.

Figure 2.1 Income and asset poverty lines

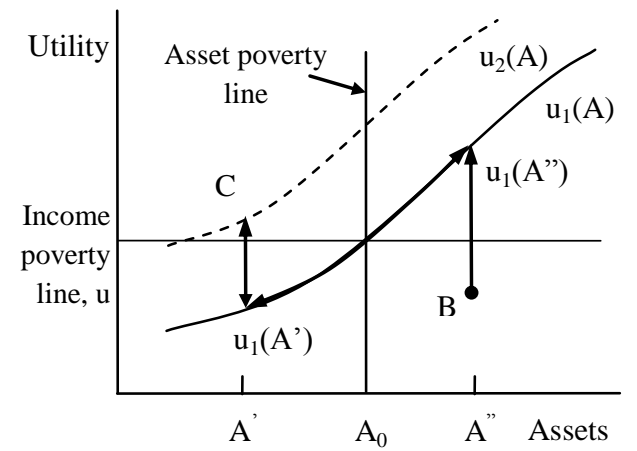

Source: Carter and May (2001)

A household is structurally poor if its asset level is so low that it is unlikely to be able to rise above the poverty line in the future. On the contrary, a household is stochastically poor if it is poor in one or more periods (at $B$ for instance), yet still possess a sufficient stock of assets. This would suggest that its poverty reflects bad luck in one specific period, but may not have longer-term consequences. Households identified as chronically poor in the money dimension may be structurally poor in assets, and likewise a persistently non-poor household might be expected to be structurally non-poor, at $u_{1}(A$ ") for instance. Transient poor households, however may be stochastically poor or non-poor. The poor status might be a reflection of bad luck in that specific period or they may have made a structural shift in asset levels (Carter and Barrett, 2006).

The chance of a household escaping poverty or staying non-poor depends on its asset level and its process of accumulating key assets. Households with a very low level of assets find it difficult to accumulate human and physical capital. One possibility for asset accumulation is to follow a critical saving strategy, but this might not work because their consumption cannot be reduced further. Cutting food consumption would reduce energy to work and withdrawing children from school would affect negatively on long term human capital. They would like to borrow sufficient funds but lack access to financial markets, thus they might not able to participate in technology intensive projects that require a minimum investment (Carter and Barrett, 2006). They are therefore only able to pursue a low return strategy (expressed as a curve $L_{1}$ in Figure 2.2), while households with higher asset holdings are able to follow a higher return strategy (expressed as a curve $L_{2}$ ). If a household's stock is not too far from the asset level where increasing returns occur $\left(A_{S}\right.$ in Figure 2.2) it finds it feasible to accumulate assets in order to pursue a higher return strategy. Otherwise, the household is consequently caught in a poverty trap and is expected 
to reach an equilibrium asset holding at the low level $\left(A_{l}\right)$. The critical asset level where household finds it feasible to accumulate assets $\left(\mathrm{A}^{*}\right)$ is called a "Micawber threshold" (Zimmerman and Carter, 2003: 234), a household with an asset level above that threshold is expected to move out of poverty or remain above the poverty line.

Figure 2.2 The dynamic asset poverty line

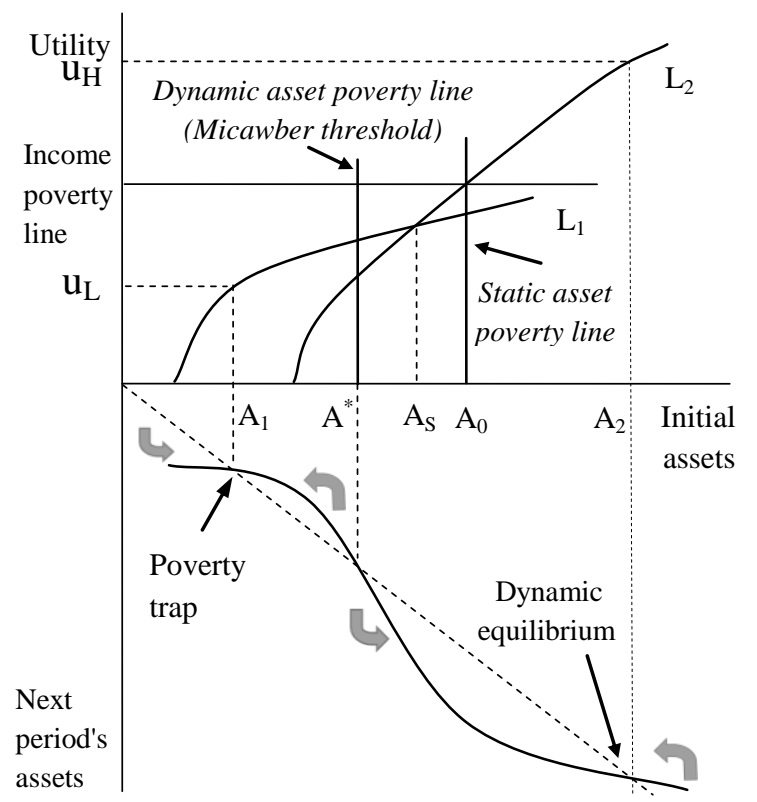

Source: Carter and Barrett (2006)

As discussed above, low income households are usually associated with a limited asset base thereby often making them reliant on natural resources (Arun, 2008), which in turn potentially exposes them to greater risks. In addition, they might also receive inadequate protection from the law, lack a voice, have higher risks from possible conflicts, and could often be discriminated against. An unexpected adverse event, for instance a flood, a drought, an illness, an unemployment spell, or a price shock might cause a decline in asset stocks or livestock, wash away land and plantations, and sometimes reduce household income. Poor households usually have few assets and the assets they possess are often more prone to risk, thus a shock might cause them to fall into a poverty trap. Furthermore, after a shock, poor households might have to sell assets to smooth consumption because they have limited access to financial and labour markets. This will reduce their asset stocks further and they might face a doubly slow recovery process (Carter et al., 2007). On the contrary, wealthier households that have better access to financial markets might use credit or their savings to rebuild their asset stock quickly and fully after the shock (Carter et al., 2007).

Therefore, the changes in a household's poverty status can be explained via the stock of assets the household possesses and the changes in the asset levels. The stock of assets includes human capital, physical capital, financial and social capital. The changes in 
household assets may be the results of asset accumulation and negative shocks that destroy assets. Asset accumulation in turn depends on the initial asset stock level the household possesses, if it is lower than the minimum level, then the household might be unable to accumulate assets for its advancement.

Households in developing countries are generally poor and possess few assets which consequently making them vulnerable to shocks and therefore to poverty. An unexpected event might cause a decline in income and assets and therefore makes a nearly poor household fall into poverty or traps poor households in poverty. This hypothesis will be tested by empirical analyses.

\subsubsection{Empirical evidence from the literature on poverty dynamics}

Poverty dynamics have been discussed extensively in a number of empirical studies as well. They have applied different approaches and methods to many countries to find the effects of a household's characteristics and assets on poverty dynamics. In a study on British households applied to the first-order Markov model, Cappellari and Jenkins (2002) find that married couples have both lower poverty entry rates and lower poverty persistence rates than single mothers. Additionally, results from the duration model in Cappellari and Jenkins (2004) show that the education of the household head is positively associated with the transition out of poverty. Also, household heads of some ethnic groups have much higher probabilities of falling into poverty than those of European origin, and that households that are composed of multi-generations or a high ratio of children have a higher probability of being poor.

In addition, various non-parametric methods are also applied in the analyses of poverty dynamics. Carter and May (1999) find from South Africa that poverty is not only a matter of having few assets, but also of the constraints that limit the effectiveness of using the assets. This method is also applied to compare the dynamics of monetary and non-monetary indicators in Vietnam in the 1990s with the results showing that during the early years of the economic boom the monetary poverty rate decreased faster than that of non-monetary indicators (Baulch and Masset, 2003; Günther and Klasen, 2008).

A microgrowth model is also applied by Glewwe et al. (2000) and Litchfield and Justino (2004) where the results show that education contributes to escaping poverty, that the occupation of the household head and spouse affect a household's well-being. Additionally, they find that the rate of poverty reduction varied across urban and rural areas as well as across regions in the 1990s Vietnam. Using the same approach, Jalan and Ravalion (2002) find from China that households' consumption growth is divergently affected by geographic 
capital, which is related to publicly provided goods such as rural roads. Woolard and Klasen (2005) find that demographic changes, as a result of the changes in fertility and mortality, and employment changes were the most important determinants of mobility in South Africa in the 1990s. In addition, large household size, low level of assets, poor initial education, and poor participation in the labour market trap a household in poverty.

The studies of McCulloch and Baulch (1999) on Pakistan, and of Bhide and Mehta (2005) and Bigsten et al. (2003) on Ethiopia apply OLS, probit and logit models to show the importance of household size, number of dependents, education, and the percentage of females on the level of a household's well-being. They also find that livestock, less land and other physical assets are correlated with poverty transitions (McCulloch and Baulch, 1999; Bhide and Mehta, 2005). Contrarily, Bigsten et al. (2003) show that the amount of land households cultivate is correlated significantly with their per capita expenditure but insignificantly with poverty dynamics.

Kedir and McKay (2005) apply a multinomial logit model for urban chronic poverty in Ethiopia and find that it is strongly associated with high dependency rates, low levels of human capital, unemployment, and being homeless. The study of Lawson et al. (2006) in 1990s Uganda also applies this logitic model and shows that education attainment, engagement of members in non-agricultural activities and assets acquired through purchases or inheritances are often important escape routes while losing productive assets is an entry into poverty. In addition, market constraints, a feeling of exploitation, increased taxation and impacts of HIV/AIDS are also identified as factors that deteriorate living standards.

There has also been increasing discussion on the effects of exogenous factors on poverty dynamics. In a study in 2000s Vietnam, Niimi et al. (2007) find that the result of trade reform was reduced poverty because exports and imports boomed and the prices of some tradable goods increased strongly which in turn benefited those who engaged in rice, coffee and light manufacturing sectors. Justino et al. (2008) then find the mechanisms of trade openness brings changes in household employment patterns toward export sectors. Trade also resulted in an increase in the price of agricultural products and a decrease in fertiliser prices which benefited rice, coffee and other crops producers (Justino and Litchfield, 2003). Nevertheless, households that live in the remote areas, belong to ethnic minority groups, have a large number of members and low levels of education are not prevented from falling into poverty in the process of economic reforms (Justino and Litchfield, 2003).

Among the exogenous factors of poverty dynamics, shocks is of particular interest in many studies. In a study from South Africa, Carter and May (2001) use a transition matrix and 
find that falling into poverty is a consequence of transitory entitlement failure and shocks such as losses of economic or social assets. Dercon (2004) finds that rainfall shocks have a substantial impact on consumption growth, which persisted for many years in Ethiopia. Quisumbing and Baulch (2009) find from Bangladesh that negative shocks, including covariate and idiosyncratic shocks, and positive shocks have significant effects on the accumulation of assets over time. Thomas et al. (2010) estimated the effects of natural disasters on a household's well-being, applied the estimates to the standard consumption model, and find that floods, droughts and hurricanes can cause substantial short-run losses and long-run negative effects on households' livelihoods in Vietnam. Kristjanson et al. (2010) also indicate that health problems and the resulting expenses cause a decline in households' well-being in some zones. As far as climate and theft go, they are important sources of vulnerability in the poorest zone while unemployment is a main cause of falling into poverty in urban zones. Imai et al. (2011) find in the 2000s Vietnam that lack of land, access to infrastructure, and education are associated with higher probability of being vulnerable to poverty, which is measured by the "Vulnerability as Expected Poverty". These associations vary across ethnic groups and locations. Additionally, in the context of rapid integration in the global economy and better infrastructural support, both poverty and vulnerability are likely to decline.

\subsubsection{Summary}

The literature on poverty dynamics has shown that households with higher levels of human and physical capital, better access to public services, and better access to markets benefit more from economic growth and reforms and thus find it easier to escape poverty. In contrast, those with poor assets benefit little from the economic growth, which causes them to have a higher risk of falling into poverty and could affect their ability to move out of it. The recent studies have paid more attention to the effects of adverse events on poverty dynamics, which cause a decline in household's income and assets. A shock could cause a household to fall into poverty or prevent it from moving forward. However, little evidence of the effects of shocks on poverty dynamics in Vietnam has been found. This study aims to make a contribution the literature on vulnerability, particularly on the empirical analysis of poverty dynamics in Vietnam, by investigating whether a household's asset level and its changes determine the moving into or out of poverty and whether a shock causes a household to fall into poverty or become trapped it in poverty.

In order to investigate poverty dynamics in the context of shocks in Vietnam, this study proposes the hypotheses that higher levels of household human and physical capital are helpful in improving households' well-being and that a shock causes severe losses in assets 
and incomes that might make some groups of households to fall into poverty. Nevertheless, how the effects of a shock influence falling into poverty might depend on the severity of the shock and the household's ability to cope with the shock.

Additionally, the choice of data makes this study a new contribution to the literature on poverty dynamics. Previous studies on the exogenous factors affecting poverty dynamics are based on only a few types of events such as the effect of trade reform on poverty dynamics (Justino and Litchfield, 2003; Niimi et al., 2007; Justino et al., 2008) and several type of shocks such as storms, floods, droughts (Dercon, 2004; Carter et al., 2007; Thomas et al., 2010) and health shocks (Kristjanson et al., 2010). The Vulnerability Surveys data contain information on many types of shocks that occurred to households, which allows the analysis to come closer to the real life situation. In addition, shocks in our Vulnerability Surveys are self and subjectively reported by respondents (see Section 2.3.1), making it possible to identify all the shocks that occurred to a household as sometimes one shock might follow another and could go unrecorded. Thus this analysis might not be possible with many other data sources.

\subsection{Empirical strategy}

\subsubsection{Data}

This study is based on panel household surveys from 2007, 2008 and 2010 from the provinces of Ha Tinh, Thua Thien Hue and Dak Lak in Vietnam for the purpose of the research project "Vulnerability in Southeast Asia" being run by a consortium of German universities and local research institutes (see Klasen and Waibel, 2012). The survey covers more than 2000 households located in rural and peri-urban areas in the three provinces. The three provinces have a diversity of agricultural and ecological conditions with mountainous, highland, lowland and coastal zones. The surveys collect information on household demographics, health, education, economic activities, employment, access to financial markets, public transfers, household expenditures and assets, and particularly on shocks and risks.

There are already several available household data sets such as the Vietnam Living Standard Surveys (VLSS) from the 1990s and 2000s and the Vietnam Population Censuses. Though these have a large sample size, VLSSs are semi-panel surveys and are spread out over the entire country consequently making it difficult to have a panel data set which is rich in the number observations of a specific province. Moreover, both of the two types of surveys contain much less information on risks which causes them to be less suitable for our analysis. 
This study is applied to the context in which the livelihood in Vietnam was increasingly affected by a number of risks. Agricultural activities were increasing affected by livestock diseases and extreme weather conditions. Inflation started to rise in 2007 and peaked in 2008 with a rate of more than 30 percent (World Bank, 2013), which raised food price and consequently made the poor worse-off. The inflation was then followed by the economic recession that started in 2008, in which thousands of firms went bankrupt every year causing a number of job losses and forcing many migrants to return to their home villages.

\subsubsection{The drivers of poverty transitions}

This study applies a multinomial logit model (MNL) presented in Wooldridge (2002). Changes in household poverty statuses over a period can be classified into several mutually exclusive outcomes. The MNL model determines the probability that household $i$ experiences one of the $j$ mutually exclusive outcomes. The probability is expressed as:

$$
p_{i j}=P\left(Y_{i}=j\right)=\frac{e^{\beta_{j} x_{i}}}{\sum_{k=1}^{J} e^{\beta_{k} x_{i}}}, \text { for } j=0,1,2, . ., J
$$

where $Y_{i}$ is the outcome experienced by household $i, \beta_{k}$ are the set of coefficients to be estimated and $x_{i}$ includes a household's covariates and their changes. The model is, however unidentified since there is more than one solution for $\beta_{0} \ldots \beta_{J}$ that leads to the same probabilities $Y=0, Y=1, Y=2 \ldots, Y=J$. To identify the model, one of the $\beta_{j}$ must be set to zero, and all other sets are estimated in relation to that base category. For convenience, $\beta_{0}$ is set to zero, therefore the above probability function can be written as:

$$
p_{i j}=P\left(Y_{i}=j\right)=\frac{e^{\beta_{j} x_{i}}}{1+\sum_{k=1}^{J} e^{\beta_{k} x_{i}}} \text {, for } j=1,2, . ., J \quad \text { and } \quad p_{i 0}=P\left(Y_{i}=0\right)=\frac{1}{1+\sum_{k=1}^{J} e^{\beta_{k} x_{i}}}
$$

In the panel years 2007 - 2008 - 2010, poverty dynamics can be classified into eight categories of 1) being non-poor - non-poor - non-poor, 2a) poor - poor - non-poor, 2b) poor - non-poor - non-poor, 3a) non-poor - poor - poor, 3b) non-poor - non-poor - poor, 4a) nonpoor - poor - non-poor, 4b) poor - non-poor - poor, 5) poor - poor - poor. These eight categories can be grouped into five mutually exclusive outcomes, $J=4$ and $P(Y=0)$ is the household's probability of being non-poor in all periods, $P(Y=1)$ is the probability of rising (includes categories $2 \mathrm{a}$ and $2 \mathrm{~b}$ ), $P(Y=2)$ is the probability falling (includes categories $3 \mathrm{a}$ and $3 \mathrm{~b}$ ), and $P(Y=3)$ is the probability of churning (includes categories $4 \mathrm{a}$ and $4 \mathrm{~b}$ ), and $P(Y=4)$ is the probability of being poor in all periods. Thus, the specific model applied in this study when standardising $\beta_{0}=0$ is expressed as: 
$p_{i j}=P\left(Y_{i}=j\right)=\frac{e^{\beta_{j} x_{i}}}{1+\sum_{k=1}^{4} e^{\beta_{k} x_{i}}}$, for $j=1,2,3,4 \quad$ and $\quad p_{i 0}=P\left(Y_{i}=0\right)=\frac{1}{1+\sum_{k=1}^{4} e^{\beta_{k} x_{i}}}$

The multinomial logit model will estimate coefficients for four categories relative to the omitted category, which represent the category of being non-poor in all periods. In order to interpret the results more easily, the results of multinomial logit model are used to predict marginal effects, which measure the conditional probabilities of a change in the regressors on the outcome and are estimated as:

$\frac{\partial p_{i j}}{\partial x_{i}}=p_{i j}\left(\beta_{j}-\sum_{k=1}^{4} p_{i k} \beta_{k}\right)$

A marginal effect shows the impact of a change in an explanatory variable on the probability of a household of being in each of the five categories.

In addition, the results of multinomial logit model are also applied to adjusted predictions, another expression of recycle predictions, which predict marginal effects at an assigned value of a regressor while keeping other regressors at their means. The results of the adjusted predictions tell us the percentages of households belonging to each of the five categories.

Household income and consumption are available in the data, however consumption is a better measure of a rural household's well-being (Deaton, 1997) because it might also have in-kind income which cannot be captured by a household survey. Therefore, this paper is based mainly on per capital consumption instead, and refers to the equivalence scale expenditure in some analyses. The equivalence scale expenditure is calculated as the total household expenditure divided by household equivalence size using the OECD (1982) scale $^{9}$. Poverty status refers to the Vietnam national poverty line estimated by the World Bank and the Vietnam Statistics Office using the Vietnam Living Standard Survey 2008, which is $\$ 1.67 \mathrm{PPP}$ a day.

Explanatory variables include household asset levels in the first period and changes in key assets over the years. Household assets are measured by household and individual characteristics as proxies for human capital; household location as a proxy for market access; land use and asset index represent physical assets; migration and remittance as proxies for social asset; and shocks reflecting changes in asset levels.

\footnotetext{
${ }^{9}$ This scale was proposed by OECD (1982) which assigns a scale of 1 to the first household member, of 0.7 to each additional adult and of 0.5 to each child.
} 
Household characteristics include household size and the dependency ratio. The dependency ratio is measured by the ratio of members of less than 18 or more than 65 years old to household size. The changes in household demographics are measured by two dummy variables showing if the household has had a new birth or if someone has left the household between 2007 and 2008 and between 2008 and 2010.

Head characteristics include gender, age, ethnicity, education attainment and occupation. As discussed in Section 2.2, these characteristics are expected to be correlated with a household's well-being. Occupation of the head is classified into the two categories of agriculture and non-agriculture. Agricultural jobs include: doing own agriculture, fishing, collecting, hunting, and permanent or casual off-farm labour in agriculture, etc. Some heads are unemployed or unable to work, they account for less than one percent of the sample. However, people in rural areas still work in their garden or take care of livestock so they are somehow involved in agricultural activities hence it is reasonable to consider they are working in the agricultural sector. Non-agricultural jobs include government servants, offfarm self employment, and being permanent or casually employed in non-agriculture, etc. Agriculture requires less skills, yields lower incomes and is more vulnerable to shocks compared to non-agriculture hence this paper takes agriculture as the reference.

Rural poor households lack access to insurance and official financial markets so they have to rely on their migrants, friends, and relatives to invest in their assets and cope with shocks. The social asset is measured by dummy variables of migration and remittance. A migrant is a household member that is away from home for a consecutive period of more than three months during the 12 month reference period of each survey wave. Remittance includes money and in-kind gifts from household members and non-household members. A dummy variable expresses if the household got any remittance during the period or not. Public transfer includes transfers from governmental or non-governmental organisations and is measured by a dummy variable expressing if the household got public transfers or not.

Physical assets are represented by village infrastructure, household asset index and land area. Village infrastructure such as roads, schools, health clinics, electricity net, post offices and banks, etc. are often commensurate with one another. The quality of the main road in the village is chosen as a proxy for all of these and is measured by a dummy variable referring to the non-paved condition. Household assets include quantitative and qualitative items. The quantitative assessment concerns whether the household has: a motorbike, a bike, a television, a radio, a CD player, an electric fan, an electric rice cooker, a fridge, and a mattress. The assessment of quality includes: having improved flooring condition, having improve housing condition, having access to improved sanitation facility, and using 
improved cooking fuel ${ }^{10}$. House size is also included and is measured in square meters. These items are included in the estimation of the asset index via principal component analysis. Among the items, motorbike plays an important role (with a weight of 24 percent) then comes television (10 percent) while the other items are less important, each of which contributes less than 10 percent to the asset index (see Table 2.5).

Location of household includes dummy variables indicating provincial and ecological location. Dak Lak is located in the highlands with basalt soil, which is suitable for planting high value added crops such as coffee, pepper, cashew and rubber. The population density in the province is also lower allowing households there to possess more land than their peers in the other provinces. On the contrary, Ha Tinh and Hue are in the coastal area frequently hit by storms and floods. These differences make it reasonable to treat Dak Lak as a reference. Infrastructure in the mountains or highlands is of poorer quality that limits their access to markets, ergo these areas are treated as another reference.

Shocks in our surveys are defined as events negatively affecting a household's well-being and are subjectively and self reported by respondents. Respondents are also asked to scale severity of the shocks by four levels: high, medium, low, and no impact. Shocks that have no impact on the household are not included in the analyses. A number of shock types were recorded in the surveys, which are then classified into five groups: climatic, agricultural, business, health or social events. Climatic shocks include storms, floods, droughts, heavy rains, cold weather, etc. Agricultural shocks include landslides, land erosion, crop pest, storage pest, livestock disease, etc. Business shocks refer to job loss, collapse of a business, unable to pay back loan, rise of interest rate, rise (or fall) of price of input (or output), a change in market regulation, etc. Health shocks concern illness, death, accidents, etc. Social shocks are comprised of theft, conflict with neighbours, getting no more remittance, and law suits accidents, etc. Two dummy variables are included in the model representing if a household experienced any shock between 2007 and 2008 or between 2008 and 2010.

\subsection{The dynamics of poverty in Vietnam}

\subsubsection{Trends in poverty and inequality}

The overall poverty rate in Vietnam continued to decrease from 16 percent in 2006 to 14.5 percent in 2008 and 14.2 percent in 2010 (GSO, 2011a). The poverty rates in the three provinces were higher than the average levels of the entire country but showed faster

\footnotetext{
${ }^{10}$ Reference categories: The floor is made of cement or ceramic. The main walls are made of concrete and the roof is made of slates or concrete. The household uses flushed toilet. The household cooks with gas or electricity.
} 
progress reaching rates of nearly 27, 15 and 18 percent in 2007, 2008 and 2010 respectively (see Table 2.1). All of the three provinces had similar patterns in poverty reduction that show a sharp fall between 2007 and 2008 but a slight increase over the period 2008 to 2010 . Apparently, poverty rates at $\$ 2.50$ a day showed a much higher incidence of nearly 54 percent in 2007 and nearly 40 percent in 2008 and 2010. These numbers suggest that the majority of the population in central provinces of Vietnam live in poverty. However, the incidence of poverty becomes much lower when poverty is measured by the equivalence scaled expenditure with reference to the poverty line of $\$ 1.67$ a day, which showed poverty rates of 14,7 and 12 percent over the years respectively. The three provinces not only made good progress in poverty reduction, but were successful in keeping the equity of the development as well. The gap between the first and the fifth income quintiles increased slightly from 4.8 to 4.8 and 5.2 over the years respectively and the Gini index also increased only marginally from 0.301 to 0.301 and 0.315 over the period.

Table 2.1 Poverty rate by poverty line, province and year, percent

\begin{tabular}{lccccc}
\hline Poverty line & Year & Ha Tinh & Thua Thien Hue & Dak Lak & Average \\
\hline \$1.25 PCE & 2007 & 13.8 & 8.0 & 12.8 & 12.1 \\
& 2008 & 5.7 & 5.8 & 5.0 & 5.5 \\
& 2010 & 6.9 & 5.6 & 7.0 & 6.6 \\
\$1.67 PCE & 2007 & 31.2 & 22.4 & 25.3 & 26.9 \\
& 2008 & 16.2 & 13.7 & 14.4 & 14.9 \\
\multirow{5}{*}{ \$1.67 ESE } & 2010 & 20.6 & 14.1 & 16.2 & 17.5 \\
& 2007 & 18.9 & 7.8 & 11.6 & 13.6 \\
\multirow{5}{*}{ \$2.50 PCE } & 2008 & 7.9 & 7.8 & 5.3 & 6.8 \\
& 2010 & 16.8 & 10.3 & 9.2 & 12.4 \\
& 2007 & 61.6 & 49.5 & 37.5 & 41.6 \\
& 2008 & 41.5 & 48.0 & 37.9 & 33.9 \\
\hline
\end{tabular}

Notes: PCE refers to per capita expenditure, ESE refers to equivalence scaled expenditure.

Source: Author's calculations from Vulnerability Surveys in Vietnam.

\subsubsection{A profile of poverty dynamics}

Over the three year period, the majority of households stayed non-poor (nearly 65 percent) and the other 35 percent was vulnerable to poverty at some level. This pattern shows good progress in poverty reduction in which a large share of the population rose up, nearly 16 percent, and a small share of the population fell down at slightly more than 6 percent. Additionally, only a small share of the population moved around the poverty line (7 percent) and a similar share stayed poor in all periods (nearly 7 percent) (see Table 2.2). The changes in poverty statuses also differ across sub-groups of the population, a matter that will be discussed in the remaining part of this sub-section. 
Table 2.2 Household and head characteristics by poverty trajectory, percent

\begin{tabular}{|c|c|c|c|c|c|c|}
\hline & Non-poor & Rising & Falling & Churning & Poor & Average \\
\hline Household size & 4.1 & 4.9 & 4.2 & 4.7 & 5.1 & 4.3 \\
\hline Size of FHH & 4.3 & 5.1 & 4.4 & 4.9 & 5.4 & 4.5 \\
\hline Size of MHH & 3.1 & 3.8 & 2.8 & 3.6 & 3.8 & 3.3 \\
\hline Dependency ratio & 0.4 & 0.5 & 0.5 & 0.5 & 0.6 & 0.5 \\
\hline Head is female & 66.2 & 13.5 & 6.1 & 7.2 & 6.9 & $(15.6)$ \\
\hline Head is male & 64.5 & 16.0 & 6.1 & 7.0 & 6.5 & $(84.4)$ \\
\hline Head is less than 36 years old & 56.2 & 17.0 & 5.5 & 10.2 & 11.1 & $(17.2)$ \\
\hline Head is $36-50$ years old & 66.2 & 16.9 & 5.1 & 6.2 & 5.7 & $(45.4)$ \\
\hline Head is $51-65$ years old & 72.7 & 12.0 & 7.4 & 4.4 & 3.4 & $(23.7)$ \\
\hline Head is 66 years old and beyond & 56.9 & 15.5 & 8.1 & 10.3 & 9.2 & $(13.7)$ \\
\hline Head has no schooling & 40.8 & 18.0 & 11.4 & 14.7 & 15.2 & $(13.3)$ \\
\hline Head attains primary school & 57.5 & 18.5 & 6.5 & 8.6 & 8.9 & $(23.1)$ \\
\hline Middle school and beyond & 72.4 & 14.0 & 4.9 & 4.8 & 3.9 & $(63.6)$ \\
\hline Ethnic minority groups & 33.3 & 24.4 & 11.1 & 13.6 & 17.5 & $(15.8)$ \\
\hline Kinh (majority) & 70.6 & 13.9 & 5.2 & 5.8 & 4.5 & $(84.2)$ \\
\hline Head engages in agriculture & 61.6 & 16.7 & 6.4 & 7.8 & 7.4 & $(82.5)$ \\
\hline Head engages in non-agriculture & 79.5 & 10.2 & 4.5 & 3.0 & 2.7 & $(17.5)$ \\
\hline Asset index & 0.59 & 0.42 & 0.42 & 0.38 & 0.30 & 0.51 \\
\hline Land area & 0.91 & 0.80 & 0.65 & 0.75 & 0.60 & 0.84 \\
\hline Share of households has migrant & 41.2 & 23.8 & 33.1 & 27.3 & 15.8 & 34.7 \\
\hline Remittance inflow (\$) & 419 & 161 & 154 & 278 & 41 & 319 \\
\hline Had any shock 02-07 (\%) & 82.2 & 84.8 & 85.6 & 90.3 & 92.1 & 84.3 \\
\hline Had any shock 07-08 (\%) & 74.0 & 84.4 & 88.5 & 85.5 & 82.5 & 78.2 \\
\hline Had any shock 08-10 (\%) & 78.0 & 80.0 & 75.5 & 86.1 & 84.2 & 79.3 \\
\hline Lowlands & 66.4 & 14.7 & 6.4 & 6.6 & 5.9 & $(48.3)$ \\
\hline Mountainous and highlands & 63.2 & 16.4 & 5.9 & 7.3 & 7.2 & $(51.7)$ \\
\hline Ha Tinh & 58.9 & 18.0 & 7.5 & 7.8 & 7.9 & $(38.9)$ \\
\hline Thua Thien Hue & 68.4 & 14.4 & 6.0 & 6.7 & 4.5 & $(22.3)$ \\
\hline Dak Lak & 68.4 & 13.9 & 4.8 & 6.4 & 6.4 & $(38.8)$ \\
\hline Total & 64.7 & 15.6 & 6.1 & 7.0 & 6.6 & \\
\hline
\end{tabular}

Notes: FHH (MHH) refers to female (male) headed household. Values in hyphentheses show population shares and those of the same category sum to 100 .

Poverty is usually associated with a large sized family and a higher burden of dependency. Non-poor households tend to have fewer members and a lower dependency ratio, 4.1 and 0.3 respectively, while those who are poor in at least one period have nearly five members and a higher dependency ratio of 0.5. In fact, the poor have low incomes and low asset levels so they tend to live together and share their limited resources. Moreover, poverty in this case is measured by per head expenditure, which transfers the effect of household size directly to poverty (see Table 2.2).

In a typical Vietnamese household, the oldest man is often the head. In cases where the man is unable to manage the household because of his lack of ability, health problems, or is missing because of death, divorce, etc. the women will be the head. This explains why more 
than 84 percent of the heads are men and also explains why female headed households are of a smaller size (see Table 2.2).

There is a tendency that young and old households, headed by young or old persons, are more vulnerable to poverty than middle-aged ones. They are less likely to stay non-poor and are more likely to fall into poverty, fluctuate around the poverty line or stay poor. Young households are usually newly formed ones which mean they also have to invest in bearing and caring for children. Older households are usually wealthier because they have experience in agriculture and livestock production and have accumulated more savings and assets. However, older heads are associated with having lower skills and being less healthy subsequently making them more vulnerable to poverty, which is confirmed by the result of a $t$ test.

The education of household heads differs significantly across poverty trajectories. Nearly sixty percent of households headed by men or women without any schooling are vulnerable to poverty. On the contrary, only eight percent of households headed by men or women with a tertiary education are poor in at least one period, almost none are poor forever. In addition, only 10 percent of the Kinh heads are illiterate while 32 percent of the other heads cannot read or write. Moreover, the Kinh are usually located in lowlands, which enables them to have better access to markets giving them a much lower risk of being poor.

Similarly, the occupation of the head also plays an important role in the improvement of a household's wealth. A large share of households (nearly 83 percent) in central Vietnam is from an agricultural background. Agricultural activities in Vietnam are generally still at a low level of development and yield low incomes. Additionally, this production depends heavily on natural resources and weather conditions which causes individuals in this sector to be more vulnerable to poverty than those who engage in non-agricultural activities.

The industrial development in urban areas results in a massive rural-urban flow of migration. Skilled people have more chances to migrate because it is easier for them to find a job or to gain more skills in urban areas. In addition, migrants and especially students might need financial support at the beginning, and wealthier households are more capable of providing this. This explains why non-poor households are more likely to have migrants and tend to have a greater number of migrants than poor households. Correspondingly, nonpoor households have more migrants, live with non-poor neighbours, friends and relatives and send more remittances to other people with the result that they get more remittances than poorer households. A non-poor household has an average in or out flow of more than $\$ 130$ per year while a poor household has much lower amount (see Table 2.2). Obviously, 
the chronically poor households are the ones that should be supported the most, but they actually get a smaller amount of remittance ( $\$ 14$ per year) on account of their being poor not only in income but in social capital as well. On the contrary, poor households tend to receive more public transfer, which is of various forms such as the poverty and hunger fund, contingency fund, natural disaster aid, etc. Non-poor households get less public transfer, the majority of which is in the form of a pension.

A household's physical capital can be measured by various proxy indicators. Since the majority of households engage in agricultural activities and land is a primary and important input, it is thus a reasonable measure of household wealth. Households in Ha Tinh are particularly more disadvantaged than their counterparts as they have less land which is also not very fertile. Dak Lak households have more land which is suitable for the production of high value agricultural products such as coffee and pepper. Hence, more land could enable a household in Dak Lak to generate a higher income. However, in some mountainous areas in Ha Tinh and Thua Thien Hue, households in the forest margins are usually poor and are allocated forest from local governments. Yet, forest is still a low value added activity in Vietnam so households there are land rich but income poor.

The asset index is also believed to be a good proxy for household wealth (see Filmer and Pritchett, 2001). It differs significantly across groups; non-poor households are again owners of higher asset levels while stay-poor households have the least, being 0.59 and $0.3^{11}$ respectively. In addition, the location of the household can be used as a proxy for public physical asset such as infrastructure and some regional differences. More than half of the households are in mountainous and highland areas where infrastructure such as roads, electricity, schools and health clinics are in poorer condition and thus result in worse market access. Among the chronically poor households, the majority of them are in the mountainous and highland areas in Thua Thien Hue, particularly in two districts of Nam Dong and A Luoi, which are home to ethnic minority groups, poor soil quality and a poor condition of infrastructure.

In general, the living standards in these provinces are still low and households there mainly engage in agricultural production perpetuating their vulnerability to shocks. This point is supported by the numbers in Table 2.2, which show stay-poor households faced more shocks than non-poor ones. There are a number of natural disasters in that region every year including storms, floods, heavy rains, droughts, landslides, and cold weather, etc. Households also suffer from agricultural shocks in the forms of livestock's death or disease,

\footnotetext{
${ }^{11}$ The asset index is scaled to the range of $[0,1]$
} 
crop pest, storage pest, etc. Health shocks cause an income loss because the patient and other household members cannot work for days and incur hospital medical costs. Social and business shocks are not frequent, with a mean of less than 0.1 shocks each wave hence it is not necessary to include them in the analysis. Looking at shocks by location we see households in Ha Tinh and Thua Thien Hue experienced more climatic shocks than the other households because the two provinces are located in a coastal area.

\subsubsection{Drivers of poverty dynamics}

Households in Vietnam have a tendency to have smaller sizes owing to the lower birth rate, the increasing migration, and the inclination of living in two generation households. Nevertheless, poor households usually have a larger size because they have more children, less chances to migrate, and have limited resources which prevents them from separating into smaller households. The empirical results show that households of a larger sized household and higher dependency ratio have a lower probability of staying non-poor and higher probability of being poor in at least one period. Particularly, the marginal effects of rising is greater than those of falling, of churning, and of staying-poor (see Table 2.3) showing the overall improvement in households' well-being. More precisely, as household size increases from one to two, nearly nine percent of households no longer have a chance to be non-poor, nearly three percent more falls into poverty, nearly four more percent rises, almost two percent more fluctuates, and 0.2 percent more becomes poor in all periods. As the household size gets larger, the effects of an additional household member tend to be smaller (see Table 2.4).

The changes in household demographics such as births and leaves are also important drivers of poverty transitions. A new birth between 2007 and 2008 reduces the probability of a household staying non-poor by nearly 0.15 and increases the probability of it churning and staying poor by nearly $0.05,0.02$ but at low levels of significance respectively. Similarly, a new birth between 2008 and 2010 increases the probability of it falling by nearly 0.06 and affects at low levels of significance on other trajectories (see Table 2.3). A new birth usually makes the mother reduce working hours, as well as adds an additional member to the household size consequently negatively affecting the household's well-being as measured by per capita. On the contrary, the new birth usually incurs more expenditures to the household thus making its effect positive on the probability of a household's rising but at low levels of significance. The effects of a leave member is mostly insignificant except for between 2007 and 2008 where they have an effect on falling into poverty. If the member who leaves unexpectedly is the main breadwinner, this could negatively affect household's wealth, or could improve household per capita income owing to having a smaller size. 
Table 2.3 Marginal effects from multinomial logit model with shocks since 2007

\begin{tabular}{|c|c|c|c|c|c|}
\hline & Non-poor & Rising & Falling & Churning & Poor \\
\hline Household size 07 & $\begin{array}{c}-0.102 * * * \\
(0.00990)\end{array}$ & $\begin{array}{c}0.0640 * * * \\
(0.00685)\end{array}$ & $\begin{array}{l}0.0102 * * \\
(0.00449)\end{array}$ & $\begin{array}{c}0.0207 * * * \\
(0.00377)\end{array}$ & $\begin{array}{c}0.00701 * * * \\
(0.00159)\end{array}$ \\
\hline Dependency ratio 07 & $\begin{array}{c}-0.151 * * \\
(0.0610)\end{array}$ & $\begin{array}{l}0.105 * * \\
(0.0466)\end{array}$ & $\begin{array}{c}-0.00893 \\
(0.0263)\end{array}$ & $\begin{array}{c}0.0383 \\
(0.0250)\end{array}$ & $\begin{array}{c}0.0162 * * * \\
(0.00626)\end{array}$ \\
\hline Head is male 07 & $\begin{array}{l}-0.0382 \\
(0.0379)\end{array}$ & $\begin{array}{l}0.00821 \\
(0.0287)\end{array}$ & $\begin{array}{c}0.0207 \\
(0.0150)\end{array}$ & $\begin{array}{c}0.00892 \\
(0.0141)\end{array}$ & $\begin{array}{l}0.000330 \\
(0.00312)\end{array}$ \\
\hline Head age 07 & $\begin{array}{l}0.000613 \\
(0.00113)\end{array}$ & $\begin{array}{l}-0.000966 \\
(0.000815)\end{array}$ & $\begin{array}{l}0.000911^{*} \\
(0.000481)\end{array}$ & $\begin{array}{l}-0.000445 \\
(0.000410)\end{array}$ & $\begin{array}{c}-0.000113 \\
(8.18 \mathrm{e}-05)\end{array}$ \\
\hline Head is from the Kinh 07 & $\begin{array}{c}0.378 * * * \\
(0.0484)\end{array}$ & $\begin{array}{l}-0.0439 \\
(0.0313)\end{array}$ & $\begin{array}{c}-0.160 * * * \\
(0.0416)\end{array}$ & $\begin{array}{c}-0.0995 * * * \\
(0.0303)\end{array}$ & $\begin{array}{c}-0.0739 * * * \\
(0.0226)\end{array}$ \\
\hline Attains primary school & $\begin{array}{c}0.0714 * \\
(0.0425)\end{array}$ & $\begin{array}{l}-0.0134 \\
(0.0316)\end{array}$ & $\begin{array}{c}-0.0352 * * \\
(0.0146)\end{array}$ & $\begin{array}{l}-0.0206 \\
(0.0127)\end{array}$ & $\begin{array}{l}-0.00225 \\
(0.00257)\end{array}$ \\
\hline Attains middle school + & $\begin{array}{c}0.152 * * * \\
(0.0473)\end{array}$ & $\begin{array}{l}-0.0325 \\
(0.0322)\end{array}$ & $\begin{array}{c}-0.0549 * * \\
(0.0218)\end{array}$ & $\begin{array}{c}-0.0532 * * * \\
(0.0189)\end{array}$ & $\begin{array}{c}-0.0117 * * \\
(0.00464)\end{array}$ \\
\hline Non-agriculture & $\begin{array}{c}0.0189 \\
(0.0383)\end{array}$ & $\begin{array}{c}0.00170 \\
(0.0289)\end{array}$ & $\begin{array}{l}0.0115 \\
(0.0204)\end{array}$ & $\begin{array}{c}-0.0292 * * \\
(0.0131)\end{array}$ & $\begin{array}{l}-0.00292 \\
(0.00303)\end{array}$ \\
\hline Asset index 07 & $\begin{array}{c}1.788 * * * \\
(0.116)\end{array}$ & $\begin{array}{c}-1.009 * * * \\
(0.0807)\end{array}$ & $\begin{array}{c}-0.294 * * * \\
(0.0519)\end{array}$ & $\begin{array}{c}-0.378 * * * \\
(0.0481)\end{array}$ & $\begin{array}{c}-0.108 * * * \\
(0.0243)\end{array}$ \\
\hline Land area 07 & $\begin{array}{c}0.0311 * * \\
(0.0133)\end{array}$ & $\begin{array}{l}-0.00714 \\
(0.00829)\end{array}$ & $\begin{array}{l}-0.0110 \\
(0.00823)\end{array}$ & $\begin{array}{l}-0.00645 \\
(0.00531)\end{array}$ & $\begin{array}{c}-0.00646 * * * \\
(0.00195)\end{array}$ \\
\hline Village road is paved 07 & $\begin{array}{c}0.0800 * * \\
(0.0336)\end{array}$ & $\begin{array}{c}-0.0489 * * \\
(0.0240)\end{array}$ & $\begin{array}{c}-0.00970 \\
(0.0154)\end{array}$ & $\begin{array}{l}-0.0175 \\
(0.0128)\end{array}$ & $\begin{array}{l}-0.00389 \\
(0.00261)\end{array}$ \\
\hline Any birth 07-08 & $\begin{array}{c}-0.150 * * * \\
(0.0544)\end{array}$ & $\begin{array}{c}0.0632 \\
(0.0389)\end{array}$ & $\begin{array}{c}0.0181 \\
(0.0257)\end{array}$ & $\begin{array}{l}0.0494 * \\
(0.0263)\end{array}$ & $\begin{array}{l}0.0195 * * \\
(0.00866)\end{array}$ \\
\hline Any birth $08-10$ & $\begin{array}{c}-0.104 \\
(0.0636)\end{array}$ & $\begin{array}{c}0.000251 \\
(0.0411)\end{array}$ & $\begin{array}{l}0.0578 * \\
(0.0343)\end{array}$ & $\begin{array}{c}0.0341 \\
(0.0278)\end{array}$ & $\begin{array}{c}0.0121 \\
(0.00761)\end{array}$ \\
\hline Member left 07-08 & $\begin{array}{c}0.0274 \\
(0.0544)\end{array}$ & $\begin{array}{l}-0.0328 \\
(0.0348)\end{array}$ & $\begin{array}{c}-0.0344 * \\
(0.0197)\end{array}$ & $\begin{array}{c}0.0434 \\
(0.0310)\end{array}$ & $\begin{array}{l}-0.00363 \\
(0.00324)\end{array}$ \\
\hline Member left 08-10 & $\begin{array}{c}0.0230 \\
(0.0351)\end{array}$ & $\begin{array}{c}-0.00137 \\
(0.0257)\end{array}$ & $\begin{array}{l}-0.0136 \\
(0.0155)\end{array}$ & $\begin{array}{c}-0.00923 \\
(0.0132)\end{array}$ & $\begin{array}{l}0.00126 \\
(0.00293)\end{array}$ \\
\hline Has migrant $07-08$ & $\begin{array}{l}0.0577 * \\
(0.0300)\end{array}$ & $\begin{array}{l}-0.0303 \\
(0.0214)\end{array}$ & $\begin{array}{c}-0.00355 \\
(0.0141)\end{array}$ & $\begin{array}{l}-0.0176 \\
(0.0116)\end{array}$ & $\begin{array}{c}-0.00636 * * \\
(0.00265)\end{array}$ \\
\hline Get remittance 07 & $\begin{array}{c}-0.00614 \\
(0.0325)\end{array}$ & $\begin{array}{l}0.0167 \\
(0.0242)\end{array}$ & $\begin{array}{c}-0.00500 \\
(0.0149)\end{array}$ & $\begin{array}{c}-0.00216 \\
(0.0126)\end{array}$ & $\begin{array}{l}-0.00340 \\
(0.00246)\end{array}$ \\
\hline Get public transfer 07 & $\begin{array}{l}-0.0253 \\
(0.0325)\end{array}$ & $\begin{array}{c}0.0152 \\
(0.0233)\end{array}$ & $\begin{array}{l}-0.0118 \\
(0.0136)\end{array}$ & $\begin{array}{c}0.0190 \\
(0.0134)\end{array}$ & $\begin{array}{c}0.00288 \\
(0.00272)\end{array}$ \\
\hline Any shock 07-08 & $\begin{array}{l}-0.0143 \\
(0.0332)\end{array}$ & $\begin{array}{l}0.00283 \\
(0.0239)\end{array}$ & $\begin{array}{l}0.0277 * \\
(0.0142)\end{array}$ & $\begin{array}{l}-0.0121 \\
(0.0142)\end{array}$ & $\begin{array}{l}-0.00412 \\
(0.00329)\end{array}$ \\
\hline Any shock 08-10 & $\begin{array}{c}0.0845^{* *} \\
(0.0362)\end{array}$ & $\begin{array}{c}-0.0451 * \\
(0.0272)\end{array}$ & $\begin{array}{c}-0.0408 * * \\
(0.0197)\end{array}$ & $\begin{array}{c}0.00464 \\
(0.0137)\end{array}$ & $\begin{array}{l}-0.00316 \\
(0.00341)\end{array}$ \\
\hline Ha Tinh & $\begin{array}{c}-0.404 * * * \\
(0.0515)\end{array}$ & $\begin{array}{c}0.106 * * * \\
(0.0365)\end{array}$ & $\begin{array}{c}0.0787 * * \\
(0.0313)\end{array}$ & $\begin{array}{c}0.125 * * * \\
(0.0333)\end{array}$ & $\begin{array}{c}0.0943 * * * \\
(0.0262)\end{array}$ \\
\hline Thua Thien Hue & $\begin{array}{c}-0.278^{* * * *} \\
(0.0530)\end{array}$ & $\begin{array}{l}0.0635 * \\
(0.0345)\end{array}$ & $\begin{array}{c}0.0744 * * \\
(0.0291)\end{array}$ & $\begin{array}{c}0.0996 * * * \\
(0.0282)\end{array}$ & $\begin{array}{c}0.0408^{* * * *} \\
(0.0124)\end{array}$ \\
\hline Highlands & $\begin{array}{l}-0.0363 \\
(0.0306)\end{array}$ & $\begin{array}{c}0.0176 \\
(0.0216)\end{array}$ & $\begin{array}{l}0.00946 \\
(0.0144)\end{array}$ & $\begin{array}{l}0.00892 \\
(0.0119)\end{array}$ & $\begin{array}{l}0.000269 \\
(0.00238)\end{array}$ \\
\hline
\end{tabular}

Notes: Omitted categories: head has no schooling, head is from ethnic minority groups, head engages in agriculture, Dak Lak, lowlands, poverty dynamics are referred to \$1.67 a day. 07 refers to in year 2007, 07-08 refers to period 2007-2008. Pseudo R2 $=0.286$, Observations $=1,901$. Passes tests of IIA assumption. Standard errors in parentheses, $* * * \mathrm{p}<0.01, * * \mathrm{p}<0.05, * \mathrm{p}<0.1$

Female headed households (FHH) have a lower probability of falling into poverty than their counterparts. This could be attributed to the fact that FHHs usually have less access to 
markets which might be an advantage in the context of high inflation and economic recession. In addition, a head's age appears to have an insignificant effect on most dynamic trajectories except for staying poor because of two reasons. First, there was a small change in heads' age during the short three year period and only a small share of households changed their heads over the period. Second, as discussed in Section 2.4.2, head's age has a concave effect on poverty thus the continuous variable does not show significant effects. Similarly, the effect of head's occupation on poverty dynamics turns out to be insignificant because the earning gap between agricultural and non-agricultural jobs is not very large. In addition, if only the head engages in non-agricultural activity while his or her spouse engages in the other sector, the household will still find it hard to become wealthy.

Among 54 ethnic groups in Vietnam, the Kinh is the majority and accounts for nearly 86 percent of the entire population. They usually live in lowlands with better access to markets and public services. These allow them to benefit more from the economic growth and the advancement of the society. Kinh households have nearly 0.4 higher probability of being non-poor, and lower probabilities of being poor in one or more periods than their counteparts (see Table 2.3). It is also evident that nearly 77 percent of Kinh households have no risk of being poor but this share is only about 39 percent with households from minority groups (see Table 2.4 ).

Households with educated heads have a higher probability of being non-poor and a lower probability of being poor in one or more than one period. If the head attains middle school and beyond as oppose to no schooling, about 13 percentage points more of households will be permanently non-poor (see Table 2.4). The more the head is educated the better his access to production resources, labour, and output markets is, he is also able to manage household resources more efficiently enabling his or her household to escape poverty more easily. Nevertheless, the impact of education is insignificant as the head attains primary school which could be attributed to the fact that primary education is not enough to improve access to markets and resources as compared with no schooling.

Rural households can cope with shocks by insurance, loans from formal and informal financial markets, selling agriculture products and assets and getting remittances or public aid. Insurance and financial markets are per se in poor conditions in rural areas in Vietnam hence remittances might be useful for recovering from shocks. However, the results show no significant difference in the vulnerability to poverty between households that received remittances and households that received no remittance. This could be attributed to the fact that remittance flows to rural households are of small amounts, which are mostly in the form of a little help from relatives or neighbours when a household has important events 
such as weddings, accidents or funerals. Remittances from migrants are usually of bigger amounts making it probably more useful for the advancements of poor households. However, the empirical result does not support this hypothesis (see Table 2.3) because nonpoor households often have more migrants than poorer ones (see Section 2.4.2).

Table 2.4 Percentage predictions from multinomial logit models

\begin{tabular}{lccccc}
\hline & Non-poor & Rising & Falling & Churning & Poor \\
\hline Household has 1 member & 95.6 & 0.8 & 3.4 & 0.2 & 0.0 \\
\multicolumn{1}{c}{3} & 86.2 & 5.5 & 6.2 & 1.9 & 0.2 \\
4 & 79.1 & 9.4 & 5.7 & 5.2 & 0.5 \\
5 & 77.1 & 12.5 & 5.2 & 4.6 & 0.7 \\
\multicolumn{1}{c}{ 7 and more } & 63.6 & 20.4 & 6.6 & 8.4 & 1.0 \\
& 52.5 & 29.8 & 6.8 & 7.8 & 3.0 \\
Head attains less than middle school & 33.6 & 30.9 & 13.5 & 14.8 & 7.2 \\
Head attains middle school \& beyond & 74.9 & 13.6 & 6.1 & 4.5 & 2.6 \\
Head engages in agriculture & 69.8 & 14.8 & 7.2 & 6.6 & 1.0 \\
Head engages in non-agriculture & 71.3 & 15.4 & 8.7 & 3.6 & 1.5 \\
Head is from ethnic minority groups & 38.8 & 18.3 & 20.8 & 14.2 & 7.9 \\
Head is from the majority group & 76.6 & 13.9 & 4.8 & 4.2 & 0.5 \\
First (poorest) & 24.7 & 40.0 & 11.4 & 14.5 & 9.4 \\
Second asset quintile & 48.8 & 30.0 & 8.3 & 9.8 & 3.1 \\
Third asset quintile & 74.5 & 12.9 & 5.5 & 6.3 & 0.8 \\
Fourth asset quintile & 83.4 & 7.8 & 5.8 & 2.7 & 0.2 \\
Fifth (richest) & 94.5 & 2.8 & 1.7 & 1.0 & 0.0 \\
Had no shock between 2008-2010 & 64.0 & 19.2 & 10.2 & 5.3 & 1.2 \\
Had a shock between 2008-2010 & 72.5 & 14.7 & 6.2 & 5.8 & 0.9 \\
\hline
\end{tabular}

Notes: Percentages are estimated from the same multinomial logit model which is used to predict marginal effects in Table 2.3. Each category is predicted separately and independently from one another based on MNL model. Values in the same row sum to 100.

Household wealth as measured by the asset index shows a strong and clear effect on poverty dynamics. It prevents households from being poor and is negatively correlated with being poor in any period (see Table 2.3). If a household's asset level moves from the first quintile to the second quintile, nearly 24 percentage points more of households will not be vulnerable to poverty any more. The mean asset index of the five quintiles in 2007 are 0.25 , $0.41,0.51,0.61$, and 0.77 respectively. Similarly, when a household's assets belong to the top group, only more than 5 percent of households are vulnerable to poverty in one or two periods and almost no household are chronically poor (see Table 2.4).

Village infrastructure such as roads, schools, health clinics, and post offices enables households to access public services as well as markets. For simplicity, this study uses the condition of the main road in the village as a proxy for village infrastructure because a better transportation brings about the improvement in other public facilities as well (see 
Kessides, 1992). The majority of villages where the main roads are of dirt or soil are in mountainous or remote areas, where the population density is low and a large share of the households belongs to ethnic minority groups. Thus, households there have limited access to markets, which consequently makes them more vulnerable to poverty. Indeed, households there have a lower probability of staying non-poor, and a higher probability of staying poor than their peers. In addition, the road condition in this model is measured in 2007 while it might change substantially in the years 2008 and 2010. The improvement in village infrastructure might have strong effects on households' well-being and make them move out of out of poverty at higher rates than their counterparts.

Among the three provinces, Thua Thien Hue and Ha Tinh are on the coastline and frequently suffer from extreme weather conditions such as storms, floods, and heat waves. Additionally, households in remote villages in these two provinces have low incentives to improve their living standards because they have been living with the poor communities for generations. On the contrary, Dak Lak suffers less from natural disasters, and natural disasters in this region is mainly in the type of droughts, which usually come slowly and are thus much less destructive as well as are less likely to cause multiple losses than the short duration events of storms and floods. Moreover, economic activities are more dynamic in Dak Lak which is due in part to the coffee industry and also in part to the fact that a large share of the population in Dak Lak are immigrants whose incentive of moving forward is higher than their counterparts in the other two provinces.

Between the two provinces on the coastline, economic activities in Thua Thien Hue are more dynamic owing to the development of the tourism sector and of industrial parks which create job opportunities for a number people. Therefore, the probability of Ha Tinh households staying non-poor is lower than that of their Thua Thien Hue peers, and much lower than the Dak Lak people. Similarly, the probabilities of churning and of staying poor are highest for Ha Tinh households then come Thua Thien Hue and Dak Lak households respectively (see Table 2.3). Among those who were poor in 2007, the Ha Tinh group escaped poverty at a faster rate than its peers (see Table 2.3) because they started to have more job opportunities as a result of an increasing line of migration and new investment projects in recent years in the province.

It is widely accepted that a shock causes a decline in assets and incomes and there has been evidence on the effects of a shock on poverty dynamics (see Pistaferri, 2001; Glewwe, 2000; Carter and Barrett, 2006; Thomas et al. 2010). Some results in this study contribute to this strand of argument, for instance a shock in the first period (2007-2008) makes households fall into poverty, a shock in the second period (2008-2010) prevents households 
from rising. However, some other results do not support this strand of argument since they show unexpected effects or insignificant effects (see Table 2.3). This could be blamed on the possible endogeneity between shocks and household covariates. Shocks in our surveys are self and subjectively reported by respondents so the same amount of loss might be a shock to a poor household but not for a wealthier household, and poor households might have different opinions about shocks. In addition, different types of shocks might have different consequences. An illness might last for a long period of time and incur a number of expenditures such as medical, hospital, caring costs, as well as incur invisible costs since households members sacrifice their market working hours to look after the patient. A storm might be not very loss causing but it is usually followed by days of heavy rain which might consequently create a flood. They together might damage houses, wash away agricultural lands and crops, and kill livestock.

\subsection{Robustness check}

In order to check the robustness of the multinomial logit model of poverty dynamics, the study applies various other types of models with different controls and exogenous variables, and the dependent variable is referred to different poverty lines. First, a similar model is applied with the only difference being the inclusion of shocks before 2007 (see Table 2.6). Second, two probit models with reference to the poverty line of $\$ 1.67$ a day are applied; one for those who fall into poverty given that they are non-poor in 2007, and the other for those who stay poor in all periods given that they are poor in 2007 (see Table 2.7). Third, a multinomial logit model with the same explanatory variables is applied but with poverty dynamics now referring to the poverty line of $\$ 2.5$ a day (see Table 2.8). Fourth, the same multinomial logit model and poverty dynamics refer to the equivalence scale expenditure and the poverty line of $\$ 1.67$ a day (see Table 2.9). The equivalence scale expenditure is calculated with reference to the OECD (1982) method. It is also important to note that all of the multinomial logit models in Table 2.3, Table 2.6, Table 2.8, and Table 2.9 pass the Hausman tests or suest tests of independence of irrelevant alternatives (IIA), which indicates that assumptions of IIA could not be rejected hence estimates from multinomial logit models are efficient. Additionally, probit models in Table 2.7 also pass log likelihood tests that means the marginal effects from the two probit models are efficient. The four reference models in general show similar effects to those in the basic one. However, there are differences in the size of the effects in these models compared to the referenced one because poverty dynamics in the additional models refer to different poverty lines, different exogenous variables, and different methods. 


\subsection{Conclusion}

This study uses panel data on rural and peri-urban households from a poor region in Vietnam in the context of increasing uncertainties to investigate the transitions into and out of poverty of different household groups. A multinomial logit model is employed as a key method to find out which household groups find it easier to move forward, which groups are left behind, which groups stay poor over time, and importantly whether a shock causes a household to fall into poverty.

The results show a sharp reduction in the poverty rate over the period which is the result of the fast economic growth and could be partially the result of the high inflation rate. Nevertheless, a large share of the population is vulnerable to poverty where 35 percent of households have a risk of being either transient or chronically poor. This risk varies substantially across household group; households of a large size, ethnic minority group, low level of head's education, and has limited physical and social assets have a higher risk of being poor since they typically have less access to markets than the other groups, which consequently prevents them from greatly benefiting from the economic growth. These findings are in line with most previous studies such as Carter and May (1999), Glewwe et al. (2000), and Woolard and Klasen (2005). An interesting finding is that female headed households have a slightly higher probability of moving ahead, which is inconsistent with the finding of Cappellari and Jenkins (2002) which shows that married couples have both lower poverty entry rates and lower poverty persistence rates than single mothers. This is attributed to the fact that female headed households have fewer members and usually follow less risky livelihood strategies.

Shocks appear to have a weak relationship with the transitions into and out of poverty during the period because the poor in general face many shocks hence an additional shock in this short period of time is not necessary to change their poverty status. Additionally, households might suffer many shocks where one follows another, which makes it hard to identify the effect of a single shock on the poverty dynamics. Furthermore, households' incomes and consumptions in this period are affected substantially by the fluctuation in the inflation rate, the poor economic performance, and the subsequent high unemployment rate, all which could distort the effects of a shock. Lastly, there might be endogeneity between having a shock and a household's covariates since shocks are self and subjectively reported. The results of this study suggest that poverty reduction policies should focus on not only the poor but the vulnerable groups as well. Among the vulnerable group, households from ethnic minority groups, households of a large size, and households with low education 
attainment should be paid more attention to. Further investigation of the effects of shocks on a household's well-being could examine the effects of a shock on some specific indicators of well-being such as health and food expenditure, as well as on changes in investment patterns and livelihood strategy. Additionally, the effects of shocks could be better understood when the analysis is proceeded with a wider range of time. 


\section{Appendix 2}

Table 2.5 Components of asset index and their weights

\begin{tabular}{lcc}
\hline Assets & Eigenvalue & Proportion \\
\hline Household has a motobike & 3.42 & 0.24 \\
Household has a television & 1.36 & 0.10 \\
Household has an electric rice cooker & 1.13 & 0.08 \\
Household has a mattress & 1.05 & 0.07 \\
Household has a video player & 0.96 & 0.07 \\
Household cooks with electricity/gas & 0.89 & 0.06 \\
Household uses improved sanitation facility & 0.81 & 0.06 \\
Household has an electric fan & 0.76 & 0.05 \\
Household has a fridge & 0.68 & 0.05 \\
Household has improved flooring & 0.64 & 0.05 \\
House size & 0.63 & 0.05 \\
House (wall and roof) is made of improved materials & 0.61 & 0.04 \\
Household has radio & 0.55 & 0.04 \\
Household has a bike & 0.52 & 0.04 \\
\hline
\end{tabular}

Note: Proportions sum to one. 
Table 2.6 Marginal effects from multinomial logit model with shocks since 2002

\begin{tabular}{|c|c|c|c|c|c|}
\hline & Non-poor & Rising & Falling & Churning & Poor \\
\hline Household size 07 & $\begin{array}{c}-0.101 * * * \\
(0.00991)\end{array}$ & $\begin{array}{c}0.0641 * * * \\
(0.00687)\end{array}$ & $\begin{array}{l}0.0101 * * \\
(0.00451)\end{array}$ & $\begin{array}{c}0.0201 * * * \\
(0.00374)\end{array}$ & $\begin{array}{c}0.00681 * * * \\
(0.00156)\end{array}$ \\
\hline Dependency ratio 07 & $\begin{array}{c}-0.150 * * \\
(0.0610)\end{array}$ & $\begin{array}{l}0.105 * * \\
(0.0466)\end{array}$ & $\begin{array}{c}-0.00931 \\
(0.0263)\end{array}$ & $\begin{array}{c}0.0382 \\
(0.0249)\end{array}$ & $\begin{array}{c}0.0161 * * * \\
(0.00620)\end{array}$ \\
\hline Head is male 07 & $\begin{array}{l}-0.0379 \\
(0.0379)\end{array}$ & $\begin{array}{c}0.00808 \\
(0.0288)\end{array}$ & $\begin{array}{c}0.0208 \\
(0.0150)\end{array}$ & $\begin{array}{c}0.00863 \\
(0.0140)\end{array}$ & $\begin{array}{c}0.000386 \\
(0.00305)\end{array}$ \\
\hline Head age 07 & $\begin{array}{c}0.000606 \\
(0.00113)\end{array}$ & $\begin{array}{l}-0.000953 \\
(0.000815)\end{array}$ & $\begin{array}{c}0.000909 * \\
(0.000481)\end{array}$ & $\begin{array}{l}-0.000449 \\
(0.000408)\end{array}$ & $\begin{array}{c}-0.000112 \\
(8.07 \mathrm{e}-05)\end{array}$ \\
\hline Head is from the Kinh & $\begin{array}{c}0.376 * * * \\
(0.0485)\end{array}$ & $\begin{array}{l}-0.0457 \\
(0.0315)\end{array}$ & $\begin{array}{c}-0.161 * * * \\
(0.0417)\end{array}$ & $\begin{array}{c}-0.0978 * * * \\
(0.0301)\end{array}$ & $\begin{array}{c}-0.0710 * * * \\
(0.0220)\end{array}$ \\
\hline Attains primary school & $\begin{array}{l}0.0712 * \\
(0.0425)\end{array}$ & $\begin{array}{l}-0.0133 \\
(0.0317)\end{array}$ & $\begin{array}{c}-0.0353 * * \\
(0.0145)\end{array}$ & $\begin{array}{l}-0.0204 \\
(0.0126)\end{array}$ & $\begin{array}{l}-0.00216 \\
(0.00253)\end{array}$ \\
\hline Attains middle school + & $\begin{array}{c}0.152 * * * \\
(0.0473)\end{array}$ & $\begin{array}{l}-0.0317 \\
(0.0322)\end{array}$ & $\begin{array}{c}-0.0554 * * \\
(0.0219)\end{array}$ & $\begin{array}{c}-0.0535 * * * \\
(0.0188)\end{array}$ & $\begin{array}{c}-0.0119 * * \\
(0.00464)\end{array}$ \\
\hline Non-agriculture & $\begin{array}{c}0.0172 \\
(0.0384)\end{array}$ & $\begin{array}{l}0.00111 \\
(0.0289)\end{array}$ & $\begin{array}{c}0.0123 \\
(0.0205)\end{array}$ & $\begin{array}{c}-0.0278 * * \\
(0.0132)\end{array}$ & $\begin{array}{l}-0.00272 \\
(0.00302)\end{array}$ \\
\hline Asset index 07 & $\begin{array}{c}1.785 * * * \\
(0.116)\end{array}$ & $\begin{array}{c}-1.010 * * * \\
(0.0808)\end{array}$ & $\begin{array}{c}-0.293 * * * \\
(0.0519)\end{array}$ & $\begin{array}{c}-0.374 * * * \\
(0.0479)\end{array}$ & $\begin{array}{c}-0.107 * * * \\
(0.0240)\end{array}$ \\
\hline Land area 07 & $\begin{array}{c}0.0314 * * \\
(0.0132)\end{array}$ & $\begin{array}{l}-0.00711 \\
(0.00830)\end{array}$ & $\begin{array}{l}-0.0112 \\
(0.00824)\end{array}$ & $\begin{array}{l}-0.00666 \\
(0.00533)\end{array}$ & $\begin{array}{c}-0.00644 * * * \\
(0.00194)\end{array}$ \\
\hline Village road is paved 07 & $\begin{array}{c}0.0795 * * \\
(0.0336)\end{array}$ & $\begin{array}{c}-0.0493 * * \\
(0.0240)\end{array}$ & $\begin{array}{c}-0.00961 \\
(0.0154)\end{array}$ & $\begin{array}{l}-0.0169 \\
(0.0127)\end{array}$ & $\begin{array}{l}-0.00368 \\
(0.00256)\end{array}$ \\
\hline Any birth 07-08 & $\begin{array}{c}-0.151 * * * \\
(0.0544)\end{array}$ & $\begin{array}{c}0.0635 \\
(0.0390)\end{array}$ & $\begin{array}{c}0.0178 \\
(0.0256)\end{array}$ & $\begin{array}{c}0.0499 * \\
(0.0262)\end{array}$ & $\begin{array}{c}0.0196 * * \\
(0.00865)\end{array}$ \\
\hline Any birth $08-10$ & $\begin{array}{c}-0.104 \\
(0.0635)\end{array}$ & $\begin{array}{c}-0.000892 \\
(0.0409)\end{array}$ & $\begin{array}{c}0.0576^{*} \\
(0.0343)\end{array}$ & $\begin{array}{c}0.0348 \\
(0.0278)\end{array}$ & $\begin{array}{c}0.0124 \\
(0.00769)\end{array}$ \\
\hline Member left 07-08 & $\begin{array}{l}0.0270 \\
(0.0543)\end{array}$ & $\begin{array}{l}-0.0332 \\
(0.0347)\end{array}$ & $\begin{array}{c}-0.0341 * \\
(0.0198)\end{array}$ & $\begin{array}{c}0.0438 \\
(0.0311)\end{array}$ & $\begin{array}{l}-0.00357 \\
(0.00319)\end{array}$ \\
\hline Member left 08-10 & $\begin{array}{l}0.0229 \\
(0.0350)\end{array}$ & $\begin{array}{c}-0.00193 \\
(0.0257)\end{array}$ & $\begin{array}{l}-0.0136 \\
(0.0155)\end{array}$ & $\begin{array}{c}-0.00877 \\
(0.0132)\end{array}$ & $\begin{array}{c}0.00144 \\
(0.00292)\end{array}$ \\
\hline Has migrant $07-08$ & $\begin{array}{c}0.0583 * \\
(0.0300)\end{array}$ & $\begin{array}{l}-0.0304 \\
(0.0214)\end{array}$ & $\begin{array}{c}-0.00393 \\
(0.0141)\end{array}$ & $\begin{array}{l}-0.0178 \\
(0.0115)\end{array}$ & $\begin{array}{c}-0.00621 * * \\
(0.00261)\end{array}$ \\
\hline Get remittance 07 & $\begin{array}{c}-0.00539 \\
(0.0325)\end{array}$ & $\begin{array}{c}0.0171 \\
(0.0242)\end{array}$ & $\begin{array}{c}-0.00525 \\
(0.0149)\end{array}$ & $\begin{array}{c}-0.00293 \\
(0.0125)\end{array}$ & $\begin{array}{l}-0.00356 \\
(0.00242)\end{array}$ \\
\hline Get public transfer 07 & $\begin{array}{l}-0.0242 \\
(0.0325)\end{array}$ & $\begin{array}{l}0.0152 \\
(0.0233)\end{array}$ & $\begin{array}{l}-0.0119 \\
(0.0136)\end{array}$ & $\begin{array}{c}0.0182 \\
(0.0132)\end{array}$ & $\begin{array}{l}0.00277 \\
(0.00267)\end{array}$ \\
\hline Any shock 02-07 & $\begin{array}{l}-0.0252 \\
(0.0360)\end{array}$ & $\begin{array}{c}-0.00994 \\
(0.0281)\end{array}$ & $\begin{array}{c}0.00895 \\
(0.0164)\end{array}$ & $\begin{array}{c}0.0219 * \\
(0.0126)\end{array}$ & $\begin{array}{c}0.00431 * \\
(0.00248)\end{array}$ \\
\hline Any shock 07-08 & $\begin{array}{l}-0.0126 \\
(0.0333)\end{array}$ & $\begin{array}{c}0.00344 \\
(0.0240)\end{array}$ & $\begin{array}{c}0.0273^{*} \\
(0.0142)\end{array}$ & $\begin{array}{l}-0.0136 \\
(0.0143)\end{array}$ & $\begin{array}{l}-0.00445 \\
(0.00333)\end{array}$ \\
\hline Any shock 08-10 & $\begin{array}{c}0.0864 * * \\
(0.0364)\end{array}$ & $\begin{array}{c}-0.0451 * \\
(0.0272)\end{array}$ & $\begin{array}{c}-0.0415^{* *} \\
(0.0198)\end{array}$ & $\begin{array}{c}0.00348 \\
(0.0138)\end{array}$ & $\begin{array}{l}-0.00330 \\
(0.00341)\end{array}$ \\
\hline Ha Tinh & $\begin{array}{c}-0.411 * * * \\
(0.0520)\end{array}$ & $\begin{array}{c}0.102 * * * \\
(0.0367)\end{array}$ & $\begin{array}{c}0.0804 * * \\
(0.0318)\end{array}$ & $\begin{array}{c}0.131 * * * \\
(0.0342)\end{array}$ & $\begin{array}{c}0.0973 * * * \\
(0.0270)\end{array}$ \\
\hline Thua Thien Hue & $\begin{array}{c}-0.281 * * * \\
(0.0532)\end{array}$ & $\begin{array}{l}0.0629 * \\
(0.0346)\end{array}$ & $\begin{array}{c}0.0757 * * * \\
(0.0294)\end{array}$ & $\begin{array}{c}0.102 * * * \\
(0.0284)\end{array}$ & $\begin{array}{c}0.0411 * * * \\
(0.0125)\end{array}$ \\
\hline Highlands & $\begin{array}{l}-0.0354 \\
(0.0306)\end{array}$ & $\begin{array}{c}0.0182 \\
(0.0217)\end{array}$ & $\begin{array}{c}0.00928 \\
(0.0144)\end{array}$ & $\begin{array}{l}0.00779 \\
(0.0118)\end{array}$ & $\begin{array}{l}0.000153 \\
(0.00234)\end{array}$ \\
\hline
\end{tabular}

Notes: Omitted categories: head has no schooling, head is from minority groups, head engages in agriculture, Dak Lak, lowlands, poverty dynamics are referred to $\$ 1.67$ a day. 07 refers to in year 2007, 07-08 refers to period 2007-2008. Standard errors in parentheses, $* * * \mathrm{p}<0.01$, ** $\mathrm{p}<0.05,{ }^{*} \mathrm{p}<0.1$, Pseudo R2 = 0.287, Obs. $=$ 1,901 , passes tests of IIA assumption. 
Table 2.7 Marginal effects from probit models with shocks since 2007

\begin{tabular}{|c|c|c|}
\hline & Fall in to poverty & Stay poor \\
\hline Household size 07 & $\begin{array}{c}0.00211 * * \\
(0.00103)\end{array}$ & $\begin{array}{c}0.0710 * * * \\
(0.0168)\end{array}$ \\
\hline Dependency ratio 07 & $\begin{array}{l}-0.00200 \\
(0.00309)\end{array}$ & $\begin{array}{c}0.216 \\
(0.136)\end{array}$ \\
\hline Head is male 07 & $\begin{array}{c}0.00251 \\
(0.00157)\end{array}$ & $\begin{array}{c}0.00734 \\
(0.0744)\end{array}$ \\
\hline Head age 07 & $\begin{array}{c}9.39 \mathrm{e}-06 \\
(5.27 \mathrm{e}-05)\end{array}$ & $\begin{array}{l}-0.00138 \\
(0.00200)\end{array}$ \\
\hline Head is from the Kinh & $\begin{array}{l}-0.0200 \\
(0.0136)\end{array}$ & $\begin{array}{c}-0.484 * * * \\
(0.0878)\end{array}$ \\
\hline Attains primary school & $\begin{array}{l}-0.00263 \\
(0.00168)\end{array}$ & $\begin{array}{l}-0.0391 \\
(0.0678)\end{array}$ \\
\hline Attains middle school + & $\begin{array}{l}-0.00706 \\
(0.00514)\end{array}$ & $\begin{array}{c}-0.195 * * * \\
(0.0714)\end{array}$ \\
\hline Non-agriculture & $\begin{array}{l}-0.00152 \\
(0.00178)\end{array}$ & $\begin{array}{c}-0.113 \\
(0.0720)\end{array}$ \\
\hline Asset index 07 & $\begin{array}{c}-0.0368 * * \\
(0.0171)\end{array}$ & $\begin{array}{c}-1.066 * * * \\
(0.207)\end{array}$ \\
\hline Land area 07 & $\begin{array}{c}5.20 \mathrm{e}-05 \\
(0.000791)\end{array}$ & $\begin{array}{c}-0.106 * * \\
(0.0424)\end{array}$ \\
\hline Village road is paved 07 & $\begin{array}{l}4.57 \mathrm{e}-06 \\
(0.00178)\end{array}$ & $\begin{array}{l}-0.0331 \\
(0.0577)\end{array}$ \\
\hline Any birth 07-08 & $\begin{array}{c}0.00643 \\
(0.00687)\end{array}$ & $\begin{array}{c}0.195 * * \\
(0.0848)\end{array}$ \\
\hline Any birth $08-10$ & $\begin{array}{c}0.000673 \\
(0.00319)\end{array}$ & $\begin{array}{c}0.267 * * \\
(0.105)\end{array}$ \\
\hline Member left 07-08 & $\begin{array}{l}-0.00247 \\
(0.00152)\end{array}$ & $\begin{array}{c}-0.0511 \\
(0.102)\end{array}$ \\
\hline Member left 08-10 & $\begin{array}{c}0.00233 \\
(0.00273)\end{array}$ & $\begin{array}{c}0.0387 \\
(0.0664)\end{array}$ \\
\hline Has migrant $07-08$ & $\begin{array}{c}-0.00444 * \\
(0.00266)\end{array}$ & $\begin{array}{c}-0.107 * * \\
(0.0535)\end{array}$ \\
\hline Get remittance 07 & $\begin{array}{l}7.23 e-05 \\
(0.00180)\end{array}$ & $\begin{array}{c}-0.124 * * \\
(0.0554)\end{array}$ \\
\hline Get public transfer 07 & $\begin{array}{c}0.00143 \\
(0.00216)\end{array}$ & $\begin{array}{c}0.0613 \\
(0.0564)\end{array}$ \\
\hline Any shock 07-08 & $\begin{array}{c}-0.000153 \\
(0.00173)\end{array}$ & $\begin{array}{c}-0.109 \\
(0.0696)\end{array}$ \\
\hline Any shock 08-10 & $\begin{array}{l}-0.00478 \\
(0.00385)\end{array}$ & $\begin{array}{c}0.0133 \\
(0.0666)\end{array}$ \\
\hline Ha Tinh & $\begin{array}{c}0.00714 \\
(0.00628)\end{array}$ & $\begin{array}{c}0.653 * * * \\
(0.0897)\end{array}$ \\
\hline Thua Thien Hue & $\begin{array}{c}0.00246 \\
(0.00355)\end{array}$ & $\begin{array}{c}0.433 * * * \\
(0.0880)\end{array}$ \\
\hline Highlands & $\begin{array}{l}-0.00184 \\
(0.00198)\end{array}$ & $\begin{array}{c}0.0147 \\
(0.0541)\end{array}$ \\
\hline Observations & 1,295 & 455 \\
\hline Pseudo R2 & 0.411 & 0.306 \\
\hline LR $\operatorname{chi} 2(7)$ & $1475.8 * * *$ & $180.4 * * *$ \\
\hline
\end{tabular}

Notes: Omitted categories: head has no schooling, head engages in agriculture, Dak Lak, lowlands, poverty dynamics are referred to $\$ 1.67$ a day. 07 refers to in year 2007, 07-08 refers to period 2007-2008. Standard errors in parentheses, $* * * \mathrm{p}<0.01, * * \mathrm{p}<0.05, * \mathrm{p}<0.1$. 
Table 2.8 Marginal effects from MNL of poverty dynamics as referred to \$2.5

\begin{tabular}{|c|c|c|c|c|c|}
\hline & Non-poor & Rising & Falling & Churning & Poor \\
\hline Household size 07 & $\begin{array}{c}-0.103 * * * \\
(0.00896)\end{array}$ & $\begin{array}{c}0.0376 * * * \\
(0.00983)\end{array}$ & $\begin{array}{c}-0.0307 * * * \\
(0.00649)\end{array}$ & $\begin{array}{l}0.00594 \\
(0.00821)\end{array}$ & $\begin{array}{c}0.0903 * * * \\
(0.00720)\end{array}$ \\
\hline Dependency ratio 07 & $\begin{array}{c}-0.157 * * * \\
(0.0485)\end{array}$ & $\begin{array}{l}-0.0931 \\
(0.0604)\end{array}$ & $\begin{array}{l}-0.0300 \\
(0.0334)\end{array}$ & $\begin{array}{c}0.0304 \\
(0.0495)\end{array}$ & $\begin{array}{c}0.250 * * * \\
(0.0479)\end{array}$ \\
\hline Head is male 07 & $\begin{array}{l}-0.0287 \\
(0.0348)\end{array}$ & $\begin{array}{c}-0.00325 \\
(0.0388)\end{array}$ & $\begin{array}{c}0.0113 \\
(0.0223)\end{array}$ & $\begin{array}{c}0.0295 \\
(0.0303)\end{array}$ & $\begin{array}{c}-0.00883 \\
(0.0294)\end{array}$ \\
\hline Head age 07 & $\begin{array}{l}0.00124 \\
(0.00104)\end{array}$ & $\begin{array}{l}-0.00158 \\
(0.00114)\end{array}$ & $\begin{array}{c}0.00107 \\
(0.000720)\end{array}$ & $\begin{array}{l}-4.33 \mathrm{e}-05 \\
(0.000931)\end{array}$ & $\begin{array}{r}-0.000684 \\
(0.000765)\end{array}$ \\
\hline Head is from the Kinh & $\begin{array}{c}0.179 * * * \\
(0.0256)\end{array}$ & $\begin{array}{c}0.137 * * * \\
(0.0346)\end{array}$ & $\begin{array}{l}-0.0102 \\
(0.0290)\end{array}$ & $\begin{array}{c}0.00828 \\
(0.0332)\end{array}$ & $\begin{array}{c}-0.314 * * * \\
(0.0465)\end{array}$ \\
\hline Attains primary school & $\begin{array}{l}0.107 * * \\
(0.0545)\end{array}$ & $\begin{array}{c}0.0205 \\
(0.0493)\end{array}$ & $\begin{array}{l}-0.0248 \\
(0.0255)\end{array}$ & $\begin{array}{l}-0.0408 \\
(0.0341)\end{array}$ & $\begin{array}{c}-0.0621 * * \\
(0.0254)\end{array}$ \\
\hline Attains middle school + & $\begin{array}{c}0.162 * * * \\
(0.0401)\end{array}$ & $\begin{array}{l}-0.0231 \\
(0.0461)\end{array}$ & $\begin{array}{l}-0.0117 \\
(0.0283)\end{array}$ & $\begin{array}{l}-0.0336 \\
(0.0367)\end{array}$ & $\begin{array}{c}-0.0931 * * * \\
(0.0321)\end{array}$ \\
\hline Non-agriculture & $\begin{array}{c}0.0892 * * \\
(0.0350)\end{array}$ & $\begin{array}{l}-0.0435 \\
(0.0366)\end{array}$ & $\begin{array}{c}0.0349 \\
(0.0273)\end{array}$ & $\begin{array}{l}-0.0183 \\
(0.0308)\end{array}$ & $\begin{array}{c}-0.0624 * * * \\
(0.0241)\end{array}$ \\
\hline Asset index 07 & $\begin{array}{c}1.549 * * * \\
(0.0946)\end{array}$ & $\begin{array}{c}-0.300 * * * \\
(0.104)\end{array}$ & $\begin{array}{c}0.0919 \\
(0.0677)\end{array}$ & $\begin{array}{c}-0.257 * * * \\
(0.0865)\end{array}$ & $\begin{array}{c}-1.084 * * * \\
(0.0795)\end{array}$ \\
\hline Land area 07 & $\begin{array}{l}0.0178 * * \\
(0.00864)\end{array}$ & $\begin{array}{c}0.0125 \\
(0.0105)\end{array}$ & $\begin{array}{l}0.0109 * * \\
(0.00534)\end{array}$ & $\begin{array}{c}-0.00203 \\
(0.0103)\end{array}$ & $\begin{array}{c}-0.0391 * * * \\
(0.0123)\end{array}$ \\
\hline Village road is paved 07 & $\begin{array}{c}0.0685 * * \\
(0.0289)\end{array}$ & $\begin{array}{c}-0.113 * * * \\
(0.0313)\end{array}$ & $\begin{array}{c}0.0182 \\
(0.0211)\end{array}$ & $\begin{array}{l}0.00461 \\
(0.0275)\end{array}$ & $\begin{array}{c}0.0213 \\
(0.0237)\end{array}$ \\
\hline Any birth 07-08 & $\begin{array}{c}-0.0945^{* * *} \\
(0.0322)\end{array}$ & $\begin{array}{c}-0.0800 * \\
(0.0416)\end{array}$ & $\begin{array}{l}-0.0231 \\
(0.0285)\end{array}$ & $\begin{array}{c}0.0861 * * \\
(0.0436)\end{array}$ & $\begin{array}{c}0.112 * * * \\
(0.0430)\end{array}$ \\
\hline Any birth 08-10 & $\begin{array}{c}-0.0981 * * * \\
(0.0348)\end{array}$ & $\begin{array}{c}-0.177 * * * \\
(0.0418)\end{array}$ & $\begin{array}{c}0.131 * * * \\
(0.0483)\end{array}$ & $\begin{array}{c}0.0754 \\
(0.0505)\end{array}$ & $\begin{array}{c}0.0691 \\
(0.0464)\end{array}$ \\
\hline Member left 07-08 & $\begin{array}{l}-0.0334 \\
(0.0405)\end{array}$ & $\begin{array}{c}0.0206 \\
(0.0522)\end{array}$ & $\begin{array}{l}-0.0222 \\
(0.0297)\end{array}$ & $\begin{array}{c}0.0863^{*} \\
(0.0518)\end{array}$ & $\begin{array}{l}-0.0513 \\
(0.0323)\end{array}$ \\
\hline Member left 08-10 & $\begin{array}{c}0.0211 \\
(0.0299)\end{array}$ & $\begin{array}{c}-0.00833 \\
(0.0338)\end{array}$ & $\begin{array}{c}0.0233 \\
(0.0235)\end{array}$ & $\begin{array}{c}-0.00895 \\
(0.0290)\end{array}$ & $\begin{array}{l}-0.0271 \\
(0.0246)\end{array}$ \\
\hline Has migrant $07-08$ & $\begin{array}{c}0.0911 * * * \\
(0.0269)\end{array}$ & $\begin{array}{l}-0.0265 \\
(0.0291)\end{array}$ & $\begin{array}{c}0.00408 \\
(0.0194)\end{array}$ & $\begin{array}{c}0.0191 \\
(0.0253)\end{array}$ & $\begin{array}{c}-0.0878 * * * \\
(0.0208)\end{array}$ \\
\hline Get remittance 07 & $\begin{array}{l}-0.0275 \\
(0.0258)\end{array}$ & $\begin{array}{c}-0.00691 \\
(0.0310)\end{array}$ & $\begin{array}{l}0.0406 * \\
(0.0221)\end{array}$ & $\begin{array}{l}0.00187 \\
(0.0264)\end{array}$ & $\begin{array}{c}-0.00806 \\
(0.0234)\end{array}$ \\
\hline Get public transfer 07 & $\begin{array}{c}0.0141 \\
(0.0285)\end{array}$ & $\begin{array}{l}-0.0114 \\
(0.0310)\end{array}$ & $\begin{array}{l}-0.0255 \\
(0.0190)\end{array}$ & $\begin{array}{l}0.00669 \\
(0.0266)\end{array}$ & $\begin{array}{c}0.0160 \\
(0.0230)\end{array}$ \\
\hline Any shock 07-08 & $\begin{array}{l}-0.0443 \\
(0.0285)\end{array}$ & $\begin{array}{c}0.0250 \\
(0.0315)\end{array}$ & $\begin{array}{c}0.0213 \\
(0.0201)\end{array}$ & $\begin{array}{c}0.0152 \\
(0.0270)\end{array}$ & $\begin{array}{l}-0.0173 \\
(0.0250)\end{array}$ \\
\hline Any shock 08-10 & $\begin{array}{c}0.0159 \\
(0.0269)\end{array}$ & $\begin{array}{c}-0.00174 \\
(0.0327)\end{array}$ & $\begin{array}{c}0.0114 \\
(0.0205)\end{array}$ & $\begin{array}{c}0.0202 \\
(0.0275)\end{array}$ & $\begin{array}{c}-0.0457 * \\
(0.0278)\end{array}$ \\
\hline Ha Tinh & $\begin{array}{c}-0.243 * * * \\
(0.0316)\end{array}$ & $\begin{array}{c}0.0333 \\
(0.0446)\end{array}$ & $\begin{array}{l}-0.0101 \\
(0.0301)\end{array}$ & $\begin{array}{l}-0.0128 \\
(0.0379)\end{array}$ & $\begin{array}{c}0.233 * * * \\
(0.0455)\end{array}$ \\
\hline Thua Thien Hue & $\begin{array}{c}-0.169 * * * \\
(0.0324)\end{array}$ & $\begin{array}{l}-0.0672 \\
(0.0421)\end{array}$ & $\begin{array}{c}0.0469 \\
(0.0337)\end{array}$ & $\begin{array}{c}0.0647 \\
(0.0404)\end{array}$ & $\begin{array}{c}0.125^{* * * *} \\
(0.0389)\end{array}$ \\
\hline Highlands & $\begin{array}{c}0.0181 \\
(0.0269)\end{array}$ & $\begin{array}{l}-0.0345 \\
(0.0297)\end{array}$ & $\begin{array}{c}0.00846 \\
(0.0200)\end{array}$ & $\begin{array}{c}-0.000678 \\
(0.0259)\end{array}$ & $\begin{array}{l}0.00862 \\
(0.0216)\end{array}$ \\
\hline
\end{tabular}

Notes: Omitted categories: head has no schooling, head engages in agriculture, Dak Lak, lowlands, poverty dynamics are referred to $\$ 1.67$ a day. 07 refers to in year 2007, 07-08 refers to period 2007-2008. Pseudo R2= 0.257 , Observations $=1,901$, passes tests of IIA assumption. Standard errors in parentheses, $* * * \mathrm{p}<0.01, * *$ $\mathrm{p}<0.05, * \mathrm{p}<0.1$. 
Table 2.9 Marginal effects from MNL of poverty dynamics based on equivalence scaled expenditure

\begin{tabular}{|c|c|c|c|c|c|}
\hline & Non-poor & Rising & Falling & Churning & Poor \\
\hline Household size 07 & $\begin{array}{c}-0.0162 * * * \\
(0.00527)\end{array}$ & $\begin{array}{c}0.00667 * * \\
(0.00315)\end{array}$ & $\begin{array}{l}0.00379 \\
(0.00306)\end{array}$ & $\begin{array}{c}0.00535 * * * \\
(0.00194)\end{array}$ & $\begin{array}{c}0.000407^{*} \\
(0.000210)\end{array}$ \\
\hline Dependency ratio 07 & $\begin{array}{l}-0.0166 \\
(0.0351)\end{array}$ & $\begin{array}{c}0.0227 \\
(0.0216)\end{array}$ & $\begin{array}{l}-0.0226 \\
(0.0199)\end{array}$ & $\begin{array}{c}0.0153 \\
(0.0141)\end{array}$ & $\begin{array}{c}0.00124 \\
(0.00103)\end{array}$ \\
\hline Head is male 07 & $\begin{array}{c}0.0167 \\
(0.0245)\end{array}$ & $\begin{array}{c}0.000439 \\
(0.0140)\end{array}$ & $\begin{array}{l}-0.0162 \\
(0.0152)\end{array}$ & $\begin{array}{c}-0.000289 \\
(0.00881)\end{array}$ & $\begin{array}{l}-0.000597 \\
(0.000713)\end{array}$ \\
\hline Head age 07 & $\begin{array}{c}-0.00238 * * * \\
(0.000667)\end{array}$ & $\begin{array}{l}0.000587 \\
(0.000392)\end{array}$ & $\begin{array}{c}0.00132 * * * \\
(0.000391)\end{array}$ & $\begin{array}{c}0.000431 * \\
(0.000245)\end{array}$ & $\begin{array}{l}3.38 \mathrm{e}-05^{*} \\
(2.04 \mathrm{e}-05)\end{array}$ \\
\hline Head is from the Kinh & $\begin{array}{c}0.252 * * * \\
(0.0435)\end{array}$ & $\begin{array}{c}-0.125 * * * \\
(0.0336)\end{array}$ & $\begin{array}{c}-0.0460 * * \\
(0.0221)\end{array}$ & $\begin{array}{c}-0.0615^{* * *} \\
(0.0230)\end{array}$ & $\begin{array}{c}-0.0199 * \\
(0.0113)\end{array}$ \\
\hline Attains primary school & $\begin{array}{l}0.0368 * \\
(0.0224)\end{array}$ & $\begin{array}{l}-0.0131 \\
(0.0135)\end{array}$ & $\begin{array}{l}-0.0167 \\
(0.0124)\end{array}$ & $\begin{array}{l}-0.00693 \\
(0.00782)\end{array}$ & $\begin{array}{l}-8.73 e-05 \\
(0.000451)\end{array}$ \\
\hline Attains middle school + & $\begin{array}{c}0.0543 * * \\
(0.0268)\end{array}$ & $\begin{array}{l}-0.0139 \\
(0.0154)\end{array}$ & $\begin{array}{l}-0.0241 \\
(0.0159)\end{array}$ & $\begin{array}{l}-0.0150 \\
(0.0102)\end{array}$ & $\begin{array}{c}-0.00137 \\
(0.000944)\end{array}$ \\
\hline Non-agriculture & $\begin{array}{c}0.0480 * * \\
(0.0224)\end{array}$ & $\begin{array}{l}-0.0169 \\
(0.0141)\end{array}$ & $\begin{array}{l}-0.0201 \\
(0.0136)\end{array}$ & $\begin{array}{l}-0.0101 \\
(0.00865)\end{array}$ & $\begin{array}{r}-0.000838 \\
(0.000613)\end{array}$ \\
\hline Asset index 07 & $\begin{array}{c}0.739 * * * \\
(0.0641)\end{array}$ & $\begin{array}{c}-0.291 * * * \\
(0.0396)\end{array}$ & $\begin{array}{c}-0.256 * * * \\
(0.0376)\end{array}$ & $\begin{array}{c}-0.178 * * * \\
(0.0285)\end{array}$ & $\begin{array}{c}-0.0133 * * \\
(0.00613)\end{array}$ \\
\hline Land area 07 & $\begin{array}{c}0.0285^{* * * *} \\
(0.0103)\end{array}$ & $\begin{array}{c}-0.0167 * * \\
(0.00756)\end{array}$ & $\begin{array}{l}0.000714 \\
(0.00435)\end{array}$ & $\begin{array}{c}-0.0121 * * \\
(0.00502)\end{array}$ & $\begin{array}{c}-0.000520 * \\
(0.000313)\end{array}$ \\
\hline Village road is paved 07 & $\begin{array}{c}0.0269 \\
(0.0199)\end{array}$ & $\begin{array}{c}1.73 \mathrm{e}-05 \\
(0.0119)\end{array}$ & $\begin{array}{l}-0.0185 \\
(0.0115)\end{array}$ & $\begin{array}{l}-0.00818 \\
(0.00746)\end{array}$ & $\begin{array}{l}-0.000291 \\
(0.000448)\end{array}$ \\
\hline Any birth 07-08 & $\begin{array}{c}0.00352 \\
(0.0287)\end{array}$ & $\begin{array}{l}-0.0177 \\
(0.0142)\end{array}$ & $\begin{array}{l}0.00906 \\
(0.0189)\end{array}$ & $\begin{array}{c}0.00406 \\
(0.0116)\end{array}$ & $\begin{array}{l}0.00110 \\
(0.00114)\end{array}$ \\
\hline Any birth $08-10$ & $\begin{array}{l}-0.0217 \\
(0.0356)\end{array}$ & $\begin{array}{l}-0.0201 \\
(0.0150)\end{array}$ & $\begin{array}{c}0.0451 \\
(0.0278)\end{array}$ & $\begin{array}{c}-0.00223 \\
(0.0117)\end{array}$ & $\begin{array}{c}-0.00108 * \\
(0.000577)\end{array}$ \\
\hline Member left 07-08 & $\begin{array}{c}-0.0716 * \\
(0.0399)\end{array}$ & $\begin{array}{l}0.00782 \\
(0.0216)\end{array}$ & $\begin{array}{l}0.00652 \\
(0.0177)\end{array}$ & $\begin{array}{c}0.0566 * * \\
(0.0253)\end{array}$ & $\begin{array}{l}0.000697 \\
(0.00117)\end{array}$ \\
\hline Member left 08-10 & $\begin{array}{c}-0.128 * * * \\
(0.0265)\end{array}$ & $\begin{array}{c}0.0217 \\
(0.0141)\end{array}$ & $\begin{array}{c}0.0872 * * * \\
(0.0192)\end{array}$ & $\begin{array}{l}0.0178 * \\
(0.01000)\end{array}$ & $\begin{array}{c}0.000928 \\
(0.000788)\end{array}$ \\
\hline Has migrant $07-08$ & $\begin{array}{c}-0.0602 * * * \\
(0.0201)\end{array}$ & $\begin{array}{c}0.0349 * * * \\
(0.0126)\end{array}$ & $\begin{array}{l}0.00823 \\
(0.0113)\end{array}$ & $\begin{array}{l}0.0161 * * \\
(0.00800)\end{array}$ & $\begin{array}{c}0.000964 \\
(0.000658)\end{array}$ \\
\hline Get remittance 07 & $\begin{array}{l}-0.0231 \\
(0.0202)\end{array}$ & $\begin{array}{l}0.00533 \\
(0.0120)\end{array}$ & $\begin{array}{c}0.0130 \\
(0.0121)\end{array}$ & $\begin{array}{c}0.00430 \\
(0.00774)\end{array}$ & $\begin{array}{l}0.000469 \\
(0.000574)\end{array}$ \\
\hline Get public transfer 07 & $\begin{array}{c}-0.0378 * \\
(0.0199)\end{array}$ & $\begin{array}{l}0.0240 * \\
(0.0127)\end{array}$ & $\begin{array}{l}0.00787 \\
(0.0113)\end{array}$ & $\begin{array}{c}0.00542 \\
(0.00740)\end{array}$ & $\begin{array}{l}0.000490 \\
(0.000540)\end{array}$ \\
\hline Any shock 07-08 & $\begin{array}{c}-0.00898 \\
(0.0206)\end{array}$ & $\begin{array}{c}-0.00768 \\
(0.0132)\end{array}$ & $\begin{array}{c}0.0181 \\
(0.0117)\end{array}$ & $\begin{array}{l}-0.00143 \\
(0.00823)\end{array}$ & $\begin{array}{c}2.25 \mathrm{e}-05 \\
(0.000521)\end{array}$ \\
\hline Any shock 08-10 & $\begin{array}{c}0.00752 \\
(0.0218)\end{array}$ & $\begin{array}{l}0.00118 \\
(0.0130)\end{array}$ & $\begin{array}{l}0.00228 \\
(0.0128)\end{array}$ & $\begin{array}{l}-0.00994 \\
(0.00960)\end{array}$ & $\begin{array}{c}-0.00104 \\
(0.000945)\end{array}$ \\
\hline Ha Tinh & $\begin{array}{c}-0.209 * * * \\
(0.0404)\end{array}$ & $\begin{array}{c}0.0825 * * * \\
(0.0268)\end{array}$ & $\begin{array}{c}0.0653 * * * \\
(0.0243)\end{array}$ & $\begin{array}{c}0.0503 * * \\
(0.0198)\end{array}$ & $\begin{array}{l}0.0110 * \\
(0.00626)\end{array}$ \\
\hline Thua Thien Hue & $\begin{array}{c}-0.151 * * * \\
(0.0365)\end{array}$ & $\begin{array}{c}0.0193 \\
(0.0181)\end{array}$ & $\begin{array}{c}0.0762 * * * \\
(0.0242)\end{array}$ & $\begin{array}{c}0.0510 * * * \\
(0.0179)\end{array}$ & $\begin{array}{l}0.00504 * \\
(0.00284)\end{array}$ \\
\hline Highlands & $\begin{array}{c}-0.0369 * * \\
(0.0181)\end{array}$ & $\begin{array}{c}0.0248 * * \\
(0.0109)\end{array}$ & $\begin{array}{c}0.00784 \\
(0.0109)\end{array}$ & $\begin{array}{c}0.00456 \\
(0.00711)\end{array}$ & $\begin{array}{l}-0.000373 \\
(0.000495)\end{array}$ \\
\hline
\end{tabular}

Notes: Omitted categories: head has no schooling, head engages in agriculture, Dak Lak, lowlands, poverty dynamics are referred to $\$ 1.67$ a day and measured by equivalence scaled expenditure. 07 refers to in year 2007, 07-08 refers to period 2007-2008. Pseudo R2 $=0.233$, Observations $=1,901$, passes tests of IIA assumption. Standard errors in parentheses, ${ }^{* * *} \mathrm{p}<0.01, * * \mathrm{p}<0.05, * \mathrm{p}<0.1$. 


\title{
Chapter 3
}

\section{Household's Coping Strategies and Recoveries from Shocks}

\begin{abstract}
There has been a great deal of the literature on the effects of shocks on a household's wellbeing as well as on the choice of ex-ante and ex-post strategies in the context of risk exposure. However, researchers have paid little attention to the ability of a household to recover from an adverse event. Additionally, the livelihood of those in the developing world has been increasingly affected by macroeconomic instabilities and extreme weather conditions. This study aims to investigate the forces that shape a household's recovery from misfortune. The analyses are applied to the case of Vietnam by using data collected from household surveys from years 2007 to 2010 and a discrete time proportional hazard model to find the determinants of the shock recovery. The results show that a household's characteristics do not strongly determine the shock recovery but physical assets do. Shocks covariates such as more losses and higher severity make the misfortune harder to recover from. Additionally, coping strategies sometimes help poor households recover better from the losses.
\end{abstract}

\subsection{Introduction}

In the literature on vulnerability, there has been increasing discussion on the effects of shocks on a household's well-being and their responses to such adverse events. A number of methodological studies (Paxson, 1992; Paxson, 1993; Morduch, 1994; Dercon, 1996; Elbers et al., 2007) and empirical studies (Kochar, 1995; Dercon and Krishman, 2003; Hoddinott, 2006; Thomas et al., 2010; Imai et al., 2011) have been conducted using different approaches and country cases. They have identified the effects of shocks on the well-being of different types of household groups, have discovered the coping strategies that households employ when facing these shocks, and have found the ex-ante strategies that household apply in an effort to reduce risk. Recently the literature has been focusing on the forces that shape the recovery paths during the aftermath of shocks. It argues that wealthier households might be able to cope with shocks by selling livestock or borrowing from others, thereby allowing them to recover fully and quickly from the bad luck while poorer households might suffer for a longer period of time (Carter et al., 2007). Despite these findings, there is still a lot of room for further investigation and discussion on this complicated matter. 
A full examination of the effects of a household's assets, a shock's covariates, and coping strategies on the post-shock recovery is thus an important contribution to the literature on vulnerability, particularly to the literature that discusses the resilience paths during the aftermath of adverse events. It will also be helpful for the evaluation and assessment of poverty alleviating policies, especially in the context of the increasing uncertainties in the developing world. The main goal of this study is to find which household groups are able to recover quickly from shock, which household groups are able to apply coping strategies, and exactly which coping strategies are helpful for quick and speedy recoveries.

This study finds the answers to these research questions in the context of Vietnam, as it is an appropriate case study for developing countries. Vietnam has been successful in sustaining unprecedented economic growth rates and making a sharply reducing poverty during the last two decades. However, risk remains a central part of the livelihoods since more than two fifths of the population live on less than $\$ 2$ a day (World Bank, 2013). Additionally, agriculture is still the main income source of more than 70 percent of the population in rural areas (World Bank, 2013), and absorbs 64 percent of the nation's labour force (GSO, 2011a). Obviously, this important sector is increasingly affected by livestock diseases such as Avian Flu and Swine Flu as well as by extreme weather conditions such as storms, floods and droughts. Furthermore, the rapid economic growth and globalisation process bring about more market uncertainties, especially for the poor.

This study employs data from more than 2000 households in Vietnam collected in 2007, 2008 and 2010. These surveys interviewed households about the shocks they experienced, what their responses to each shock were, and how many months the household needed to recover from each shock. The duration of the recovery is estimated via a discrete time proportional hazard model and is based on the hypothesis that wealthier households usually have more access to markets thus they recover better from shocks. Another hypothesis is that coping strategies are helpful in recovering from the adverse events, particularly for poor households.

The remainder of this study is organised as follows: Section 3.2 discusses the theoretical and empirical studies on post-shock resilience; Section 3.3 describes the data sets employed in the analysis and specifies the discrete time proportional hazard model. After that, Section 3.4 discusses the prevalence of shocks of different household groups. Section 3.5 discusses the determinants of recovery including a household's and a shock's covariates. Lastly, Section 3.6 concludes the key messages of the study. 


\subsection{The literature on post-shock resilience}

\subsubsection{Household coping strategies and resilience paths}

An adverse event has the possibility of causing a decline in assets and incomes in the shortrun and might have negative effects on a household's livelihood in the long-run. These effects depend on the type of the shock that occurs, the asset dynamics and on coping strategies ultilised in the aftermath of the shock. When facing shocks, households with access to markets might be able to employ external resources such as insurance (Dercon, 2002) and credit (Clarke and Dercon, 2009) as ex-post strategies. However, insurance and financial markets are not accessible by a large share of the population in developing countries (see Zimmerman and Carter, 2003), especially in rural areas. In that case, poor households might get credit from informal markets with a high interest rate, but this could push them into a higher debt burden from which they would find it even harder to recover. Hence, households with limited access to markets may need to rely on public support (Tran et al., 2008) or informal risk-sharing arrangements (Dercon and Krishman, 2003; Carter and Castillo, 2005). However, the effect of public safety nets might be not so large (Dercon, 2002) due to having limited resources in developing countries, particularly in the context of having an increasing number of risks. In addition, risk-sharing arrangements might not be effective as the poor usually live in a community of poor people and often many households in the same community face the same covariant shock (Dercon, 2002). Alternatively, farm households often have other crops or livestock to compensate for the lost ones. They can also increase their market working hours if they have access to the labour market. Nevertheless, when there is limited access to external resources households need to use their own resources to cope with the shocks.

Shocks can be classified as being either asset shocks or income shocks. An asset shock, such as a storm or a flood, might cause a decline in physical assets or livestock and could reduce income as well. It might have small effects on wealthy households but tends to have long-run effects on poor households. Figure 3.1 shows asset accumulation paths of wealthy and poor households. The horizontal axis measures time and the vertical axis measures asset stocks and income level. A wealthier household has the initial asset stock at $A_{w p}$ while a poorer household has a lower initial asset stock at $A_{b p}$. If there is no shock, the poorer household might be able to follow the dashed asset accumulation path and catch up with the wealthier household. An asset shock is usually in the form of a short, temporary event that causes the asset levels of the wealthy and poor households to fall to $A_{w p}$ and $A_{s p}$ 
respectively. The shock might also reduce current incomes of both households by an amount $\varepsilon$ (see Carter et al., 2007).

Figure 3.1 Asset shocks and resilience paths

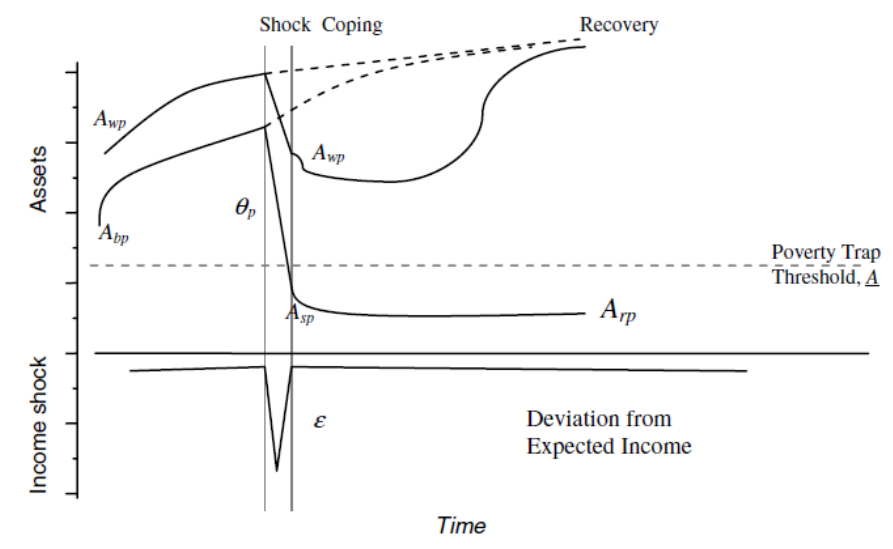

Source: Carter et al. (2007)

The post-shock recovery is influenced by coping strategies applied in the immediate aftermath of the shock and by long-run patterns of asset dynamics (Carter et al., 2007). Market access and social mechanisms shape a household's resilience and the speed of its post-shock asset accumulation trajectory. As discussed above, a household with access to financial markets might use insurance or credit to smooth their consumption without further asset depletion. This household would be expected to recover quickly and return to the convergent long-term trajectory illustrated in Figure 3.1. A household with limited access to financial markets might have to sell their assets further to keep consumption smooth. However, unfavorable asset price swings might occur when many households sell assets in order to buy food during a shortage after a covariant shock, which could lead to those households falling into a poverty trap (Carter et al., 2007). A household that fell below the poverty trap would be expected to recover at a slower pace and could even be unable to accumulate assets; the household would thus stay poor, rather than rejoining its convergent pre-shock trajectory (see Carter and Barrett, 2006; Carter et al., 2007).

An income shock, such as a drought or a heavy rain, might affect a household's asset stocks over an extended period of time. This effect is illustrated in Figure 3.2 with the assumption that there are no direct asset losses associated with the income shock. An initially wealthier household that begins with a higher asset level $\left(A_{b w}\right)$ could be expected to draw on their assets when being faced with income shocks in order to smooth its consumption level. Thus, it could be expected to rebuild its asset stocks, returning toward its initial trajectory. Alternatively, consider an initially poorer household, which begins with a lower asset level $\left(A_{b p}\right)$. This household might instead choose to reduce consumption and smooth its assets in order to avoid falling into the poverty trap, denoted by $A$ if it exists (Carter et al., 2007). 
However, poor households usually have low levels of consumption, hence cutting them further by reducing food consumption or withdrawing children from school might have negative effects on human capital in the long-run.

Figure 3.2 Income shocks and resilience paths

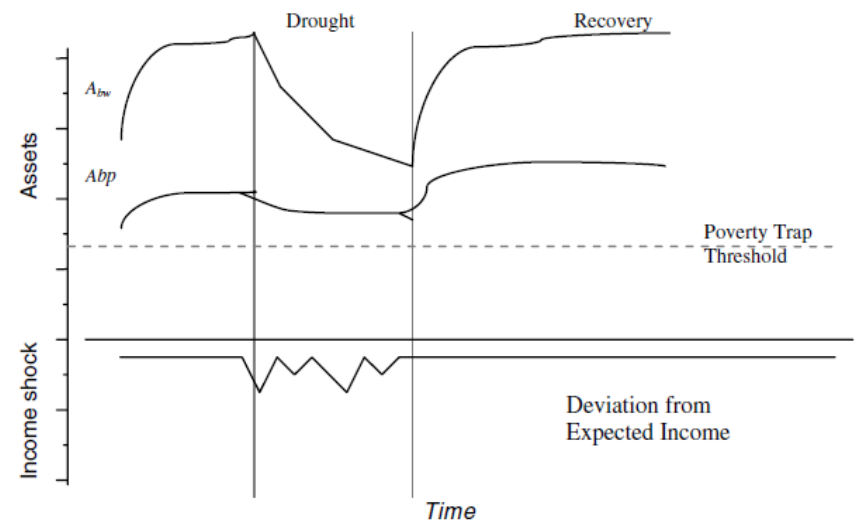

Source: Carter et al. (2007)

A large share of the population in Vietnam lives in poverty and faces a number uncertainties (see Section 3.1). When facing shocks, households are expected to be able to employ external resources such as insurance and credit as coping strategies. However, not many households have access to those markets, particularly poor households in remote areas and of ethnic minority groups. Therefore, many households are expected to also use their own resources such as savings, livestock and other physical assets to cope with shocks. Households of different wealth levels are also expected to cope with shocks differently. Wealthier households, that have enough available resources might follow consumption smoothing strategies and are hypothesied to recover quickly from shocks. On the contrary, poor households, which possess limited assets, might have to follow asset smoothing strategies in order to avoid falling into the asset poverty trap. However, cutting consumption further might cause negative effects on long-term human capital. Therefore, poor households are hypothesied to find it harder to recover from shocks.

\subsubsection{Empirical evidence from the literature on shock recovery}

There have been a number of empirical studies on the effects of shocks on a household's well-being. They find that the poor, especially the poorest of the poor are the major victims and suffer more losses from shocks (Moris et al., 2002; Little et al., 2006). In some cases, the poorest households are immune to the shocks because they have so little to lose (Moris et al., 2002). Other studies find that farm households may be more vulnerable to demographic shocks than income shocks (Kochar, 1995). However, one case from Bangladesh shows that non-poor households face a larger share of shocks, especially a larger share of asset shocks than the poor do (Santos, 2011). The shocks can cause 
substantial short-run losses in assets, incomes (Moris et al., 2002; Elbers et al., 2007; Thomas et al., 2010), and health (Dercon and Hoddinott, 2003; Maccini and Yang, 2009), and could have long-run negative effects on a household's livelihood (Thomas et al., 2010). The adverse events can also cause the household to have a higher vulnerability to poverty (Santos, 2011; Imai et al., 2011).

In order to cope with the income losses, poorer households tend to smooth assets and let consumption fall while wealthier households sell assets to smooth consumption (Hoddinott, 2006). Wealthier households have more assets so they are able to follow a consumption smoothing strategy. Conversely, poorer households try to hold on to their few assets and sacrifice consumption (McPeak, 2004; Carter et al., 2007; Lawson, 2009). This strategy could have long-run negative effects since poor households might cut consumption further by consuming less food or withdrawing their children from school. The alternative is however not much better, if they sell assets to smooth consumption they might fall into the poverty trap (see Carter and Barrett, 2006).

In addition, households can also deplete their total stock of liquid assets in response to exogenous economic shocks and idiosyncratic insurable shocks (Wainwright and Newman, 2011). Financial savings, particularly cash and gold held at home, can be important buffers when faced with spatially covariant natural shocks (Paxson, 1993; Wainwright and Newman, 2011). However, poorer households typically have no savings, thus they need loans from formal and informal financial markets in addition to increased hours of work (see Kochar, 1999; Kazianga and Urdy, 2006). Another possibility for them is to use formal and informal risk-sharing arrangements (Alderman and Paxson, 1992; Fafchamps and Lund, 2003; Jalan and Ravallion, 1999; Townsend, 1994: Kazianga and Urdy, 2006; Carter and Castillo, 2005). However, risk sharing does not work when there are covariant shocks that occur to many households in the area.

There are a limited number of studies on post-shock recovery. In a study on the effects of political-social conflicts, shrimp disease, and a tsunami in the Indonesian province of Aceh, Mills et al. (2011) use data from 161 households collected annually from 1994 to 2008. Their statistical analyses show that all households had at least some level of recovery after a tsunami. The provision of subsidised aquaculture and agriculture inputs, the improved availability of technical assistance, supervision, training and infrastructure rehabilitation were all crucial for this recovery.

In another study in Indonesia, Newhouse (2005) analyses the effect of three common types of shocks including rainfall shocks, changes in the net value of farmland purchases, and 
changes in the net value of livestock purchases. He employs Indonesian Family Life Surveys from 1993 and 1997 that cover a sample of more than 7000 households in order to measure the changes in household income that resulted from shocks during the period. The results show that roughly 30 percent of the 1993 income shock remained four years later. Positive shocks last longer than negative shocks and both types of shocks last for shorter periods of time for poor households. The effect of income and other shocks on other important household outcomes besides future income, such as household's wealth or children's schooling, may greatly depend on the economic position of the household and the type of shock the household experiences.

Using also Indonesian Family Life Surveys data from 2000, Maccini and Yang (2009) examine the effect of rainfall variation around the time of birth on the health, education and socioeconomic outcomes of Indonesian adults born between 1953 and 1974. They find that the higher amount of rainfall during a person's early life has positive effects on the outcomes of women but not men. The explanation is that the rainfall has positive impacts on agriculture output and leads to higher household incomes and therefore better health for infant girls. The difference effects between men and women could be the result of the discrimination against girls.

In order to fight a rebel group in northern Uganda, the country's government forced the majority of the population in the area into semi-permanent camps in 2002. After a peace agreement in 2006, people began to return home. In an attempt to find the impact of such displacement, Fiala (2011) uses household data from the Northern Uganda Surveys from 2004 and 2008 to analyse the difference in household's consumptions between the two periods. He finds that displaced households experienced an initial decrease in consumption of between 28 percent and 35 percent, as well as a decrease in the value of assets. Two years after households returned home, the effects of displacement were greatly decreased, but not yet eliminated. Displaced households still lag behind non-displaced households with 20 percent lower consumption levels, and a fifth standard deviation less assets.

As an illustrative case study for their prediction of shock resilience paths, Carter et al. (2007) employ data from surveys from 1998 to 2001 covering more than 800 households in six provinces in Honduras, locations were severity hit by Hurricane Mitch in late 1998. The authors estimate asset growth rates as a function of initial asset stocks, as well as the effects of income shocks and asset shocks on household's access to labour and financial markets, and household covariates. They find that the effects of Hurricane Mitch differ by the household's initial wealth. Wealthy households were able to partially rebuild their lost assets in the three years following the shock. The lowest wealth groups suffered the effects 
of the shock for a longer period. Households with asset levels below the estimated threshold of $\$ 250$ found it hard to recover from the shock.

\subsubsection{Summary}

The literature on shock coping and recovery has shown that the short-run and long-run effects of shocks are shaped by the choice of coping strategies, as well as by the asset dynamics during the aftermath of the shock. Wealthy households usually have better access to markets giving them the ability to use insurance and credit to cope with the shocks. They can also use savings or sell their assets to smooth consumption. These reactions allow them to recover quickly and fully from the adverse events. On the contrary, poorer households have limited access to financial markets thus they need to use their own resources to cope with the shocks. However, they do not have too many spare resources that they can use, and once they deplete too many they will fall into the poverty trap, making it much more difficult for them to overcome the shocks.

In a study of self reported shock coping strategies and recovery in Vietnam, it is hypothesied that wealthy households are generally better able to apply coping strategies that allow them recover quickly from shocks. However, shocks that are reported by wealthy households might be of higher severity than shocks reported by their poorer counterparts. These two forces might make the shock recovery between the two household groups not so different. In addition, coping strategies on the one hand help households recover better, on the other hand coping strategies are more likely to be applied for severe shocks. Therefore, the observed impact of coping strategies on the recovery can be weaker than they actually are.

This study is expected to contribute to the literature on vulnerability by providing a better understanding of the mechanisms under which a household's assets and coping strategies affect the recovery and by indentifying what the key drivers of recovery are. The unique Vulnerability Surveys data also make this study a new contribution in many aspects. First, previous studies on post-shock recovery are mainly based on a few types of covariant shocks such as natural disasters, agricultural failures, and social conflicts. This study uses rich data on many types of shocks including covariant and idiosyncratic shocks (see Section 3.3.1). Second, the information in the data allows for one to identify different shocks to a household where one might follow another (see Section 3.3.1), which is not possible in other studies. Third, this data also has information about coping strategies, which might play an important role in the recovery (Carter et al., 2007). Such information is not available from many previous studies. Fourth, recovery in many studies was measured by 
income or consumption. These measures might not be accurate because of data collection and estimation errors (Deaton, 1997; Dercon and Krishman, 2000). In addition, a shock might have negative effects on health and happiness, which cannot be estimated by money measures. Finally, other studies identified post-shock recoveries from one survey to another, which makes it impossible to distinguish which household recovered earlier and which one later. This study fills in that gap by using self-reported length of recovery.

\subsection{Empirical strategy}

\subsubsection{Data}

In order to find the answers to the research questions, this study uses data from household surveys from 2007, 2008 and 2010 within the context of the research project on "Vulnerability in Southeast Asia" that is being run by a consortium of German universities (see Klasen and Waibel, 2012). The surveys cover more than 2000 households in rural and peri-urban areas in the three central, poor and vulnerable provinces of Ha Tinh, Thua Thien Hue, and Dak Lak in Vietnam. These three provinces have diverse ecological conditions including coastal, plains and mountainous areas. Among all of the regions in the entire country, the central region is the most prone to natural disaster due to its topography (see Thomas et al., 2010).

The data contains information about household demographics, agricultural activities, nonagricultural activities, expenditures, assets, and housing conditions and especially about shocks and risks. Households were asked if they had experienced any shock during the reference periods. They were further questioned on every single shock they experienced and about the type of the shock, the severity of the shock, and the income and asset lost from that shock. Additionally, they were asked if the shock occurred only to that household or to other households in that area as well. Furthermore, the households were asked what they did to cope with the shock and lastly how many months were needed to recover from the shock. Most of the information about the shocks is self and subjectively reported by respondents.

\subsubsection{Discrete time proportional hazard model of shock recovery}

In order to find factors influencing the shock recovery, this study applies a discrete time proportional hazard model which can be used to estimate the relative hazard rate of recovery for a household with certain characteristics. A hazard rate is defined as the probability of recovery at a unit of time for shocks, which lasts till the beginning of the time interval. The proportional hazard model assumes that the hazard rate can be disaggregated into two components, a baseline hazard which is a function of time, and an exponential 
function of independent covariates which affect the baseline hazard proportionately; they raise or lower the rate of recovery at every month by the same proportion. The discrete time proportional hazard model is expressed as the following formula:

$$
h(t, X)=h_{0}(t) \cdot e^{\beta X}
$$

where $h_{0}(t)$ is the base line hazard function, $X$ represents independent covariates, and $\beta$ represents coefficients of the covariates.

A proportional hazard model is similar to a logistic regression model, both predict probabilities of recovery and thus their outputs should be interpreted in a similar vein. $\beta_{i}$ is also known as a hazard ratio and its exponentiated value, $e^{\hat{\beta}_{i}}=1.15$ for instance, tells us that a one unit of increase in $X_{i}$ increases the baseline hazard by a factor of 1.15 . The main advantages of the proportional hazard model over the logistic regression model are that it allows censored observations to be included up to the point it is observed, also it allows for the inclusions of time-dependent covariates, neither of which is possible in a logistic regression model. Censored observations are shocks that were not yet recovered from at the last observation period or were no longer observed during the observation period because of some reasons.

In our survey, shocks, their severity, losses, coping strategies, and months needed to recover from shocks are self and subjectively reported by respondents. Shocks are understood as adverse events including storms, droughts, heavy rains, an illness of a household member, job loss, or price shocks which cause negative effects on a household's well-being. The time needed to recover from shocks in the first survey wave is measured in years: less than one year, one year, and more than one year. In the next two waves, time needed to recover from shocks is then measured in months. In order to make data in the first wave comparable to that in the others, the lengths of recovery are set in a monthly format and thus the durations of recovery in the first wave are adjusted. Shocks that needed less than one year to recover are adjusted to six months and those that needed more than one year are adjusted to 18 months.

The covariate term includes shock and household characteristics. Shock characteristics include the onset, type of shock, severity of shock, income-and-asset loss ${ }^{12}$ from shock, and types of coping strategies. Adverse events are classified into four groups: agricultural, business, health or social shocks that happened to a household during the periods 2002-

\footnotetext{
${ }^{12}$ It includes income loss and asset loss
} 
2007, 2007-2008 and 2008-2010. Agricultural shocks include storms, floods, droughts, heavy rains, cold weather, landslide, crop pest, storage pest, livestock disease, etc. Business shocks refer to job loss, bankruptcy of business, unable to pay back loan, rise of interest rate, rise (fall) in price of input (output), and a change in market regulation, etc. Health shocks refer to illness, death, accidents, etc. Social shocks are comprised of house damage, theft, conflict with neighbours, getting no more remittances, lawsuit, etc. Adverse events are also classified into income shocks and asset shocks; when income losses are less than asset losses, the shock is classified as asset shock and vice versa.

Households are also asked to estimate the severity of the shocks by four scales, namely: high, medium, low, and no impact. Since "no impact" shocks cause no loss to a household, they are not included in this study. The severity of a shock is measured by two dummy variables representing high and medium levels of severity with reference to low level of severity.

The year of occurrence of a shock is also included in the hazard model in order to test two possible differences. The first comes from the fact that the reference period of the first survey is five years, which is much longer than that of the second and third survey. In fact, a longer recall period is usually correlated with a higher chance of forgetting (see Das et al., 2011), hence it might be the case that only severe shocks that occurred between 2002 and 2005 are reported. These shocks might thus be harder to recover from than shocks that occurred in later years with shorter reference periods. The second possible difference is that household characteristics might change over the years, and the household characteristics at the onset of the shock might determine the rate of recovery. In addition, the occurrence of other shocks following a shock might make the recovery take longer, or when a household experiences the same shock more frequently, it might recover better or slower. Hence, the variables expressing these are also included in the hazard models.

When faced with a shock, a household might apply more than one coping strategy. In order to simplify, this study focuses on the most important coping strategy for each shock only. Coping strategy are then classified into seven major groups, namely: "no coping", adjust income sources (take up additional job, diversify agriculture portfolio, substitute crops), reduce expenditure, resource depletion (sell livestock, sell land, sell storage or other assets), savings, credit (formal and informal loans), external help (public help, remittance from relatives and friends), and unspecified coping actions.

Household characteristics are measured by a household's and its head's characteristics which proxy for human capital; a household's location which proxies for access to markets; 
a household's land area and the asset index which represent physical assets. According to intra-household resource allocation theory, households with different head characteristics, for example, gender, age, ethnicity, and education attainment might have different levels of well-being (Haddad et al., 1997), and thus different shock coping strategies, which means their recovery might be different. Among the 54 ethnic groups in Vietnam, the Kinh is the majority group accounting for more than 86 percent of the national population, the remaining 14 percent includes people from 53 ethnic minority groups such as Tay, Thai, Muong, Nung, Ê Đê (Rhade), Pa Co, Co Tu, Ta Oi, etc. The Kinh usually live in lowerlands and have better access to education as well as to markets (see Baulch et al., 2007).

Physical assets are measured by a household's asset index and land area. A household's assets include quantities as well as assessments of quality. The quantitative assessments take into account whether the household has a motorbike, a bike, a radio, a television, a CD player, an electric fan, an electric rice cooker, a fridge, and a mattress. The assessment of quality focuses on whether the household has improved housing condition, improved flooring condition, access to safe drinking water, uses improved sanitation facilities, and uses improved cooking fuel ${ }^{13}$. The size of the dwelling is also taken into account and is measured in square meters. These items are included in the estimation of the asset index via principal component analysis. Among the items, motorbikes play an important role over the years (with a weight of 24 percent) then comes television, rice cooker or cooking fuel, while the other items are less important, which contribute less than 10 percent to the asset index (see Table 3.7).

The location of a household includes dummy variables indicating provincial and ecological locations. Dak Lak is located in the highlands with basalt soil, which is suitable for planting high value added crops such as coffee, pepper and rubber. The population density in the province is also lower allowing households there to possess more land than their peers in the other provinces. On the contrary, Ha Tinh and Hue are in the coastal area that are frequently hit by storms and floods. These differences make it reasonable to treat Dak Lak as a reference. The infrastructure in the mountainous and highland areas is of poorer quality which limits households' access to markets, ergo these areas are treated as another reference.

\footnotetext{
${ }^{13}$ Reference categories: The main walls are made of concrete or bricks and the roof is made of slates, or concrete. The floor is made of cement or ceramic. The household uses flushed toilet. The household cooks with gas or electricity.
} 


\subsection{The prevalence of shocks among household groups}

Households in Vietnam, particularly in the central regions, are typically characterised as being poor and their main income source comes from farming activities. Additionally, the country has been increasingly affected by extreme weather conditions, macroeconomic instability including a high inflation rate and an ongoing economic recession, and the subsequent stagnation in investment as well as an increased unemployment. About 82 percent of households experienced at least one shock during the eight year period (see Table 3.1). Many households experienced more than one shock in the same year. An example is a storm that causes house damage, this storm also brings along heavy rain and might cause a flood or landslide, which then causes crop losses. There were more than nine thousand shocks experienced by more than two thousand households during the observation period. On average, a shock caused income and asset losses of more than \$165. Among the four types of shocks (see classification of shocks in Section 3.3.2), agricultural shock was the most widespread type and health shocks followed; they respectively affected nearly 47 and 23 percent of households. Business and health shocks struck only a small share of households. Business shocks caused the greatest losses because they were more likely to be related to the coffee industry, one of the highest value farming products in the central provinces. Agricultural and health shocks caused similar losses of $\$ 160$, while social shocks caused the least loss of $\$ 90$ (see Table 3.1). Although the overall economy experienced the economic crisis and recession, only a few households in rural areas reported that they were affected by those changes, this was due to the fact that most households in these provinces engage in agricultural activities and have limited access to markets making them immune to the bad economic performances.

Table 3.1 Shock prevalence by type, 2002 - 2010

\begin{tabular}{lcccccc}
\hline & Agriculture & Business & Health & Social & No shock & Total \\
\hline Share of households, \% & 46.6 & 4.8 & 23.2 & 7.4 & 18.0 & 100 \\
Total shocks & 5,669 & 517 & 2,741 & 956 & 0 & 9,883 \\
Average shocks/household & 5.5 & 5.0 & 5.4 & 5.9 & 0 & 4.5 \\
Average loss per shock, $\$$ & 160 & 370 & 150 & 90 & 0 & 165 \\
\hline
\end{tabular}

Note: See classification of shock types in Section 3.3.2. The losses are adjusted to price changes.

Source: Author's calculations from Vulnerability Surveys in Vietnam.

Shocks can also be classified into idiosyncratic and covariant types. Idiosyncratic shocks include illnesses, accidences, or deaths that hit households randomly, while covariant shocks are comprised of typhoons, floods, and droughts, which often hit the majority of households in the area. However, the probability that the shock occurs to the household and 
the severity of the shock might depend on a household's characteristics and their response to the adverse events.

Male headed households are the majority, accounting for 83 percent of the overall population. They tend to have a larger scale of agriculture production; on average they have 1.8 hectares of land while female headed households have 1.3 hectares of land. In addition, men tend to be more risk loving than women (see Fletschner et al., 2010), thus tending to follow riskier livelihood strategies, which consequently exposes them to greater risk. These could be some of the reasons why male headed households have more agricultural shocks than female headed households (see Table 3.2). Male heads are also more likely to engage in non-agricultural activities than female heads (20 percent compared to 14 percent), which infers that they could have better access to markets making them more vulnerable to business risks (see Table 3.2). Moreover, female heads usually have a higher age than male heads (a mean of 54 years compared to 47 years) which could cause them to have a higher risk to health shocks (see Table 3.2).

Table 3.2 Household characteristics and shock prevalence by shock type

\begin{tabular}{|c|c|c|c|c|c|c|c|c|}
\hline & \multicolumn{5}{|c|}{ Shock type, percent } & \multirow{2}{*}{$\begin{array}{c}\text { Average } \\
\text { shocks }\end{array}$} & \multirow{2}{*}{$\begin{array}{c}\text { Average } \\
\text { loss, } \$\end{array}$} & \multirow{2}{*}{$\begin{array}{c}\text { Population } \\
\text { share }\end{array}$} \\
\hline & Agriculture & Business & Health & Social & No shock & & & \\
\hline Head is female & 39.9 & 4.1 & 31.4 & 7.5 & 17.1 & 4.3 & 150 & 16.7 \\
\hline Head is male & 48.0 & 4.9 & 21.5 & 7.4 & 18.2 & 4.5 & 165 & 83.3 \\
\hline Minority groups & 51.5 & 2.4 & 24.0 & 7.7 & 14.5 & 4.8 & 146 & 16.1 \\
\hline Kinh (majority) & 45.7 & 5.2 & 23.1 & 7.4 & 18.7 & 4.4 & 168 & 83.9 \\
\hline First (poorest) & 53.5 & 2.0 & 23.7 & 7.3 & 13.4 & 4.9 & 76 & 20.1 \\
\hline Third quintile & 46.4 & 3.6 & 23.5 & 8.7 & 17.8 & 4.7 & 147 & 19.9 \\
\hline Fifth (richest) & 35.8 & 10.3 & 23.5 & 6.7 & 23.7 & 4.1 & 238 & 20.0 \\
\hline Ha Tinh & 49.8 & 3.8 & 22.2 & 8.1 & 16.2 & 5.0 & 93 & 38.0 \\
\hline Thua Thien Hue & 41.4 & 3.9 & 24.4 & 6.8 & 23.5 & 3.4 & 127 & 22.4 \\
\hline Dak Lak & 46.6 & 6.2 & 23.5 & 7.1 & 16.6 & 4.6 & 262 & 39.7 \\
\hline Average & 46.6 & 4.8 & 23.2 & 7.4 & 18.0 & 4.5 & 165 & \\
\hline
\end{tabular}

Notes: Shares of households by shock type in the same row sum to 100. The losses are adjusted to price changes. Values in the last column of the same category sum to 100, except for the category quintiles. Average shocks refers to mean of shocks per household during the observation period.

Source: Author's calculations from Vulnerability Surveys in Vietnam.

The Kinh generally live in the lowlands and have better access to markets than ethnic minority groups. Kinh households also typically have a higher stock of assets; the mean of their asset index is 0.54 while that of the other groups is $0.41^{14}$. The fact that the Kinh normally have more assets, better housing, and live in less climate-influenced areas makes them less prone to climatic and agricultural shocks. They also have a lower prevalence of

\footnotetext{
${ }^{14}$ The asset index is scaled to the range of $[0,1]$
} 
health shocks but a higher risk of business shocks because they have better access to markets.

A household's expenditure level in 2007 is used as a proxy for a household's wealth. It is classified into five quintiles; the first quintile is the poorest group and the fifth is the richest group. The mean expenditure of the richest group is nearly $\$ 700$ while that of the third and the poorest group are nearly $\$ 340$ and more than $\$ 180$ respectively. Richer households are less likely to have natural related shocks, for instance storm, floods, and crop pest because their livelihoods are less dependent on natural resources. More than a half of the shocks to the poorest households are in the form of agricultural shocks; this share however reduces with the middle and the richest households. On the contrary, richer households are more vulnerable to business shocks because they have better access to markets (see Table 3.2).

Since shocks are subjectively and self reported by households, a shock to a richer household might cause more losses than a shock to a poorer household. In addition, richer households often have more resources to lose while poorer households have fewer to lose. On average, a shock causes losses of nearly $\$ 80$ to households in the poorest group while a shock to a household in the richest groups causes losses of nearly $\$ 240$ (see Table 3.2).

Being near the coastline, households in Ha Tinh and Thua Thien Hue are the major victims of storms, tropical cyclones, floods and flash floods. On the contrary, Dak Lak residents face more droughts because the province is located in a highland area, where the rivers are steep and the dry seasons usually last longer. A drought might cause big losses for coffee farmers because coffee output depends a lot on water supply and it is a high value product. Dak Lak households also have a higher risk to business shocks since they have more access to markets, particularly the input and output markets for coffee production which are usually of high value and these markets themselves have high levels of fluctuation.

\subsection{Shock coping strategies and recovery}

\subsubsection{Shock coping strategies}

The major coping strategies are credit, no coping, and adjustment of income sources, which are applied to more than 30 percent, 25 percent, and 22 percent of the shocks respectively. Resource depletion is applied to nearly 9 percent of shocks. Saving is employed as a coping strategy for 6 percent of shocks, and another 5 percent of shocks is mitigated by external help (see Table 3.3). The large shares of no coping, credit, and adjustment of income sources reflect the fact that households have limited resources. They are thus more likely to 
either stay idle in the aftermath of the shock or rely on external resources by getting credit or adjusting income sources.

Households of different characteristics also have different patterns of coping strategies. Female headed households (FHH) are more likely to use external help and less likely to use savings or adjustment of income sources, or credit as coping strategies (see Table 3.3). As discussed above, women are more risk averse than men, they are thus more inclined to take coping strategies after a shock because they are afraid of the riskiness of the coping action. Households from the Kinh group are more active than their counterparts in coping with shocks. Only around 24 percent of shocks to Kinh households are not adequately coped with while this share is more than 26 percent with minority groups. The Kinh also have more access to markets, more savings, and better social networks that thus make them more likely to apply adjustment of income sources, savings, and external help as coping strategies, in contrast to households from ethnic minority groups that are more likely to sell assets or livestock and use credit as coping strategies (see Table 3.3).

Table 3.3 Choices of coping strategies, percent

\begin{tabular}{lcccccccc}
\hline & $\begin{array}{c}\text { No } \\
\text { coping }\end{array}$ & $\begin{array}{c}\text { Income } \\
\text { sources }\end{array}$ & $\begin{array}{c}\text { Resource } \\
\text { depletion }\end{array}$ & Savings & Credit & $\begin{array}{c}\text { External } \\
\text { help }\end{array}$ & $\begin{array}{c}\text { Reduce } \\
\text { expenditure }\end{array}$ & Unspecified \\
\hline Head is female & 24.8 & 20.0 & 9.0 & 4.7 & 29.5 & 9.0 & 0.1 & 3.0 \\
Head is male & 25.0 & 22.5 & 8.6 & 6.2 & 30.8 & 4.1 & 0.4 & 2.4 \\
Minority groups & 26.5 & 20.4 & 9.3 & 4.6 & 35.8 & 1.9 & 0.1 & 1.4 \\
Kinh (majority) & 24.6 & 22.4 & 8.6 & 6.3 & 29.5 & 5.6 & 0.3 & 2.8 \\
First (poorest) & 26.3 & 25.3 & 7.4 & 2.0 & 30.1 & 6.2 & 0.2 & 2.5 \\
Third quintile & 24.5 & 21.7 & 8.6 & 4.4 & 32.9 & 5.3 & 0.3 & 2.3 \\
Fifth (richest) & 24.7 & 18.1 & 9.6 & 13.8 & 26.6 & 3.9 & 0.2 & 3.0 \\
Agriculture shock & 29.7 & 30.1 & 5.7 & 3.3 & 25.7 & 3.1 & 0.3 & 2.1 \\
Business shock & 28.3 & 25.2 & 9.8 & 3.8 & 28.5 & 0.9 & 1.8 & 1.6 \\
Health shock & 12.3 & 9.0 & 12.9 & 11.1 & 42.3 & 9.0 & 0.0 & 3.2 \\
Social shock & 31.2 & 10.4 & 13.2 & 8.3 & 26.8 & 6.3 & 0.1 & 3.6 \\
Low severity & 48.7 & 14.5 & 14.2 & 6.1 & 9.8 & 4.4 & 0.0 & 2.4 \\
Medium & 32.6 & 25.0 & 9.1 & 6.7 & 19.6 & 3.8 & 0.5 & 2.9 \\
High severity & 19.0 & 21.1 & 7.9 & 5.6 & 38.2 & 5.6 & 0.2 & 2.3 \\
Average & 25.0 & 22.1 & 8.6 & 6.0 & 30.6 & 4.9 & 0.3 & 2.5 \\
\hline Notes: See classifly
\end{tabular}

Notes: See classification of coping strategies in Section 3.3.2. "Income sources" refers to adjustment of income sources. Values in the same row sum to 100.

Source: Author's calculations from Vulnerability Surveys in Vietnam.

Households with different income levels also have different patterns of shock coping strategies. To simplify, only three expenditure quintiles are presented in Table 3.3. The richest households have better access to markets and have more savings so they are more likely to use adjustment of income sources and savings as coping strategies while the poorest households tend to use credit and external help more as ex-post actions. 
Additionally, richer households are more likely to cope with shocks by using their own available resources because they have more savings, more assets, and might have more livestock, which all can be used to smooth consumption or to reinvest in the assets destroyed by the shocks. On the contrary, poorer households find it hard to cope with shocks using their own limited resources. They therefore use additional and external resources as coping strategies. Examples of external resources are remittances, formal and informal credits, and examples of additional income sources are taking up an additional job, adjusting their agricultural portfolio, and substituting crops (see Table 3.3). However, the poor usually have limited access to credit markets so they often get credit from informal financial markets and have to pay high interest rates which makes it hard for them to recover from shocks.

\subsubsection{The post-shock recovery}

This section is based on statistical and empirical evidence to discuss which household groups are able to quickly recover from shocks and which factors play a role in the recovery. Important statistical results confirm their significance with $t$ tests and empirical models are also tested for their significance (see Section 3.5.2.4).

\subsubsection{The time variation of the recovery}

Among the more than 9000 shocks reported during the eight year period, more than 73 percent of the shocks have already been recovered from while the other more than 26 percent have not. The shocks that have not yet been recovered from are then censored in the hazard models. Among the recovered shocks, more than 82 percent recovered within one year, nearly 16 percent recovered in the second year, and the remaining small share recovered in the third, fourth or fifth year (see Table 3.4). The length of recovery varies within a wide range of 1 to 91 with an average of 8.3 months (see Table 3.5 and Figure 3.3). Time dummies are included in hazard models to estimate the baseline hazard functions. The first 24 dummies show the 24 first months of recovery, then six more dummies show the next six half years, and the last dummy shows the rest of the time period from month 61 to month 91. The estimated hazard functions are in line with the results in Table 3.4; the hazard rate of recovery is rather low during the first few months after the onset and the longer the amount of time they last, the easier they are to recover from. The hazard rate of recovery particularly increases at faster rate from the first month to the 12th month. They are rather high at month 12th and 13th because respondents tend to remember major units of time better than minor units of time, i.e. if a shock lasts for a little more or less than one year they are likely to say one year. This is also true with the hazard rates of recovery at the 
end the second, third, fourth, and fifth years. Moreover, recoveries in the first survey are adjusted to 6,12 and 18 months and so on. This also contributes to the high rates of recovery at those time dummies (see Table 3.6). This result is in line with the discussion of Carter et al. (2007) that households need time to compensate for the income and asset losses.

Table 3.4 The post-shock recovery, percent

\begin{tabular}{ccccccc}
\hline \multicolumn{5}{c}{ Recovered } & & Not yet recovered \\
\cline { 1 - 4 } 1st year & 2nd year & 3rd year & 4th year & 5th year & & \\
82.2 & 15.9 & 1.2 & 0.4 & 0.4 & \\
\hline
\end{tabular}

Note: Values in the same row sum to 100.

Source: Author's calculations from Vulnerability Surveys in Vietnam.

\subsubsection{Household's characteristics and the recovery}

Household covariates are also expected to play a role in the post-shock recovery. Male headed households (MHH) face more business shocks which are also of higher severity levels than those to FHHs, causing them to need a longer amount of time to recover from the bad luck in business (see Table 3.5). However, as discussed in Section 3.4, FHHs usually have older heads and have less advantages than their counterparts in some aspects, which could make them less active in applying coping strategies. This thereby makes them need a longer amount of time to recover from the three other types of shocks; it also makes them recover slower than their counterparts from a shock in general (see Table 3.5). The odds ratios from the hazard models also confirm these results, which show that FHHs have a three percent lower rate of recovery than their peers, however the difference in the rate of recovery is insignificant (see Table 3.5).

The head's age appears to have no impact on the recovery (see Table 3.6). Generally, young headed households have fewer physical assets, and also lower incomes than their older peers. Households that had heads that were 36 years old or younger had a per capita expenditure of nearly $\$ 300$, lower than the average which is nearly $\$ 340$. They also receive less remittance because their household members are usually too young to migrate. These factors make it harder for them to recover from agriculture, health and social shocks. However, young headed households tend to have less severe business shocks than older headed households; only 37 percent of business shocks to young headed households was of high severity while that share was nearly 70 percent for older headed households. This could be the reason why young households recover faster from business shocks (see Table 3.5). 
As discussed in Section 3.4, Kinh households in general have more advantages than their counterparts which enable them to cope and recover from agriculture and business shocks better. Contrary to this however, they need a longer amount of time to recover from health and social shocks (see Table 3.5) because of two reasons. First, the Kinh households usually have better access to health care services, which might enable them to spend more for health care treatments. It is evident that a health shock to a Kinh household could cost nearly \$190, which is three times as much as that of another household. Second, the Kinh households are usually more involved in social networks, thus a social shock to them might be more costly. Consequently, these aspects make the ethnicity of the household head show no significant impacts on the recovery (see Table 3.6).

Table 3.5 The length of recoveries from shocks by shock type, months

\begin{tabular}{|c|c|c|c|c|c|c|}
\hline & Agriculture & Business & Health & Social & mean & $\mathrm{sd}$ \\
\hline Head is female & 8.0 & 8.7 & 10.2 & 8.2 & $8.7 *$ & 8.1 \\
\hline Head is male & 7.8 & 10.6 & 9.5 & 6.1 & $8.2 *$ & 7.0 \\
\hline Head age: $\leq 35$ & 8.7 & 11.4 & 10.2 & 8.9 & 9.3 & 7.0 \\
\hline Head age: $36-50$ & 8.0 & 10.5 & 9.3 & 6.0 & 8.2 & 6.9 \\
\hline Head age: $51-65$ & 7.4 & 8.9 & 9.9 & 6.2 & 8.0 & 7.3 \\
\hline Head age: $66+$ & 7.1 & 12.0 & 9.7 & 7.0 & 8.0 & 7.9 \\
\hline Minority groups & 9.3 & 11.4 & 8.8 & 5.5 & 9.0 & 5.9 \\
\hline Kinh (majority) & 7.5 & 10.4 & 9.8 & 6.6 & 8.2 & 7.4 \\
\hline Head has no schooling & 8.3 & 9.5 & 9.6 & 6.8 & 8.5 & 6.8 \\
\hline Primary school & 8.4 & 10.2 & 9.9 & 6.7 & 8.7 & 7.2 \\
\hline Middle school + & 7.6 & 10.6 & 9.5 & 6.4 & 8.1 & 7.2 \\
\hline First (poorest) & 8.0 & 7.6 & 9.8 & 7.6 & $8.5^{*}$ & 7.2 \\
\hline Third income quintile & 7.9 & 11.8 & 10.5 & 6.8 & $8.5^{*}$ & 8.0 \\
\hline Fifth (richest) & 7.6 & 11.3 & 8.3 & 6.3 & $8.0^{*}$ & 6.7 \\
\hline Low severe & 3.7 & 4.5 & 4.3 & 2.6 & $3.6^{*}$ & 3.6 \\
\hline Medium & 6.0 & 6.4 & 6.2 & 4.1 & $5.8 *$ & 5.1 \\
\hline High severe & 9.3 & 13.9 & 11.9 & 11.2 & $10.3^{*}$ & 7.8 \\
\hline No coping & 6.0 & 6.2 & 5.6 & 3.7 & $5.7 *$ & 5.0 \\
\hline Adjust income source & 8.2 & 11.0 & 10.4 & 8.5 & $8.5^{*}$ & 6.9 \\
\hline Reduce expenditure & 5.5 & 11.9 & 24.0 & 3.0 & 8.5 & 6.7 \\
\hline Unspecified & 4.6 & 5.3 & 5.4 & 9.3 & 5.5 & 6.2 \\
\hline Resource depletion & 6.6 & 7.8 & 8.5 & 5.8 & 7.3 & 6.8 \\
\hline Savings & 7.2 & 9.6 & 8.4 & 4.9 & $7.5^{*}$ & 5.4 \\
\hline Credit & 10.7 & 15.3 & 12.1 & 10.9 & $11.4^{*}$ & 8.3 \\
\hline External help & 6.5 & 35.0 & 8.2 & 4.5 & $7.1 *$ & 7.2 \\
\hline Average & 7.9 & 10.5 & 9.7 & 6.5 & 8.3 & 7.2 \\
\hline
\end{tabular}

Notes: This table applies to recovered shocks only. sd refers to standard deviation, $*$ refers to significant difference at 95 percent level

Source: Author's calculations from Vulnerability Surveys in Vietnam

As mentioned in previous paragraphs, there is evidence of endogeneity between household's characteristics and the length of recovery. The education attainment of the head is not an 
exception where a higher education attainment is usually associated with having better skills and higher incomes that help a household recover better from shocks. Nonetheless, households with educated heads might be better able to identify more losses from shocks and thus they need more time to recover. Additionally, shocks reported by these households are more costly and of higher levels of severity than shocks reported by poorer households (see Figure 3.4). Therefore, the impact of the education attainment on the recovery is insignificant (see Table 3.6).

The household consumption quintiles do not show a clear difference in the length of recovery (see Table 3.5). This is possibly blamed on the endogeneity between household wealth in general with losses from shock as well as with the recovery (see Figure 3.4). On the one hand, richer households experienced less shocks but the shocks to them caused more losses. On average, a shock cost less than $\$ 80$ to a household in the poorest group but nearly $\$ 240$ to a household in the richest group. On the other hand, richer households have more savings, more assets, more remittance, and have higher levels of mobility useful in responding to bad failures. However, two sub-groups of poor and non-poor households at the cutoff of $\$ 2$ a day show a clearer difference in recovery levels; poor households have a nearly 30 percent lower rate of recovery than non-poor households, however this rate varies slightly across different hazard models (see Table 3.6).

Other than consumption, land area might be a suitable proxy for a household's wealth in rural areas (see Deininger, 2003). A possible hypothesis is that households with more land will be wealthier and hence recover better from the shocks. However, this might not be true when comparing farming with non-farming households. Additionally, households in mountainous and forest margin areas tend to have more land than households in lowlands. Also, land in mountainous and remote areas is not suitable for high value crops because of its low fertility and the unavailability of a reliable water supply. These facts explain why the impact of land area on the hazard rate of recovery is insignificant (see Table 3.6). Another possible proxy for household wealth is the asset index (see Filmer and Pritchett, 2001). As discussed in Section 3.4, wealthier households are often more active in coping with shocks, they also have a larger variety of resources to pursue in shock coping strategies, hence households with higher stocks of assets have a higher rate of recovery (see Table 3.6).

The majority of the shocks to Dak Lak households are related to coffee production and trading, which are usually high value activities (see Section 3.4). Hence, they suffer many more losses than their peers in Thua Thien Hue and Ha Tinh. On average, a shock cost more than $\$ 260$ to a Dak Lak household while it costs only about $\$ 150$ and $\$ 80$ to a household in Thua Thien Hue and Ha Tinh respectively. This makes Dak Lak households need a much 
longer amount of time to recover than their peers (see Table 3.6). The majority of the vulnerable households in Thua Thien Hue are in the mountainous and coastal areas. People in these mountainous areas have limited access to markets so they find it hard to recover from shocks. Additionally, Thua Thien Hue coastal residents in the Tam Giang lagoon face nature shocks every year that wash away their fishing facilities which are essential for their livelihood. These are the reasons why the Thua Thien Hue people have a 20 percent lower probability of recovery than the baseline hazard (see Table 3.6).

\subsubsection{Shock covariates and the recovery}

Agriculture, business and health shocks usually cause greater declines in incomes and assets than social shocks, they are therefore reported to have higher levels of severity. Social shocks caused an average of about $\$ 90$ in losses and only less than half of which was highly severe. Other shocks caused an average of nearly \$240 in losses and of which nearly 60 percent was highly severe. Agricultural shocks ranked second after social shocks in terms of the smallest amount of losses and lowest severity. These facts explain why agricultural shocks have lower rates of recovery than social shocks; and why health and business shocks have even lower rates of recovery compared to social and agricultural shocks (see Table 3.6). Additionally, asset shocks are believed to last longer than income shock (see Carter et al., 2007) because the former usually cause a decline in incomes as well. The results from the hazard models also support this hypothesis, which show that asset shocks have about a three to five percent lower rate of recovery, depending on the form of the hazard model (see Table 3.6).

Shocks of different levels of severity differ substantially in the recovery time. A shock of low severity caused only around $\$ 13$ in losses and needed less than four months to recover from it. Contrarily, a shock of medium severity caused more than $\$ 50$ in losses and needed nearly six months to recover, while a shock of high severity caused nearly $\$ 210$ and needed more than 10 months to recover (see Table 3.5). A shock of high severity might also cause other losses besides that of incomes and assets, for instance health, lives and happiness, in which case some households might never fully recover. When compared to a shock of low severity, a high severity shock has a nearly 90 percent lower rate of recovery and a medium severe shock has a 65 percent lower rate of recovery (see Table 3.6).

The results also show that shocks that occurred between the years 2002 and 2005 have significantly low rates of recovery compared to later periods (see Table 3.6). This is the result of the differences in reference periods, of a household's poverty status, and of a household's assets rather than of the changes in the head's age and the education attainment 
over time because these last two covariates have insignificant effects on recovery (see Section 3.5.2.2). Additionally, when the year of occurrence is included in the model, the hazard rates of recovery at month 54th onward become much higher since the baseline hazard function is now based on shocks from 2002, which is far from the months 54th onward.

It is believed that the implication of a coping strategy helps households recover better from shocks. However, most coping strategies appear to be correlated with lower rates of recovery compared to "no coping", except for shocks that are coped by savings and external help (see Table 3.6). This is possibly attributed to the fact that coping strategies are usually applied to shocks of higher severity and cause massive losses. Consequently, shocks that were coped usually need longer amount of time to recover from (see Table 3.5 and Figure 3.5). No coping was more likely to be a coping strategy for shocks that caused around $\$ 60$ in losses while other coping strategies (such as adjustment of income sources, savings, and credit) were for shocks that caused more than $\$ 180$ in losses. In addition, only around 40 percent of shocks that were not coped with were of high severity while more than 60 percent of shocks of high severity had one of the three coping strategies (adjustment of income sources, savings, or credit) applied to them. Credit was most likely to be the coping strategy for the longest lasting and the most massive losses caused by shocks. A shock which was coped by credit cost nearly $\$ 300$ and needed more than 11 months to recover from it (see Table 3.5).

In order to test whether coping strategies help the poor recover quickly from shocks, interaction terms of coping strategies and poverty at \$2 a day are included in the hazard model. The results show that most interaction terms have positive impacts on recovery, except for shocks that are coped for by reducing expenditure and seeking external help (see Table 3.6). This implies that coping strategies are more helpful to poor households than to wealthier ones. Also, poor households usually find it impossible to cut expenditure further hence reducing expenditure shows lower interaction effect. Likewise, poor households usually have a network with poor communities so external helps might not be enough to help in the recovery.

\subsubsection{The contribution of unobserved heterogeneity in the hazard models}

There are sources of possible heterogeneity that are not captured by the hazard models. The first source of heterogeneity comes from the classification of household groups by household's and head's characteristics. Household heads of the same characteristics (education attainment for instance) might have different access to markets and therefore 
different abilities to cope with shocks. Also, using characteristics of household heads as proxies for household's covariates might be not accurate because household's characteristics are influenced by other members as well, particularly by breadwinners.

The second source of heterogeneity comes from the fact that shock covariates are subjectively and self reported by respondents. The length of recovery might not be accurate because it is not easy to recognise the recovery, particularly when a shock causes multiple losses including income, assets, and happiness, etc. and a shock is followed by other shocks. Shocks that are reported to have the same level of severity might not be similar; a highly severe shock to a household (a poor household for instance) might be much less severe than a highly severe shock to another household (a wealthy household for instance). Additionally, there is heterogeneity in coping strategies ultilised during the aftermath of the shocks. A household might apply a number of coping strategies for a shock but it might not recognise all the coping strategies. Moreover, a major coping strategy in the hazard model might not enough to capture the whole coping process because households might apply many coping strategies at the same time or one after another. Moreover, when a coping strategy is applied right after a shock it might help recovery better than the same coping strategy but with a few months of delay. Unfortunately, there is no information on the timing of coping strategies. Furthermore, the duration of a shock is also an issue; holding other things equal, households might find it harder to recover from a long duration event (such as an illness) than a short duration event (such as a typhoon).

Obviously, it is not easy to identify the heterogeneity and endogeneity issues in the hazard models. An example is that two highly severe shocks are reported by two different households, one might cause a large amount of loss but the other might not. The amount of loss, which is included in the model, could partially reflect the severity of a shock. Nevertheless, the amount of assets and income losses can only reflect the actual losses while shocks might cause opportunity losses as well as negative effects on other dimensions of well-being. The hazard models cannot identify clear evidence of heterogeneity and endogeneity issues among the variables. All likelihood-ratio tests of Gamma variances are significant at 99 percent of confidence (see Table 3.6). They imply that the unobserved heterogeneity does not make important contributions to the hazard models and that there are low levels of heterogeneity in the models.

\subsubsection{Robustness check}

In addition to the likelihood-ratio tests, the hazard models also confirm their significant by showing their robustness across different modifications of the model. Firstly, the four 
models in Table 3.6 are significant and show similar results. Secondly, in order to check if it is possible to check the endogeneity between recovery and household's wealth, the study applies two different hazard models, one for poor households only and the other for nonpoor households and the results are still similar to those in Table 3.6. Thirdly, in search of an answer to a question whether the recovery differ from one type of shock to another, the study applies similar hazard models for each type of shocks (agricultural, business, health, and social) separately and the results are not much different from those in Table 3.6. Additionally, various other types of econometric models such as logit model and lognormal model are also applied and the results are similar to those in Table 3.6. Therefore, it is enough to conclude that the hazard models in this study are significant and the results in Table 3.6 are empirically robust.

Additionally, the perceived recovery is cross checked with the recovery in other measures. First, it is cross checked with the changes in a household's overall well-being. Respondents were asked: "Do you think your household is better off, the same or worse off than the last five years?", and "Do you think your household is better off, the same or worse off than last year?" A shock was deemed to be recovered from if it occurred in the period of five to one years prior to the survey and the answer to the first question was better off or the same. Similarly, a shock is deemed to be recovered from if it occurred within one year prior to the survey and the answer to the second question was better off or the same. These two measures of the subjective recovery are weakly correlated with Cramer's V of 0.29, which is calculated from the contingency table, and Pearson chi square is significant at the 99 percent level (see Table 3.8).

Second, the perceived recovery is checked with an objective measure of a household's consumption. A shock is deemed to be recovered from if it occurred in between the two surveys, recovered in the same period and a household's total consumption of the later survey is no less than that of the earlier survey. Since there is no information about expenditure before 2007, shocks that occurred before 2007 are not included in this cross check. The results from the correlation test show that the self reported recovery has a weak and negative correlation with the recovery in consumption; Cramer's V is - 0.24 and Pearson chi square is significant at the 99 percent level (see Table 3.8). Another comparison also show that the correlation between the subjective recovery and the recovery in per capita consumption is also significantly weak and negative with Cramer's V is slightly lower than 0.24. Lastly, a comparison between the subjective recovery and the recovery in household's asset index also show weak and negative correlation with Cramer's V of -0.22. 
The weak correlation between self reported recovery and two other measures of recovery might be the result of various factors. A household might face many shocks, one following another during the time between the two surveys. Hence, the household might have been recovered from a certain shock but still suffered the consequences of other shocks. Another source of the mismatch between the measures of recovery might come from the fact that households care not only about incomes or expenditures but rather about well-being in general. It might also be a result of the fact that some respondents do not know all household affairs, or in some cases, the same household across surveys has different respondents, who report shocks differently.

The high level of mismatch between the self reported recovery and the recovery as measured by consumption suggests that incomes or expenditures might not be good measures of recovery because shocks might cause not only income losses but a decline in other dimensions of a household's well-being as well. Therefore, a better objective measure of recovery might take into account of the recovery in incomes or consumptions and as well as the recovery in health and happiness.

\subsection{Conclusion}

This study uses household data from three provinces in Vietnam collected in 2007, 2008 and 2010 and uses the discrete time proportional hazard models to examine which household groups recover quickly from shocks, which household groups are able to apply coping strategies when faced with shocks, as well as to investigate the effects of coping strategies on the recovery. The analyses show that natural disasters and crop losses are the major shocks because the livelihood in the region is reliant to natural resources. However, an advantage of having a large share of their income source coming from farming activities is that it prevented households from the macroeconomic turbulence during the period. Though being major threats, agricultural shocks do not cause the largest amount of loss because their frequent occurrence might make households to adjust their livelihood strategies in order to avoid losing a lot. On the contrary, health and business shocks are less forecastable thus they cause more losses and are harder to recover from.

In addition, different household groups are found to have different exposure to each type of shocks. This discrepancy in shock prevalence is the result of the differences in the livelihoods they follow, the asset levels and the human capital they possess. Poor households suffer much more shocks than their wealthier counterparts because their livelihoods are more reliant on natural conditions, their assets are more prone to shocks, and their stocks of assets are too small to remain stable when faced a shock. 
Household's physical assets show their positive effects on the recovery. However, household's human capital shows its weak and not always significant effects on the recovery. These findings are in line with Carter et al. (2007) that household's asset dynamics is one of the forces that shape the resilience path while the role of household's human capital is not emphasised in that study. However, these results are different from the finding of Newhouse (2005) that negative shocks last for shorter periods for poor households. In addition, the type, severity, and losses from shock also determine the length of recovery. Coping strategies also affect the recovery with some levels of significant because of possible heterogeneity in perceived covariates of shocks. However, coping strategies are more effective for the recovery of poor households because poor households might be homogeneity in losses from shocks, coping with and recovering from shocks.

The findings from this study show the importance of coping strategies in shock recovery, however their effects are still small and a large share of the shocks are not coped by any strategy. Therefore, development policies might focus on providing available resources such as credit and alternative job or income opportunities so that households are better able to apply coping strategies and recover quickly from the adverse events.

This study provides an overall examination of the effects of household's covariates and coping strategies on the recovery. A follow-up study on this strand of literature could investigate whether a household finds it easier to recover from shocks if it has access to the credit market. One could also link the occurrence of shocks to a household's risk forecast in order to find whether it is easier to recover from a shock if it was already foreseen. The reason behind this is that when a household expects a shock might happen, it carries out $e x$ ante actions in order to mitigate the effects of the shock. 
Table 3.6 Odds ratios from discrete time proportional hazard models with gamma frailty

\begin{tabular}{|c|c|c|c|c|c|c|c|c|}
\hline \multirow{2}{*}{$\begin{array}{l}\text { Household's and shock's } \\
\text { covariate }\end{array}$} & \multicolumn{2}{|c|}{ (1) } & \multicolumn{2}{|c|}{ (2) } & \multicolumn{2}{|c|}{ (3) } & \multicolumn{2}{|c|}{ (4) } \\
\hline & $\exp (b)$ & se & $\exp (b)$ & se & $\exp (b)$ & se & $\exp (b)$ & se \\
\hline Shock type: agriculture & $0.83 * *$ & -2.30 & $0.60 * * *$ & -5.24 & 0.88 & -1.59 & 0.89 & -1.53 \\
\hline Shock type: business & $0.35^{* * *}$ & -7.98 & $0.32 * * *$ & -7.30 & $0.38 * * *$ & -7.74 & $0.38 * * *$ & -7.71 \\
\hline Shock type: health & $0.51 * * *$ & -7.62 & $0.43 * * *$ & -8.16 & $0.55 * * *$ & -6.98 & $0.55 * * *$ & -7.05 \\
\hline Asset shock & $0.83 * * *$ & -4.09 & $0.83 * * *$ & -3.28 & $0.84 * * *$ & -3.80 & $0.84 * * *$ & -3.81 \\
\hline Severity: high & $0.10 * * *$ & -18.47 & $0.09 * * *$ & -17.16 & $0.12 * * *$ & -18.02 & $0.12 * * *$ & -17.97 \\
\hline Severity: medium & $0.33 * * *$ & -10.18 & $0.28 * * *$ & -9.53 & $0.37 * * *$ & -9.48 & $0.37 * * *$ & -9.46 \\
\hline Other shock same type & $0.86^{* * * *}$ & -5.38 & & & $0.87 * * *$ & -5.22 & $0.87 * * *$ & -5.28 \\
\hline Other shock during recovery & & & $0.34 * * *$ & -28.31 & & & & \\
\hline Occurred in 2003 & & & $1.70 * * *$ & 2.77 & & & & \\
\hline Occurred in 2004 & & & $1.75 * * *$ & 3.24 & & & & \\
\hline Occurred in 2005 & & & $2.69 * * *$ & 5.91 & & & & \\
\hline Occurred in 2006 & & & $9.89 * * *$ & 13.85 & & & & \\
\hline Occurred in 2007 & & & $64.71 * * *$ & 20.03 & & & & \\
\hline Occurred in 2008 & & & $53.83^{* * *}$ & 18.07 & & & & \\
\hline Occurred in 2009 & & & $32.70 * * *$ & 16.95 & & & & \\
\hline Occurred in 2010 & & & $46.28 * * *$ & 16.90 & & & & \\
\hline Cope: adjust income sources & & & & & $0.60 * * *$ & -8.51 & $0.56^{* * *}$ & -7.88 \\
\hline Cope: reduce expenditure & & & & & $0.27 * * *$ & -2.98 & $0.15^{* * *}$ & -3.39 \\
\hline Cope: unspecified & & & & & 0.85 & -1.14 & 0.90 & -0.69 \\
\hline Cope: resources depletion & & & & & 0.88 & -1.58 & $0.81 * * *$ & -2.24 \\
\hline Cope: savings & & & & & 1.13 & 1.33 & 1.06 & 0.56 \\
\hline Cope: credit & & & & & $0.42 * * *$ & -13.21 & $0.37 * * *$ & -13.15 \\
\hline Cope: external help & & & & & 1.17 & 1.63 & $1.25^{*}$ & 1.78 \\
\hline Adjust income sources $\times$ poor & & & & & & & $1.22 *$ & 1.68 \\
\hline Reduce expenditure $\times$ poor & & & & & & & $5.63 * *$ & 1.86 \\
\hline Unspecified $\quad \times$ poor & & & & & & & 0.80 & -0.71 \\
\hline resources depletion $\times$ poor & & & & & & & 1.33 & 1.58 \\
\hline Savings & & & & & & & 1.26 & 0.96 \\
\hline Credit & & & & & & & $1.56 * * *$ & 3.83 \\
\hline External help $\quad \times$ poor & & & & & & & 0.89 & -0.62 \\
\hline Poor & $0.71 * * *$ & -6.55 & $0.86^{* *}$ & -2.39 & $0.72 * * *$ & -6.27 & $0.59 * * *$ & -5.91 \\
\hline Asset index & $1.38 * *$ & 2.25 & $1.82 * * *$ & 3.36 & 1.22 & 1.41 & 1.20 & 1.30 \\
\hline Land area & 1.00 & 0.62 & 1.00 & -0.61 & 1.00 & 0.29 & 1.00 & 0.27 \\
\hline Head's age & 1.00 & 1.08 & 1.00 & 0.24 & 1.00 & -0.15 & 1.00 & -0.26 \\
\hline Head is male & 1.06 & 1.07 & 1.02 & 0.27 & 1.09 & 1.55 & 1.10 & 1.62 \\
\hline Head is Kinh (majority) & $0.87 * *$ & -2.35 & $0.79 * * *$ & -3.17 & 0.93 & -1.24 & 0.93 & -1.23 \\
\hline Primary school & 0.94 & -0.94 & 1.01 & 0.07 & 0.95 & -0.79 & 0.95 & -0.73 \\
\hline Middle school + & 0.94 & -0.92 & 1.08 & 0.95 & 0.93 & -1.00 & 0.94 & -0.95 \\
\hline Ha Tinh & $2.00 * * *$ & 10.24 & $2.17 * * *$ & 10.20 & $1.81 * * *$ & 9.18 & $1.79 * * *$ & 9.00 \\
\hline Thua Thien Hue & $1.43 * * *$ & 6.41 & $1.46 * * *$ & 5.54 & $1.21 * * *$ & 3.50 & $1.22 * * *$ & 3.59 \\
\hline
\end{tabular}

Continued on next page 
Table 3.6 Continued from previous page

\begin{tabular}{|c|c|c|c|c|c|c|c|c|}
\hline \multirow[b]{2}{*}{ Time interval (month) } & \multicolumn{2}{|l|}{ (1) } & \multicolumn{2}{|l|}{ (2) } & \multicolumn{2}{|l|}{ (3) } & \multicolumn{2}{|l|}{ (4) } \\
\hline & $\exp (b)$ & se & $\exp (b)$ & se & $\exp (b)$ & se & $\exp (b)$ & se \\
\hline 0 to 1 & $0.45 * * *$ & -4.30 & $0.02 * * *$ & -13.53 & $0.57 * * *$ & -2.99 & $0.61 * * *$ & -2.65 \\
\hline 1 to 2 & $0.46^{* * *}$ & -3.93 & $0.04 * * *$ & -12.36 & $0.60 * * *$ & -2.63 & $0.63 * * *$ & -2.30 \\
\hline 2 to 3 & $0.62 * *$ & -2.39 & $0.06 * * *$ & -10.41 & 0.80 & -1.11 & 0.85 & -0.80 \\
\hline 3 to 4 & $0.51 * * *$ & -3.25 & $0.06 * * *$ & -10.26 & $0.66^{* *}$ & -2.00 & $0.70 *$ & -1.70 \\
\hline 4 to 5 & $0.66 * *$ & -1.94 & $0.10^{* * *}$ & -8.52 & 0.86 & -0.70 & 0.92 & -0.41 \\
\hline 5 to 6 & $2.90 * * *$ & 4.82 & $0.63 *$ & -1.70 & $3.85 * * *$ & 6.15 & $4.09 * * *$ & 6.40 \\
\hline 6 to 7 & $0.56 * *$ & -2.40 & $0.15^{* * *}$ & -6.79 & 0.75 & -1.18 & 0.80 & -0.93 \\
\hline 7 to 8 & $0.63^{*}$ & -1.91 & $0.18 * * *$ & -6.00 & 0.84 & -0.71 & 0.89 & -0.46 \\
\hline 8 to 9 & $0.54 * * *$ & -2.47 & $0.17 * * *$ & -6.16 & 0.72 & -1.31 & 0.76 & -1.07 \\
\hline 9 to 10 & 0.97 & -0.14 & $0.34 * * *$ & -3.81 & 1.30 & 1.08 & 1.38 & 1.31 \\
\hline 10 to 11 & $0.21 * * *$ & -5.31 & $0.08 * * *$ & -7.78 & $0.28 * * *$ & -4.33 & $0.30 * * *$ & -4.13 \\
\hline 11 to 12 & $10.81 * * *$ & 9.19 & $6.16 * * *$ & 6.35 & $14.69 * * *$ & 10.64 & $15.52 * * *$ & 10.85 \\
\hline 12 to 13 & $3.67 * * *$ & 4.53 & $2.99 * * *$ & 3.59 & $5.01 * * *$ & 5.81 & $5.28 * * *$ & 6.01 \\
\hline 13 to 14 & 0.59 & -1.53 & $0.55^{* * *}$ & -1.67 & 0.82 & -0.61 & $0.86^{* * *}$ & -0.45 \\
\hline 14 to 15 & $0.45^{* *}$ & -2.21 & $0.43 * *$ & -2.22 & 0.62 & -1.35 & 0.65 & -1.21 \\
\hline 15 to 16 & 0.63 & -1.31 & 0.64 & -1.26 & 0.87 & -0.39 & 0.92 & -0.24 \\
\hline 16 to 17 & $0.16^{* * * *}$ & -3.70 & $0.16 * * *$ & -3.59 & $0.22 * * *$ & -3.08 & $0.23 * * *$ & -2.98 \\
\hline 17 to 18 & $44.34 * * *$ & 11.66 & $74.54 * * *$ & 12.72 & $60.64 * * *$ & 13.30 & $63.43 * * *$ & 13.48 \\
\hline 18 to 19 & 1.61 & 1.06 & $3.73 * * *$ & 2.88 & $2.18 * * *$ & 1.79 & $2.27 *$ & 1.89 \\
\hline 19 to 20 & $3.85 * * *$ & 3.29 & $9.31 * * *$ & 5.34 & $5.17 * * *$ & 4.19 & $5.39 * * *$ & 4.31 \\
\hline 20 to 21 & $3.74 * * *$ & 3.14 & $9.49 * * *$ & 5.26 & $5.03 * * *$ & 4.02 & $5.23 * * *$ & 4.13 \\
\hline 21 to 22 & 0.93 & -0.13 & 2.44 & 1.53 & $1.25 * * *$ & 0.39 & 1.30 & 0.46 \\
\hline 22 to 23 & 0.79 & -0.38 & 2.10 & 1.19 & 1.06 & 0.10 & 1.10 & 0.16 \\
\hline 23 to 24 & $5.71 * * *$ & 4.18 & $15.90 * * *$ & 6.53 & $7.67 * * *$ & 5.13 & $7.97 * * *$ & 5.24 \\
\hline 24 to 30 & 1.69 & 1.27 & $5.15 * * *$ & 3.93 & $2.27 * *$ & 2.10 & $2.35 * *$ & 2.20 \\
\hline 30 to 36 & $5.38 * * *$ & 4.05 & $20.47 * * *$ & 7.21 & $7.25 * * *$ & 5.07 & $7.50 * * *$ & 5.17 \\
\hline 36 to 42 & 2.24 & 1.63 & $10.48 * * *$ & 4.72 & $3.00 * *$ & 2.34 & $3.10 * *$ & 2.41 \\
\hline 42 to 48 & $4.40 * * *$ & 2.99 & $24.25 * * *$ & 6.38 & $5.87 * * *$ & 3.76 & $6.08 * * *$ & 3.85 \\
\hline 48 to 54 & $6.46 * * *$ & 3.64 & $42.05 * * *$ & 7.18 & $8.58 * * *$ & 4.42 & $8.87 * * *$ & 4.51 \\
\hline 54 to 60 & $16.42 * * *$ & 4.90 & $132.73 * * *$ & 8.49 & $21.73 * * *$ & 5.67 & $22.43 * * *$ & 5.76 \\
\hline 60 to 91 & $8.51 * * *$ & 2.56 & $154.16 * * *$ & 5.66 & $11.08 * * *$ & 2.97 & $11.37 * * *$ & 3.01 \\
\hline ln_varg & & & & & & & & \\
\hline Constant & $1.20 *$ & 1.82 & $2.06 * * *$ & 11.05 & 1.16 & 1.62 & 1.15 & 1.49 \\
\hline Gamma var. & $1.20 * * *$ & 9.94 & $2.06 * * *$ & 15.29 & $1.16^{* * *}$ & 10.91 & $1.15 * * *$ & 10.92 \\
\hline Observations & 87134 & & 87122 & & 87134 & & 87134 & \\
\hline $\begin{array}{l}\text { LR test of Gamma var.=0 } \\
\text { chibar } 2(01)\end{array}$ & $247.9 * * *$ & & $762.1 * * *$ & & $278.5 * * *$ & & $276.1 * * *$ & \\
\hline
\end{tabular}

Notes: Omitted categories: social shock, income shock, low severity, occur in 2002, no coping, minority groups, no schooling, head is female, Dak Lak. The models are estimated without constants. $\times$ refers to interaction terms. $* * * \mathrm{p}<0.01, * * \mathrm{p}<0.05, * \mathrm{p}<0.1$. Odds ratios are exponentiated. 


\section{Appendix 3}

Table 3.7 Components of asset index and their weights by year

\begin{tabular}{|lcc|lcc|lcc|}
\hline & 2007 & & \multicolumn{3}{c|}{2008} & \multicolumn{3}{c|}{2010} \\
Assets & Eigenvalue & Proportion & Assets & Eigenvalue & Proportion & Assets & Eigenvalue & Proportion \\
\hline Motobike & 3.43 & 0.25 & Motobike & 3.40 & 0.24 & Motobike & 3.32 & 0.24 \\
Television & 1.36 & 0.10 & Rice cooker & 1.42 & 0.10 & Cooking fuel & 1.40 & 0.10 \\
Rice cooker & 1.13 & 0.08 & Television & 1.12 & 0.08 & Rice cooker & 1.24 & 0.09 \\
Mattress & 1.05 & 0.07 & Mattress & 1.01 & 0.07 & Sanitation & 1.00 & 0.07 \\
Video player & 0.96 & 0.07 & Cooking fuel & 0.97 & 0.07 & Fridge & 0.96 & 0.07 \\
Cooking fuel & 0.89 & 0.06 & Sanitation & 0.95 & 0.07 & House size & 0.92 & 0.07 \\
Sanitation & 0.80 & 0.06 & Video player & 0.84 & 0.06 & Television & 0.77 & 0.06 \\
Electric fan & 0.76 & 0.05 & Fridge & 0.74 & 0.05 & Mattress & 0.75 & 0.05 \\
Fridge & 0.68 & 0.05 & House size & 0.73 & 0.05 & Video player & 0.70 & 0.05 \\
Flooring & 0.64 & 0.05 & Electric fan & 0.63 & 0.04 & Electric fan & 0.64 & 0.05 \\
House size & 0.63 & 0.05 & Housing & 0.59 & 0.04 & Housing & 0.63 & 0.04 \\
Housing & 0.61 & 0.04 & Bike & 0.55 & 0.04 & Water & 0.58 & 0.04 \\
Radio & 0.55 & 0.04 & Radio & 0.54 & 0.04 & Bike & 0.56 & 0.04 \\
Bike & 0.52 & 0.04 & Flooring & 0.52 & 0.04 & Radio & 0.51 & 0.04 \\
\hline
\end{tabular}

Note: Proportions in the same column sum to one.

Table 3.8 Correlation between self reported recovery and objective recovery

\begin{tabular}{lcccccc}
\hline \multirow{2}{*}{$\begin{array}{l}\text { Self reported } \\
\text { recovery }\end{array}$} & \multicolumn{2}{c}{ Recovery in subjective well-being } & \multicolumn{3}{c}{ Recovery in consumption } \\
\cline { 2 - 7 } Not yet recovered & 8.4 & Recovered & Total & Not yet & Recovered & Total \\
Recovered & 43.6 & 48.1 & 9.4 & 0.0 & 3.7 & 3.7 \\
Total & 51.9 & 48.1 & 100.0 & 61.4 & 38.6 & 100.0 \\
\hline Cramer's V & \multicolumn{3}{c}{$0.29 *$} & & $-0.24 *$ & 96.3 \\
\hline
\end{tabular}

Note: Cramer's Vs are calculated from the contingency tables in the upper panel. * refers to 99 percent significant

\section{Figure 3.3 Distribution of shocks by the length of recovery}

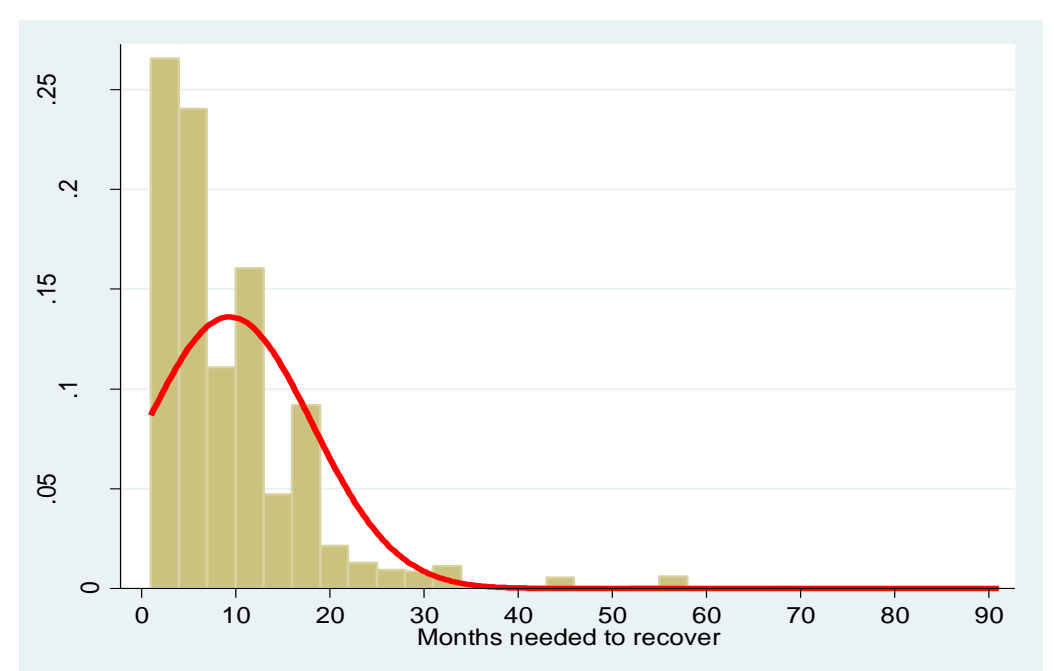

Source: Graphed from Vulnerability Surveys in Vietnam. 
Figure 3.4 Relationship between a household's characteristis and a shock's covariates
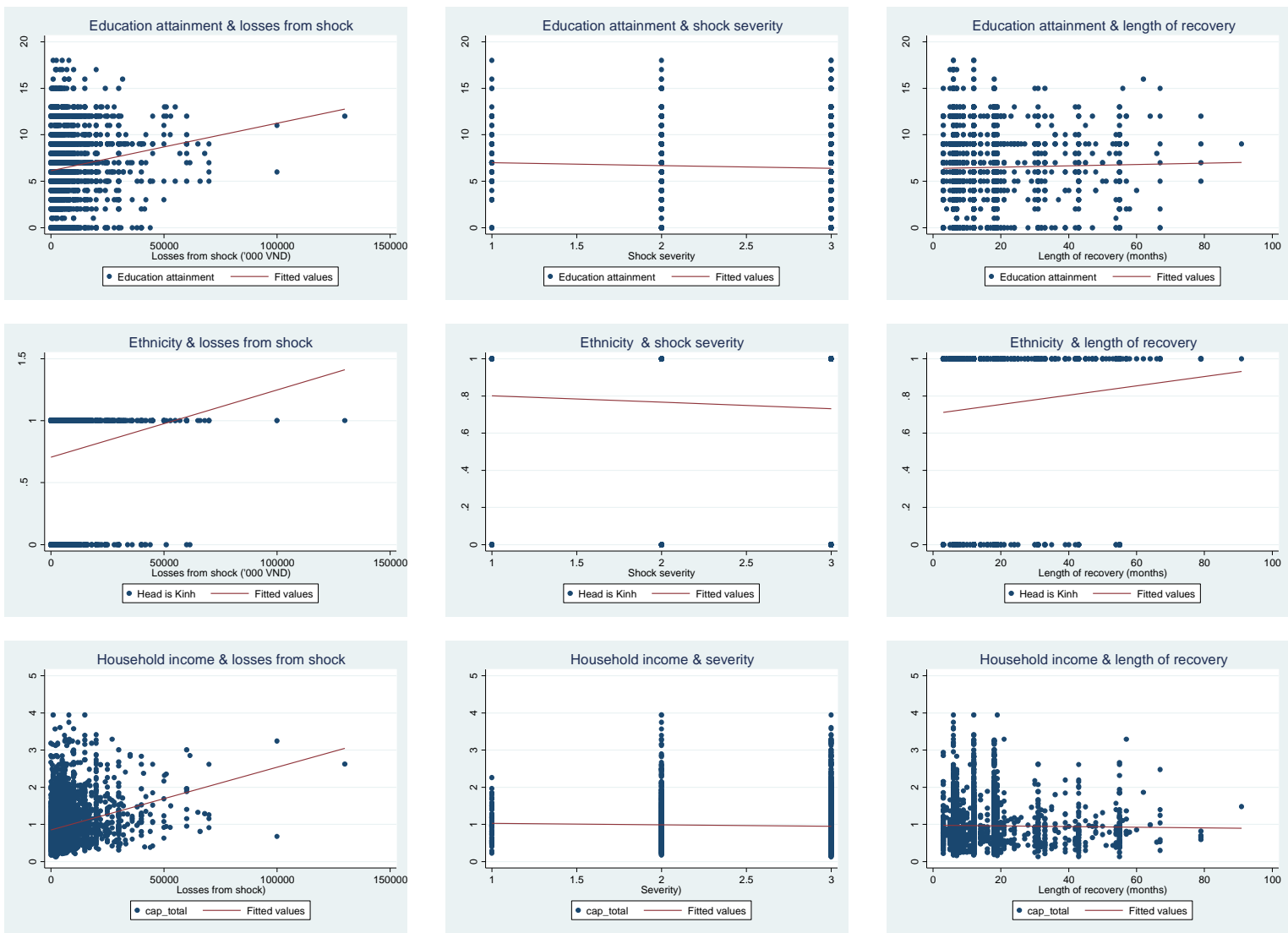

Notes: Severity levels 1, 2, 3 refer to low, medium, high.

Source: Graphed from Vulnerability Surveys in Vietnam.

Figure 3.5 Relationship between coping strategies and shock's covariates
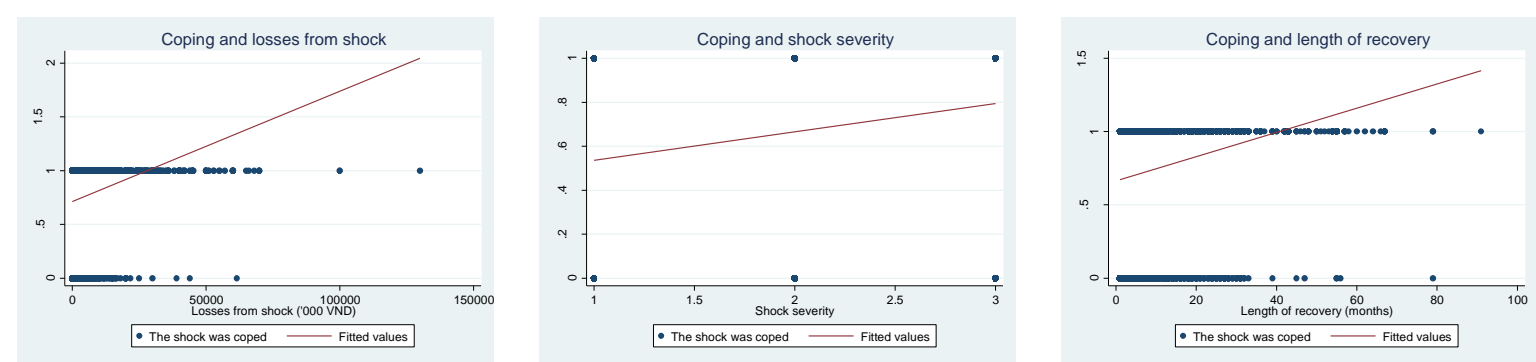

Notes: Severity levels 1, 2, 3 refer to low, medium, high.

Source: Graphed from Vulnerability Surveys in Vietnam. 


\section{Bibliography}

Alderman, H., and Paxson, C.H. (1992). Do the Poor Insure? A Synthesis of the Literature on Risk and Consumption in Developing Countries. Policy Research Working Paper 1008. The World Bank, Washington, DC. Retrieved from http://go.worldbank.org/TKC7ET1YR0.

Alkire, S., \& Foster, J. (2011). Counting and Multidimensional Poverty Measurement. Journal of Public Economics, 95(7-8), 476-487. doi: 10.1016/j.jpubeco.2010.11.006.

Alkire, S. and Santos, M.E. (2010). Acute Multidimensional Poverty: A New Index for Developing Countries. OPHI Working paper 38, Oxford Poverty and Human Development Initiative, Oxford.

Apablaza, M. and Yalonetzky, G. (2011). Measuring the dynamics of multiple deprivations among children: the cases of Andhra Pradesh, Ethiopia, Peru and Vietnam. Paper presented in CSAE conference, 2011.

Arun, S. (2008). Managing assets and vulnerability contexts: vistas of gendered livelihoods of adivasi women in South India. BWPI Working Paper 3208. Brooks World Poverty Institute, University of Manchester.

Asselin, L.M., and Vu, T.A. (2008). Multidimensional Poverty Measurement with Multiple Correspondence Analysis. In N. Kakwani \& J. Silber (Eds.) Quantitative Approaches to Multidimensional Poverty Measurement. New York: Palgrave Macmillan.

Atkinson, A.B. (2003). Multidimensional deprivation. Contrasting social welfare and counting approaches. Journal of Economic Inequality, 1, 51-65.

Badiani, R. et al. (2012). 2012 Vietnam poverty assessment - Well begun, not yet done: Vietnam's remarkable progress on poverty reduction and the emerging challenges. Hanoi: The World Bank.

Bane, M.J. and Ellwood, D. (1986). Slipping Into and Out of Poverty: The Dynamics of Spells. Journal of Human Resources, 21(1), 1-23. Retrieved from http://www.nber.org/papers/w1199.

Baulch, B. and Masset, E. (2003). Do Monetary and Nonmonetary Indicators Tell the Same Story About Chronic Poverty? A Study of Vietnam in the 1990s. World Development, 31(3), 441-53. doi: 10.1016/S0305-750X(02)00215-2.

Baulch, B., Truong, T.K.C., Haughton, D., and Haughton, J. (2007). Ethnic Minority Development in Vietnam. Journal of Development Studies, 43(7), 1151-1176. doi: 10.1080/02673030701526278.

Becker, G.S. (1967). Human Capital and the Personal Distribution of Income. Michigan: University of Michigan Press.

Becker, G. S. (1994). Human Capital: A Theoretical and Empirical Analysis with Special Reference to Education (3rd ed.). Chicago and London: The University of Chicago Press. Retrieved from http://www.nber.org/chapters/c11226.pdf.

Berger, M. and Leigh, J. (1989). Schooling, Self-selection, and Health. Journal of Political Economy, 97, 433-455. Retrieved from http://www.jstor.org/stable/145822.

Bhide, S. and Mehta, A.K. (2005). Tracking Poverty Through Panel Data: Rural Poverty in India 1970-1998. CPRC Working Paper 28. Chronic Poverty Research Centre, University of Manchester.

Bigsten, A., Bereket, K., Abebe, S. and Taddesse, M. (2003). Growth and Poverty Reduction in Ethiopia: Evidence from Household Panel Surveys. World Development, 31(1), 87-106. 
Bourguignon, F. and Chakravarty, S. (2003). The measurement of multidimensional poverty. Journal of Economic Inequality, 1(1), 25-49. doi: 10.1023/A:1023913831342.

Cappellari, L. and Jenkins, S.P. (2002). Who Stays Poor? Who Becomes Poor? Evidence from the British Household Panel Survey. The Economic Journal, 112(478), C60-C67. Retrieved from http://www.jstor.org/stable/798359.

Cappellari, L. and Jenkins, S.P. (2004). Modeling Low Income Transitions. Journal of Applied Econometrics, 19, 593-610. doi: 10.1002/jae.778.

Carter, M. and Castillo, M. (2005). Coping with disaster: Morals, markets, and mutual insurance-Using economic experiments to study recovery from Hurricane Mitch, In C. Barrett (Eds.), The Social Economics of Poverty: On Identities, Communities, Groups and Networks (pp. 268-287). New York: Routledge.

Carter, M.R. and Barrett, C.B. (2006). The economics of poverty traps and persistent poverty: An asset-based approach. Journal of Development Studies, 42(2), 178-199. doi: 10.1080/00220380500405261.

Carter, M.R., Little, P.D., Mogues, T., and Negatu, W. (2007). Poverty traps and natural disasters in Ethiopia and Honduras. World Development, 35(5), 835-856. doi: 10.1016/j.worlddev.2006.09.010.

Carter, M. R. and May, J. (1999). Poverty, livelihood and class in rural South Africa. World Development, 27, 1-20. doi: 10.1016/S0305-750X(98)00129-6.

Carter, M.R. and May, J. (2001). One Kind of Freedom: Poverty Dynamics in Post-apartheid South Africa. World Development, 29(12), 1987-2006. doi: 10.1016/S0305750X(01)00089-4.

Central Committee for Flood and Storm Control (CCFSC) (2012, November). Summary of damages caused by natural disasters, yearly. Retrieved from http://www.ccfsc.gov.vn.

Clarke, D. and Dercon, S. (2009). Insurance, Credit and Safety Nets for the Poor in a World of Risk, DESA Working Paper 81, Department of Economic and Social Affairs, Oxford University. Retrieved from http://www.un.org/esa/desa/papers/2009/wp81_2009.pdf.

Clark, D. and Hulme D. (2005). Towards A Unified Framework for Understanding the Depth Breadth and Duration of Poverty. GPRG Working Paper 020, Global Poverty Research Group, Manchester. Retrieved from http://economics.ouls.ox.ac.uk/14063/1/gprg-wps020.pdf.

Coudouel, A, Hentschel, J.S. and Wodon, Q.T. (2002). Poverty Measurement and Analysis. In J. Klugman (Eds.), A Sourcebook for Poverty Reduction Strategies. Volume 1: Core Techniques and Cross-Cutting Issues. Washington, D.C.: The World Bank. Retrieved from http://go.worldbank.org/0C60K5UK40.

Cutler, D.M., and Lleras-Muney, A. (2006). Education and health: Evaluating theories and evidence, NBER Working Paper 12352. The National Bureau of Economic Research. Retrieved from http://www.nber.org/papers/w12352.

Das, J., Hammer, J., Sánchez-Paramo, C. (2011). The Impact of Recall Periods on Reported Morbidity and Health Seeking Behavior. Policy Research Working Paper 5778, The World Bank. doi: 10.1596/1813-9450-5778.

Dasgupta, S., Laplante, B., Meisner, C., Wheeler, D., and Yan, J. (2009). The impact of sea level rise on developing countries: a comparative analysis. Climatic Change, 93, 379-388. doi: 10.1007/s10584-008-9499-5. 
Deaton, A. (1997). The Analysis of Household Surveys. Baltimore: The Johns Hopkins University Press.

Deaton, A. and Paxson, C.(1998). Economies of scales, Household Size, and the Demand for Food. Journal of Political Economy, 106(5), 897-930. Retrieved from http://www.jstor.org/stable/10.1086/250035.

Deininger, C. (2003). Land Policies for Growth and Poverty Reduction. Oxford: The World Bank and Oxford University Press.

Dercon, S. (1996). Risk, crop choice and savings: evidence from Tanzania. Economic Development and Cultural Change, 44(3), 485-514. Retrieved from http://www.jstor.org/stable/1154463.

Dercon, S. (2002). Income Risk, Coping Strategies, and Safety Nets. The World Bank Research Observer, 17(2), 141-166. doi: 10.1093/wbro/17.2.141.

Dercon, S. (2004). Growth and shocks: evidence from rural Ethiopia. Journal of Development Economics, 74, 309-329. doi:10.1016/j.jdeveco.2004.01.001.

Dercon, S. and Hoddinott, J. (2003). Health, Shocks and Poverty Persistence. WIDER Discussion Paper 8. World Institute of Development Economics Research.

Dercon, S. and Krishnan, P. (2000). Vulnerability, seasonality and poverty in Ethiopia. The Journal of Development Studies, 36:6, 25-53. doi: 10.1080/00220380008422653.

Dercon, S. and Krishnan, P. (2003). Risk sharing and public transfer, The Economic Journal, 113(486), C86-C94. Retrieved from http://www.jstor.org/stable/3590049.

Duclos, J.-Y., Sahn, D. E. and Younger, S. D. (2006a). Robust Multidimensional Poverty Comparisons. Economic Journal, 116(514), 943-968. doi: 10.1111/j.14680297.2006.01118.x.

Duclos, J.-Y., Sahn, D. E. and Younger, S. D. (2006b). Robust Multidimensional Spatial Poverty Comparisons in Ghana, Madagascar, and Uganda. World Bank Economic Review, 20(1), 91-113. doi:10.1093/wber/lhj005.

Duncan, G.J. and Rodgers, W.L. (1988). Longitudinal Aspects of Childhood Poverty. Journal of Marriage and the Family, 50(4), 1007-1021. Retrieved from http://www.jstor.org/stable/352111.

Elbers, C., and Gunning, J.W. (2003). Vulnerability in a Stochastic Dynamic Model. Tinbergen Institute Discussion Paper 2003-070/2. Tinbergen Institute, Vrije University.

Elbers, C. Gunning, J.W., and Kinsey, B. (2007). Growth and Risk: Methodology and Micro Evidence. The World Bank Economic Review, 21(1), 1-20. doi:10.1093/wber/lhl008.

Farrell, P. and Fuchs, V.R. (1982). Schooling and Health: The Cigarette Connection. Journal of Health Economics, 1(3), 217-230. doi: 10.1016/0167-6296(82)90001-7.

Fafchamps, M. and Lund, S. (2003). Risk Sharing Networks in Rural Philippines. Journal of Development Economics, 71(2), 261-287. doi: 10.1016/S0304-3878(03)00029-4.

Fiala, N. (2011). Recovery or Trapped in Poverty? The Economic Consequences of Forced Displacement in Northern Uganda. mimeo, Berlin.

Filmer, D., Pritchett L.H. (2001). Estimating wealth effects without expenditure data--or tears: an application to educational enrollments in states of India, Demography, 38(1), 115-132.

Fletschner, D., Anderson, C.L. and Cullen, A. (2010). Are Women as Likely to Take Risks and Compete? Behavioural Findings from Central Vietnam, Development Studies, 46(8), 1459-1479. 
Gaiha, R., and Deolalikar, A.B. (1993). Persistent, Expected and Innate Poverty: Estimates for Semi Arid Rural South India. Cambridge Journal of Economics, 17, 409-21. Retrieved from http://cje.oxfordjournals.org/content/17/4/409.full.pdf.

Glewwe, P., Gragnolati, M. and Zaman, H. (2000). Who Gained from Vietnam's Boom in the 1990s?. Policy Research Working Paper 2275, The World Bank.

Global Finance (2013, May). Wealth Distribution and Income Inequality by Country, http://www.gfmag.com/tools/global-database/economic-data/11944-wealth-distributionincome-inequality.html\#axzz2XWTjn08j.

GSO (2009). Result of the Vietnam Living Standard Survey 2008. Hanoi: Statistical Publishing House. Retrieved from http://www.gso.gov.vn/default_en.aspx?tabid=515\&idmid=5\&ItemID=9647.

General Statistics Office (GSO) (2010). The 2009 Vietnam Population and Housing Census: Completed Results. Hanoi: Statistical publishing house. Retrieved from: http://www.gso.gov.vn/default.aspx?tabid=512\&idmid=5\&ItemID=10798.

GSO (2011a). Result of the Vietnam Living Standard Survey 2010. Hanoi: Statistical Publishing House. Retrieved from http://www.gso.gov.vn/default_en.aspx?tabid=515\&idmid=5\&ItemID=12426

GSO (2011b). Viet Nam Multiple Indicator Cluster Survey 2011 Final Report. Ha Noi: Viet Nam. Retrieved from http://www.childinfo.org/files/MICS4_Vietnam_FinalReport_2011_Eng.pdf.

GSO (2013, July). Statistical Data: Administrative Unit, Land and Climate. Retrieved from http://www.gso.gov.vn/default_en.aspx?tabid=466\&idmid=3\&ItemID=12831.

Gonzalez, A., Boyle, M.H., Georgiades, K., Duncan, L., Atkinson, L.R., and MacMillan, H.L. (2012). Childhood and family influences on body mass index in early adulthood: findings from the Ontario Child Health Study. BMC Public Health, 12(755). doi:10.1186/14712458-12-755.

Günther, I. and Klasen, S. (2009). Measuring Chronic Non-income Poverty. In T. Addison, D. Hulme \& R. Kanbur (Eds.), Poverty Dynamics: Interdisciplinary Perspectives (pp. 77101). New York: Oxford University Press. doi: 10.1093/acprof:oso/9780199557547.001.0001.

Haddad, L., Hoddinott, J., and Alderman, H. (Eds.) (1997) Intrahousehold Resource Allocation In Developing Countries: Models, Methods, and Policy. Baltimore: Johns Hopkins University Press.

Harttgen, K., Klasen, S., and Vollmer, S. (2013). An African Growth Miracle? Or: What do Asset Indices Tell Us About Trends in Economic Performance? Review of Income and Wealth, 59(S1), S37-S61. doi: 10.1111/roiw.12016.

Hoddinott, J., (2006). Shocks and their consequences across and within households in Rural Zimbabwe. Journal of Development Studies, 42(2), 301-321. doi: 10.1080/00220380500405501.

Hulme, D., \& McKay, A. (2008). Identifying and Measuring Chronic Poverty: Beyond Monetary Measures? In Kakwani, N. and Silber, J. (Eds.), The Many Dimensions of Poverty (pp. 187-214). New York: Palgrave Macmillan.

Hulme, D., Moore, K., \& Shepherd, D. (2001). Chronic poverty: meanings and analytical frameworks Manchester. CPRC Working Paper 2. Chronic Poverty Research Centre, University of Manchester. 
Hulme, D. and Shepherd, A. (2003). Conceptualizing Chronic Poverty. World Development, 31(3), 403-423. doi: 10.1016/S0305-750X(02)00222-X.

Imai, K.S., Gaiha, R. and Kang, W. (2011). Vulnerability and poverty dynamics in Vietnam, Applied Economics, 43(25), 3603-3618. doi: 10.1080/00036841003670754.

Interantional Monetary Fund (IMF) (2013, June). Vietnam: Inflation, average consumer prices, Index. Retrieved from http://www.quandl.com/IMF-International-MonetaryFund/PCPI_582-Vietnam-Inflation-average-consumer-prices-Index.

Jalan, J., Ravallion, M. (1998). Determinants of Transient and Chronic Poverty: Evidence from Rural China. World Bank Policy Research Working Paper No. 1936. The World Bank. Retrieved from http://ssrn.com/abstract=629112.

Jalan, J., Ravallion, M. (1999). Are the poor less well insured? Evidence on vulnerability to income risk in rural China. Journal of Development Economics, 58 (1), 61-81.

Jalan, J. and Ravallion, M. (2002). Geographic poverty traps: A micro model of consumption growth in rural China. Journal of Applied Econometrics, 17, 329-346. doi: 10.1002/jae.645.

James, W., Ferro-Luizzi, A., and Waterlow, J. (1988). Definition of chronic energy deficiency in adults. European Journal of Clinical Nutrition, 42(12), 969-981.

Jenkins, S.P. (2000). Modelling household income dynamics. Journal of Population Economics, 13(4), 529-567. Retrieved from http://www.jstor.org/stable/20007735.

Justino, P. and Litchfeld, J. (2003). Poverty Dynamics in Rural Vietnam: Winners and Losers during Reform. PRUS Working Paper, Poverty Research Unit at Sussex, University of Sussex.

Justino, P., Litchfield, J. and Pham, T.H. (2008). Poverty Dynamics during Trade Reform Evidence from Rural Vietnam. Review of Income and Wealth, 54(2). 166-192. doi: 10.1111/j.1475-4991.2008.00269.x.

Kazianga, H. and Udry, C. (2006). Consumption smoothing? Livestock, insurance and drought in rural Burkina Faso. Journal of Development Economics, 79(2), 413-446. doi:10.1016/j.jdeveco.2006.01.011.

Kedir, A.M. and McKay, A. (2005). Chronic poverty in urban Ethiopia: panel data evidence. International Planning Studies, 10(1), 49-67. doi: 10.1080/13563470500159246.

Kelly, P.M. and Adger W.N. (2000). Theory and Practice in Assessing Vulnerability to Climate Change and Facilitating Adaptation. Climatic Change, 47, 325-352.

Kessides, C. (1992). The Contributions of Infrastructure to Economic Development: A Review of Experience and Policy Implications. Washington, D.C.: The World Bank. Retrieved from http://go.worldbank.org/OBUGYU96V0.

Klasen, S. (2000). Measuring poverty and deprivation in South Africa. Review of Income and Wealth, 46(1), pp. 33-58. doi: 10.1111/j.1475-4991.2000.tb00390.x.

Klasen, S. and Waibel, H. (Eds.) (2012). Vulnerability to Poverty: Theory, measurement and determinants, with case studies from Thailand and Vietnam. Basingstoke: Palgrave Macmillan.

Kochar, A. (1995). Explaining household vulnerability to idiosyncratic income shocks, American Economic Review, 85(2), pp.159-64. Retrieved from http://www.jstor.org/stable/2117911. 
Kochar, A. (1999). Smoothing consumption by smoothing income: hours-of-work responses to idiosyncratic agricultural shocks in rural India. Review of Economics and Statistics, 81(1), 50-61. doi: 10.1162/003465399767923818.

Kristjanson, P., Mango, N., Krishna, A., Redeny, M. and Kohnson, N. (2010). Understanding Poverty Dynamics in Kenya. Journal of International Development, 22(7), 978-996. doi: 10.1002/jid.1598.

Lawson, D. (2009). Insights into How The Chronically Poor Cope with HIV/AIDS: Evidence From Uganda. Field Action Scientific Reports, 3. Retrieved from http://factsreports.revues.org/254.

Lawson, D., Mckay, A. and Okidi, J. (2006). Poverty persistence and transitions in Uganda: A combined qualitative and quantitative analysis. Journal of Development Studies, 42(7), 1225-1251. doi: 10.1080/00220380600884191.

Litchfield, J. and Justino, P. (2004). Welfare in Vietnam during the 1990s: Poverty, inequality and poverty dynamics. Journal of the Asia Pacific Economy, 9(2), 145-169. doi: 10.1080/1354786042000207317.

Little, P.D., Stone, M.P., Mogues, T., Castro,P., and Negatu, W. (2006). 'Moving in place': drought and poverty dynamics in South Wollo, Ethiopia. Journal of Development Studies, 42(2), 200-225.

Maccini, S. and Yang, D. (2009). Under the Weather: Health, Schooling, and Economic Consequences of Early-Life Rainfall. American Economic Review, 99(3): 1006-1026. doi: 10.1257/aer.99.3.1006.

McCulloch, N. and Baulch, B. (1999). Dishtinguishing the Chronically from the Transitory Poor: Evidence from Pakistan. IDS Working Paper 97, Institute of Development Studies, University of Sussex.

McKay, A., and Lawson, D. (2002). Chronic Poverty: A Review of Current Quantitative Evidence. CPRC Working Paper 15, Chronic Poverty Research Centre, University of Manchester.

McKay, A., and Lawson, D. (2003). Assessing the Extent and Nature of Chronic Poverty in Low Income Countries: Issues and Evidence. World Development, 31(3), 425-439. doi:10.1016/S0305-750X(02)00221-8.

McPeak, J. (2004). Contrasting income shocks with asset shocks: livestock sales in Northern Kenya. Oxford Economic Papers, 56(2), 263-284. doi: 10.1093/oep/gpf040.

Mills, D. J., Adhuri, D.S., Phillips, M.J., Bavikumar, B. and Padiyar, A.P. (2011). Shocks, recovery trajectories and resilience among aquaculturedependent households in posttsunami Aceh, Indonesia. Local Environment, 16(5), 425-444. doi: 10.1080/13549839.2011.554804.

Morduch, J. (1994). Poverty and vulnerability. American Economic Review, 84(2), Papers and Proceedings of the Hundred and Sixth Annual Meeting of the American Economic Association (May, 1994), 221-225. Retrieved from http://www.jstor.org/stable/2117833.

Morris, S., Neidecker-Gonzales, O., Carletto, C., Munguia, M., Medina, J.M., and Wodon, Q. (2002). Hurricane Mitch and livelihoods of the rural poor in Honduras. World Development, 30(1), 39-60.

Newhouse, D. (2005). The Persistence of Income Shocks: Evidence from Rural Indonesia. Review of Development Economics, 9(3), 415-433. 
Niimi, Y., Vasudeva-Dutta, P. and Winters, A. (2007). Trade Liberalization and Poverty Dynamics in Vietnam. Journal of Economic Integration, 22(4), 819-851.

Organisation for Economic Co-operation and Development (OECD) (1982). The OECD List of Social Indicators. OECD Social Indicator Development Programme. Paris: OECD.

Paxson, C.H. (1992). Using Weather Variability to Estimate the Response of Savings to Transitory Income in Thailand. The American Economic Review, 82(1), 15-33. Retrieved from http://www.jstor.org/stable/2117600

Paxson, C.H. (1993). Consumption and income seasonality in Thailand. Journal of Political Economy, 101(1), 39-72. Retrieved from http://www.jstor.org/stable/2138673.

Perry, B. (2002). The mismatch between income measures and direct outcome measures of poverty. Social Policy Journal of New Zealand, Issue 19.

Pistaferri, L. (2001). Superior information, income shocks, and the permanent income hypothesis. Review of Economics and Statistics, 83(3), 465-476.

Powell, L.M., Auld, M.C, Chaloupka, F.J., O'Malley, P.M., Johnston, L.D. (2007). Associations Between Access to Food Stores and Adolescent Body Mass Index. American Journal of Preventive Medicine, doi:10.1016/j.amepre.2007.07.007.

Roche, J.M. (2013). Monitoring Progress in Child Poverty Reduction: Methodological Insights and Illustration to the Case Study of Bangladesh. OPHI Working Paper 57. Oxford Poverty and Human Development Initiative, Oxford.

Roelen, K. (2010). Multidimensional child poverty in Vietnam from a longitudinal perspectiveimproved lives or impoverished conditions? mimeo. Retrieved from http://www.chronicpoverty.org/uploads/publication_files/roelen_child_poverty_vietnam.pdf.

Quisumbing, A., and Baulch, B. (2009). Assets and poverty traps in rural Bangladesh. CPRC Working Paper 143. Chronic Poverty Research Centre, University of Manchester.

Sahn, D.E. and Stifel, D.C. (2000). Poverty Comparisons Over Time and Across Countries in Africa. World Development, 28(12), 2123-2155. doi: 10.1016/S0305-750X(00)00075-9.

Santos, I., Sharif, I., Rahman, H.Z., and Zaman, H. (2011). How do the poor cope with shocks in Bangladesh? Evidence from survey data. Policy Research Working Paper 5810. The World Bank.

Sen, A. (1979). Issues in the Measurement of Poverty. The Scandinavian Journal of Economics, 81(2), 285-307. Retrieved from http://darp.lse.ac.uk/papersdb/Sen_(SJE79).pdf.

Sen A. (1981). Poverty and Famines: An Essay on Entitlement and Deprivation. Oxford: Clarendon Press.

Sen, A. (2000). A Decade of Human Development. Journal of Human Development, 1(1), 17 23. Retrieved from http://www.cid.harvard.edu/events/papers/sen_jhd_2000.pdf.

Sunderlin, W.D. and and Huynh, T.B. (2005). Poverty Alleviation and Forests in Vietnam, Indonesia: Center for International Forestry Research.

Thomas, T., Christiaensen, L., Do, Q.T., Le, D.T. (2010). Natural Disasters and Household Welfare: Evidence from Vietnam, Policy Research Working Paper 5491. The World Bank. Retrieved from http://go.worldbank.org/JFMPZTN4S0.

Thorbecke, E. (2008). Multidimensional Poverty: Conceptual and Measurement Issues. In N. Kakwani and J. Silber (Eds.), The Many Dimensions of Poverty. New York: Palgrave Macmillan. 
Townsend, R.M. (1994). Risk and Insurance in Village India. Econometrica, 62(3), 539-591. Retrieved from http://www.jstor.org/stable/2951659.

Tran, P., Marincioni, F., Shaw, R., Sarti, M. and Le, V.A. (2008). Flood risk management in Central Vietnam: challenges and potentials, Natural Hazards, 46, 119-138. Retrieved from http://link.springer.com/article/10.1007\%2Fs11069-007-9186-2

Tsui, K.Y. (2002). Multidimensional Poverty Indices. Social Choice and Welfare, 19(1), 69-93. doi: 10.1007/s355-002-8326-3.

United Nations (UN) (2001). Roadmap towards the Implementation of the United Nations Millennium Declaration (Report of the Secretary-General, No. A/56/326). Retrieved from http://www.un.org/documents/ga/docs/56/a56326.pdf.

United Nations Development Programme (UNDP) (2010). Human Development Report 2010: The Real Wealth of Nations: Pathways to Human Development. Retrieved from http://hdr.undp.org/en/reports/global/hdr2010.

UNDP (2011). Human Development Report 2011: Sustainability and Equity: A Better Future for All. Retrieved from http://hdr.undp.org/en/reports/global/hdr2011/.

UNDP (2012, Novermber). The Millennium Development Goals. Retrieved from: http://www.undp.org/content/undp/en/home/mdgoverview/.

United Nations Children's Fund (UNICEF) (2012, November). Viet Nam and the MDGs. Retrieved from http://www.unicef.org/vietnam/overview_14583.html.

UNICEF (2013, July). Statistics by Area: Child Survival and Health. Retrieved from http://www.childinfo.org/mortality_imrcountrydata.php.

Wainwright, F. and Newman, C. (2011). Income shocks and household risk-coping strategies: evidence from rural Vietnam. IIIS Discussion Paper 358, Institute for International Integration Studies.

Whelan, C.T, Layte, R., and Maitre, B. (2004). Understanding the Mismatch between Income Poverty and Deprivation: A dynamics Comparative Analysis. European Sociological Review, 29(4), 287-302. doi: 10.1093/esr/jch029.

World Bank (2001). World Development Report 2000/2001: Attacking poverty. Oxford: Oxford University Press. doi: 10.1596/978-0-19-521129-0.

World Bank (2012, December). Vietnam: Vietnam Overview. Retrieved from http://www.worldbank.org/en/country/vietnam/overview.

World Bank (2013, January). Data: Indicators. Retrieved from http://data.worldbank.org/indicator.

Wolff, E.N. and Zacharias, A. (2006). Household Wealth and the Measurement of Economic Well-Being in the United States. Working Paper 447. The Levy Economics Institute of Bard College, New Work.

Woolard, I. and Klasen, S. (2005). Determinants of Income Mobility and Household Poverty Dynamics in South Africa. The Journal of Development Studies, 41(5), 865-897.

Wooldridge, J.M. (2002). Econometric Analysis of Cross Section and Panel Data, London: The MIT Press.

Zimmerman, F., and Carter, M.R. (2003). Asset smoothing, consumption smoothing and the reproduction of inequality under risk and subsistence constraints. Journal of Development Economics, 71(2), 233-260. doi: 10.1016/S0304-3878(03)00028-2. 